Portland State University

PDXScholar

Fall 12-9-2014

\title{
An Exploratory Study of Teachers' Uses of Data to Understand Students' Cognitive and Affective Engagement
}

Nicole Van Gasse

Portland State University

Follow this and additional works at: https://pdxscholar.library.pdx.edu/open_access_etds

Part of the Elementary Education and Teaching Commons Let us know how access to this document benefits you.

Recommended Citation

Van Gasse, Nicole, "An Exploratory Study of Teachers' Uses of Data to Understand Students' Cognitive and Affective Engagement" (2014). Dissertations and Theses. Paper 2097.

https://doi.org/10.15760/etd.2095

This Dissertation is brought to you for free and open access. It has been accepted for inclusion in Dissertations and Theses by an authorized administrator of PDXScholar. Please contact us if we can make this document more accessible: pdxscholar@pdx.edu. 
An Exploratory Study of Teachers' Uses of Data to Understand Students' Cognitive and Affective Engagement

\author{
by \\ Nicole Van Gasse \\ A dissertation submitted in partial fulfillment of the \\ requirements for the degree of \\ Doctor of Education \\ in \\ Educational Leadership: Curriculum and Instruction
}

Dissertation Committee:

Christine Chaille, Chair

Motoaki Hara

Jana Meinhold

Samuel Henry

Portland State University

2014 
(C) 2014 Nicole Van Gasse 
Abstract

Since its introduction in the 1980 's, student engagement has been a popular topic in educational research. In the beginning, engagement was thought of as a simple construct; however, it is now believed that student engagement involves four separate, but equally important components (Appleton, 2012; Christenson, Reschly, Appleton, Berman, Spanjers, \& Varro, 2008). The components of academic, behavioral, affective and cognitive engagement are each vital to the ongoing educational success of students, and ideally, these would remain high throughout all of the years that students are in school. Unfortunately, research shows that most students' engagement levels continuously decrease from elementary school until high school graduation (or dropout), with the biggest drops occurring when students transition to middle school and high school (Alexander, Entwisle, \& Horsey, 1997; Dunleavy \& Milton, 2008; Finn, Pannozzo, \& Voelk1, 1995; Lopez, 2011; Roeser, Strobel, \& Quihuis, 2002; Skinner et al., 2009). Much of the research is currently being done at the middle and high school level to try and re-engage students in their learning (Appleton, 2012; Appleton, Christenson, Kim \& Reschley, 2006; Fredricks, Blumenfeld, \& Paris, 2004). This research study, however, looked at the implications of engagement data collection with fourth grade students.

This mixed-methods study had two main goals. The first goal of the study was to determine the benefits of providing teachers with a systematic approach to collecting and following data on students' affective and cognitive engagement levels over time. The second goal of the study was to begin to explore interventions that appeared to increase fourth grade students' affective and cognitive engagement levels. 
The data analysis showed that students consistently reported lower engagement scores in the areas of teacher and peer relationships at school. It was also found that teachers did not report using student engagement data to make whole class interventions, but teachers did report the desire to track individual student's engagement scores in order to implement individualized interventions, when needed. Three additional findings, as well as suggestions for future research, are also presented.

In the end, the study concludes with a more broad view on how this research can be used to impact the field of education. The ideas of teacher awareness, power in schools, and the need to create safe and caring classrooms that include students in the decision making process are all discussed as important components needed to engage students. Final suggestions have also been given for both teachers and administrators on how best to increase student engagement in the school or school district where they are working. 


\section{Dedication}

This dissertation is dedicated to the five amazing people who have been with me every step of the way. Thank you to my parents, Grandma Van Gasse, Emily de la Cruz, and Moti Hara. This dissertation would not have been possible without your encouragement, your guidance, and your ongoing support. I will be forever grateful. 
Table of Contents

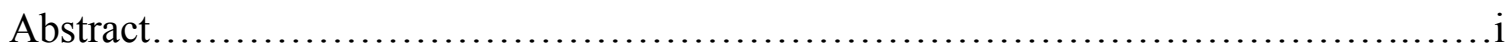

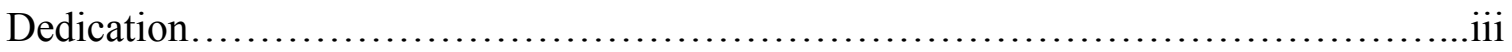

List of Tables ................................................................ vii

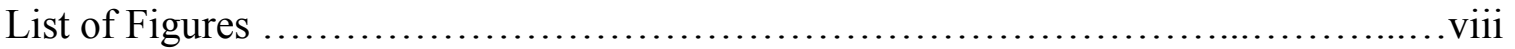

Chapter One:

Introduction.......................................................................

Definition of Key Terms

Four Components of Engagement

Disengagement

Motivation

Conceptual Framework

Research Questions

Purpose of the Study

Chapter Two: A Review of the Literature...

The History of Student Engagement

The Participation-Identification Model

Three-part Model of Engagement

Four-Part Model of Engagement

The Outcomes of Student Engagement

Academic and Behavioral Engagement and Student Achievement

Time on Task

Attendance

Attention and Defiant Behavior

Affective Engagement for Elementary Students

Early Teacher-Student Relationships

Peer Relationships

A Lack of Research on Cognitive Engagement at the Elementary Level

Measuring Cognitive Engagement

Developmental Stages for Elementary Students

Research that Supports the Developmental Stages

Motivation and Cognitive Engagement

Conclusions

Purpose and Significance of the Study

Chapter Three: Methodology

Paradigm

Brief Study Overview

Research Questions

Why Fourth Grade?

Setting 
Research Sites

Participants

Teachers

Students

Sampling

District Approval

Principal Permission

Institutional Review Board

Initial Teacher Contact

Student Participants and Parent Permission

Data Collection Timeline

Eliminating Other Student Engagement Measures

Data Sources and Collection

Student Engagement Instrument-Elementary Version

Student Implementation Process

Teacher Interviews

Data Analysis

First Survey Engagement Summary

Second Survey Change Results Summary

Two-Tailed, Independent t-test

Multiple Regression

Teacher Interviews

Synthesis

Chapter Four: Findings

Descriptive Statistics

Teacher Background Characteristics

Student Demographics in Each Classroom

Summary Statistics: Pre and Post-Survey Reports

Pre-Survey Reports

Post-Survey Reports

Inferential Statistics

Research Question One

Quantitative Findings

Qualitative Findings Around Awareness

Peer Support for Learning for TTR 4 and CTR 5

Research Question Two

Quantitative Findings

Qualitative Findings Around Control Versus Test Groups

Research Question Three

Assumptions

Quantitative Findings

Qualitative Findings About TTR 6

Summary of the Findings

Limitations of the Study 
Chapter Five: Discussion

Summary of the Study

Summary of the Findings

Returning to the Conceptual Framework

Suggestions for Future Research

Some Final Suggestions on Lessons Learned

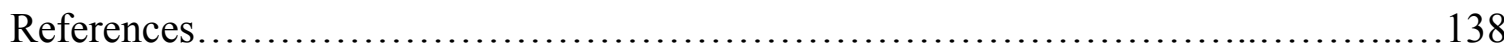

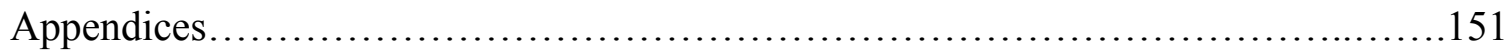

A. Principal's Letter and Consent Form

B. Email to Teachers

C. Teacher Informed Consent

D. Parent Permission Letter

E. Parent Permission Letter in Spanish

F. Student Assent Form

G. Student Assent Form in Spanish

H. Student Engagement Survey (SEI-E)

I. First Interview Questions

J. Second Interview Questions Control Group

K. Second Interview Questions Test Group

L. Pre-Survey Summary Report for Control Teacher 1

M. Post-Survey Summary Report for Control Teacher 1

N. Pre-Survey Summary Report for Test Teacher 2

O. Post-Survey Summary Report for Test Teacher 2

P. Pre-Survey Summary Report for Control Teacher 3

Q. Post-Survey Summary Report for Control Teacher 3

R. Pre-Survey Summary Report for Test Teacher 4

S. Post-Survey Summary Report for Test Teacher 4

T. Pre-Survey Summary Report for Control Teacher 5

U. Post-Survey Summary Report for Control Teacher 5

V. Pre-Survey Summary Report for Test Teacher 6

W. Post-Survey Summary Report for Test Teacher 6 


\section{List of Tables}

Table 1.1: The Four Components of Engagement with Indicators....................6

Table 2.1: The Four Components of Engagement with Indicators.....................20

Table 3.1: Data Collection Timeline..........................................52

Table 3.2: Overview of SPSS Analysis to be Completed During this Research Study....67

Table 4.1: Teacher Descriptive Statistics and Background Characteristics..............75

Table 4.2: Student Demographics Per Classroom...............................78

Table 4.3: Pre-Survey Summary Statistics by Teacher........................... 81

Table 4.4: Post-Survey Summary Statistics by Teacher...........................87

Table 4.5: T-test of Average Change Scores for Teachers 1 and 2 in Each Factor Area.97

Table 4.6: T-test of Average Change Scores for Teachers 4 and 5 in Each Factor Area..98

Table 4.7: T-test of Average Change Scores for Control vs. Test Groups

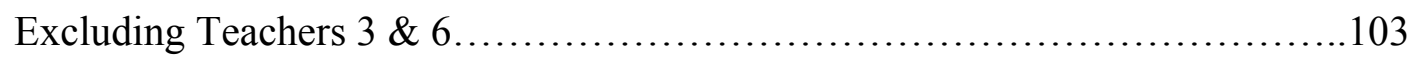

Table 4.8: T-test of Average Change Scores for Control vs. Test Groups in Each Factor

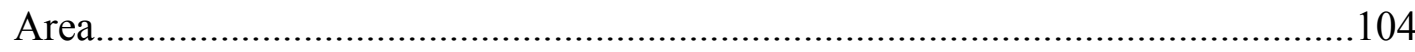

Table 4.9: Coefficients for Average Pre-Survey Score, Title Status, Ethnicity and

Gender.......................................................... 112

Table 4.10: Coefficients for Average Pre-Survey Score, Title Status and Ethnicity.....115 
Figure 1.1: Concept Map............................................... 10

Figure 2.1: Participation-Identification Model...................................17

Figure 2.2: Participation-Identification Model: Withdrawal cycle................... 18

Figure 2.3: Causational Relationships Among Belonging, Engagement, and Achievement...........................................................27

Figure 3.1: Visual of Twelve Participating Teachers.............................46

Figure 3.2: Student Engagement Results Summary Sample.......................63

Figure 3.3: Classroom Change Results Summary Sample..........................64

Figure 4.1: Control Teacher 1 Pre-Survey Engagement Summary Report..............83

Figure 4.2: Control Teacher 1 Post-Survey Engagement Summary Report.............90

Figure 4.3: Control Teacher 3 Post-Survey Engagement Summary Report...............92

Figure 4.4: Test Teacher 6 Post-Survey Engagement Summary Report................94

Figure 4.5. Histogram of Normally Distributed Residuals.......................110

Figure 4.6. Scatterplot of Standardized Residuals Against Standardized Predicted

Values...........................................................111

Figure 5.1: Concept Map................................................ 127 


\section{Chapter One: Introduction}

Schools are powerful institutions with the potential ability to change the lives of students in profound ways. When all goes well, students are consistently engaged in learning from kindergarten until high school graduation. Because the level of student engagement has frequently been found to positively correlate with academic achievement and reduce the likelihood of student dropout, engagement is a concept that is worthy of further study (Finn \& Zimmer, 2012; Fredricks, Blumenfeld, \& Paris, 2004; Marks, 2000; Skinner, Kindermann, \& Furrer, 2008; Skinner, Wellborn, \& Connell, 1990). If students are engaged throughout their school years, they should leave high school with academic, social, and emotional competencies and be ready to either enroll in post-secondary education or enter into the workforce (Furlong, Whipple, St. Jean, Simental, Soliz, \& Punthuna, 2003; Hussar \& Bailey, 2013). A main goal of schools is to create an environment where all students are engaged in learning and able to graduate high school either college or career ready. Sadly, though, that not all students are engaged and successful in school (Burrus \& Roberts, 2012; Hardre \& Reeve, 2003; Kortering \& Christenson, 2009; Warren \& Saliba, 2012).

Student struggles manifest differently depending on the age of the students in question. In the 2008-2009 school year, it is estimated that 447,000 students in first through eighth grade were retained in the United States and unable to be promoted to the next grade (Warren \& Saliba, 2012). At the high school level, approximately $25 \%$ of students do not graduate with a traditional high school diploma within four years (Tyler \& Lofstrom, 2009). While some of these students do eventually graduate or earn an equivalent General Education Development (GED) certificate, between $7.4 \%$ and $12 \%$ of 
16-through-24 year-olds never do (Institute of Education Sciences, 2012). Retention and dropout figures show the most extreme cases in schools, but many other students are working their way through the system in a state of disengagement, or an absence of effort or persistence, which can also have lasting effects on a student's education (Appleton, Christenson, \& Furlong, 2008; Finn \& Zimmer, 2012; Skinner, Kindermann, Connell, \& Wellborn, 2009; Skinner, Kindermann, \& Furrer, 2008).

The root of this problem can be seen in the engagement trends of students as they progress through school. Research indicates that, for many children, their intrinsic motivation, interest, and enthusiasm for learning in school deteriorates from kindergarten until high school completion (or dropout), with the most drastic losses during the transitions to middle and high school (Alexander, Entwisle, \& Horsey, 1997; Dunleavy \& Milton, 2008; Finn, Pannozzo, \& Voelk1, 1995; Lopez, 2011; Roeser, Strobel, \& Quihuis, 2002; Skinner et al., 2009). One theory on why engagement levels drop as students enter middle school is the adjustment students must make from having one teacher to many teachers (Furrer \& Skinner, 2003; McDougall \& Hymel, 1998). Students may feel that they had stronger adult relationships at the elementary level and that this piece is lacking as they enter the middle school environment (Furrer \& Skinner, 2003; McDougall \& Hymel, 1998). Since it is unlikely that the system will change to only a one-teacher system, it is important to attempt to build up engagement for students throughout all of their years in education.

The focus on student engagement represents a shift away from the idea that students' personal characteristics (such as ethnicity and socioeconomic status) are the primary predictors of achievement, and toward the idea that a set of potentially malleable 
academic, behavioral, cognitive and affective processes may have a greater impact on student success in school (Finn \& Voelk1, 1993; Finn \& Zimmer, 2012; Newmann, Wehlage \& Lamborn, 1992; Skinner et al., 2009). Engagement behaviors, unlike ethnicity and socioeconomic status, are responsive to teacher decisions and school practices, rather than students' innate characteristics, therefore allowing for improvements to be made when students are experiencing difficulties along the way (Finn \& Zimmer, 2012).

It is important for schools to target these four engagement processes for each student, identify disengagement when it occurs, and provide appropriate interventions to help improve the engagement trend for that student. In order to provide meaningful interventions, schools need accurate and updated information on all four areas of engagement for each student and a variety of interventions that target each of the four areas. Currently, teachers only have accurate data on students' academic and behavioral engagement, and are possibly missing key areas of need in affective and cognitive engagement. Without identifying students who are disengaged in these areas and providing appropriate interventions when necessary, it is likely that these students will continue to become more disengaged in schools and therefore less likely to achieve to their ability level (Christenson, Reschly, Appleton, Berman, Spanjers, \& Varro, 2008; Skinner, Kindermann, \& Furrer, 2008).

This paper is presented in five chapters. This introduction explains the key terms of engagement, disengagement, and motivation. It also explains that while there are positive benefits for students who are consistently engaged in school, that in reality, many students become more and more disengaged the longer they attend school. The 
chapter then looks at the use of targeted interventions as a possible way to increase the engagement trends of disengaged students. A conceptual framework is presented that modifies Klem and Connell's (2004) Reduced Self-System Process Model to also incorporate the four areas of engagement and the use of interventions.

Chapter Two provides a critical examination of the research in the field of engagement at the elementary level. This chapter takes a look at the benefits of academic, behavioral, and affective engagement for elementary students. It also explores the limited research on cognitive engagement at the elementary level.

The third chapter describes the research methodology. Using pragmatism as a research paradigm, the details of study are clearly described. This mixed-methods study studies four grade teachers and their students to see if knowledge on cognitive and affective engagement is helpful in improving overall engagement scores for students.

Chapter Four looks at the findings of the study from each of the six participating classrooms. The study takes a close look at student engagement levels in the areas of Teacher Relationships, Peer Support for Learning, Family Support for Learning and Future Goals and Aspirations. For each of the research questions, the quantitative data is analyzed first, and then the qualitative data is reviewed to add additional information.

The final chapter reviews the general findings from the study and revisited the conceptual framework. Recommendations for future research as well as suggestions for teachers and administrators are presented in the final thoughts.

\section{Definition of Key Terms}

This section begins with a description of the four components of engagement. It then breaks these four components into two groups, internal vs. external, which presents 
an important distinction that is central to the study. Next, the relationship between engagement and disengagement is explored through the use of a continuum, and the concept of disengagement is described as used in this paper. Lastly, this section discusses the distinctions between motivation and engagement. Motivation is necessary for engagement to occur, but not a guarantee that it will occur. Motivation is the intent, while engagement is the action.

Four components of engagement. According to seminal theories and more recent research, engagement is a multidimensional construct. No agreements have been made, however, on the actual components that make up the definition of engagement (Appleton, Christenon, \& Furlong, 2012; Finn, 1989; Finn \& Zimmer, 2012; Fredricks, Blumenfeld, \& Paris, 2004; Reschly \& Christenson, 2012). For the purposes of this paper, a four-component model of engagement will be used. This definition considers the four key components to consist of academic, behavioral, cognitive, and affective engagement (Appleton, 2012; Finn \& Zimmer, 2012). This definition was chosen because it provides educators enough information to design data-driven interventions that can help improve the overall engagement level of any student (Christenson et al., 2008). In order to more effectively meet the needs of students, interventions must be designed using information from all four categories of engagement (Christenson et al., 2008). Examples of the four types of engagement are listed in Table 1.1 and specifically focus on the educational outcomes that are due to student engagement (Appleton, 2012). 
Table 1.1 The Four Components of Engagement with Indicators.

External Indicators
Internal Indicators

\begin{tabular}{|c|c|}
\hline 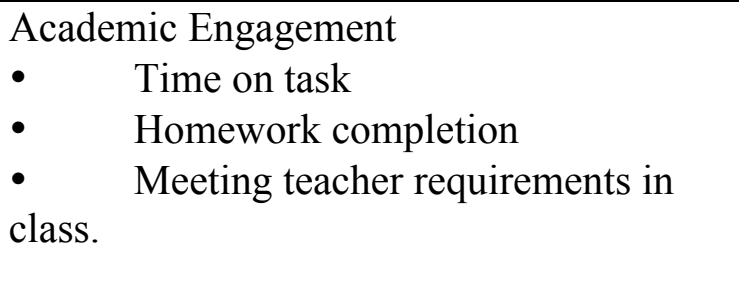 & $\begin{array}{l}\text { Cognitive Engagement } \\
\text { - } \quad \text { Self-regulation } \\
\text { - } \quad \text { Relevance of school to future } \\
\text { aspirations } \\
\text { - } \quad \text { Value of learning (goal setting) } \\
\text { - } \quad \text { Strategic thinking }\end{array}$ \\
\hline 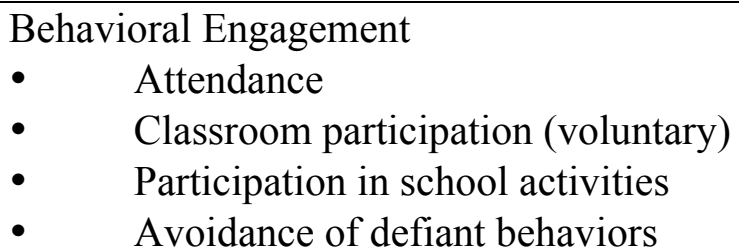 & $\begin{array}{l}\text { Affective Engagement } \\
\text { - } \quad \text { Belonging } \\
\text { - } \quad \text { Identification with staff, other } \\
\text { students, and school } \\
\text { - } \quad \text { School membership }\end{array}$ \\
\hline
\end{tabular}

When looking at the table, there is an important difference between the two engagement categories listed on the left and the two listed on the right. Of these four components, academic and behavioral engagement (on the left) comprise of factors that can be systematically measured by a third party. This means that teachers can develop a clear understanding of the academic and behavioral engagement levels of each student in their class by paying attention, watching the participation of the students, and grading student work. On the other hand, cognitive and affective engagement (listed on the right) are more internal in nature and are not measured in an equally systematic approach. If teachers want to measure these areas in their students, they often rely on student selfreports since indicators of cognitive and affective engagement are not necessarily observable to teachers in daily classroom life (Appleton, 2012). This slight, but important difference between internal and external indicators of engagement is one of the underlying questions in this study. The study hopes to answer whether or not teachers need to have specific information about the cognitive and affective engagement levels of 
each student in their class in order to provide meaningful and appropriate interventions, or if general knowledge of the importance of cognitive and affective engagement is enough to promote students' positive or consistent engagement trends. The study also begins to explore interventions that show evidence of being affective at increasing cognitive and affective engagement at the fourth grade level.

Disengagement. While engagement is ideal for all students, disengagement must also be considered in this discussion. In every school, regardless of geographic location, student demographics, or school size, each student could be placed along a continuum from strongly disengaged to strongly engaged in any of the four engagement areas (Appleton, Christenson, \& Furlong, 2008). Throughout the year, engagement levels for each student can change depending on a variety of variables (Fredricks, Blumenfeld, \& Paris, 2004). A student may be disengaged in all four areas, or in just one or two. In this study, a student is considered disengaged from school if they are lacking in one or more of the four areas of engagement. For example, a student may be considered disengaged if they have strong attendance and are meeting the teacher's requirements, but have no relationships with the students or the teacher and feel no sense of belonging at school. In this case, the student is disengaged in the area of affective engagement. Another student may also be considered disengaged, or showing signs of disengagement, if they have solid friendships at school and strong family support, but they do not complete the required assignments and their grades are below average. This second student is not academically engaged in school. In both of these cases, a major factor in school success is missing and an intervention is needed to help re-engage the student in their particular area of weakness. 
Motivation. Finally, discussions of engagement often bring up questions about the relationships between engagement and motivation. Just as there are different ideas about engagement, there are also different ideas about how engagement relates to motivation. For the purposes of this paper, motivation and engagement are considered to be separate, but related constructs (Reschly \& Christenson, 2012). Motivation is also believed to be a necessary precursor for engagement to occur (Metallidou \& Vlachou, 2007).

Engagement is defined as the overt behaviors that can be seen in students, such as their participation in class, time spent on homework, and perseverance. Said another way, motivation is the intent to do something while engagement is energy in action (Appleton et al., 2008). Motivation is thought to be necessary, but not sufficient, for engagement to occur (Appleton et al., 2008). That means that it is possible for students to be motivated but not engaged in their learning. Thus, the distinction between motivation and engagement is really the distinction between the thoughts and beliefs of a student about school or learning, and their actual participation in school (Ryan, 2000).

When looking at the four-part definition for engagement, some of the areas fall under the definition of engagement while others appear to be more representative of students' motivation. The academic and behavioral engagement categories can be seen as actions that the students do, or don't do, and can be observed or systematically measured by a third party. For example, a teacher can record when students turn in their homework, their scores on a test, and how often they interrupt the class by yelling out. Because they are active in nature, the academic and behavioral engagement components are clearly part of the overall category of engagement. Cognitive engagement, though, 
has elements of both internal beliefs and external actions that allow it to be measured in a variety of ways — including self-surveys, teacher questionnaires, and third party observations. It could be considered both part motivation and engagement depending on what was measured and how the data was collected. Affective engagement is dealing with students' feelings of belonging and is more difficult to observe by a third party. This would make it seem to fit more under the ideas of motivation. Affective engagement provides motivation for the investment of energy the other areas of engagement require (Finn \& Zimmer, 2012). Stated another way, "successful classroom performance presupposes the existence of both the 'will' and the 'skill,' which fuse through a dynamic interaction between motivation, cognition, and metacognition during the learning process and over time" (Metallidou \& Vlachou, 2007, p. 4). Because of this intertwining of motivation and engagement, I will refer to affective engagement as part of engagement, rather than motivation, for the remainder of this paper.

\section{Conceptual Framework}

A conceptual framework is the set of concepts, assumptions, expectations, beliefs, and theories that help inform and support the research behind a research study (Maxwell, 2005). Since motivation is often the precursor to engagement, it is logical that the conceptual framework for this study is based on motivational theory (Klem \& Connell, 2004; Metallidou \& Vlachou, 2007).

Using the basic structure from Klem and Connell's (2004) Reduced Self-System Process Model, the framework for this study was expanded to include both the internal and the external components of engagement, as well as a place for interventions that can be used to increase study engagement. Figure 1.1 shows one example of a motivational 
model that can be used to analyze student engagement (Hardre \& Reeve, 2003; Klem \&

Connell, 2004; Skinner, Wellborn, \& Connell; 1990).

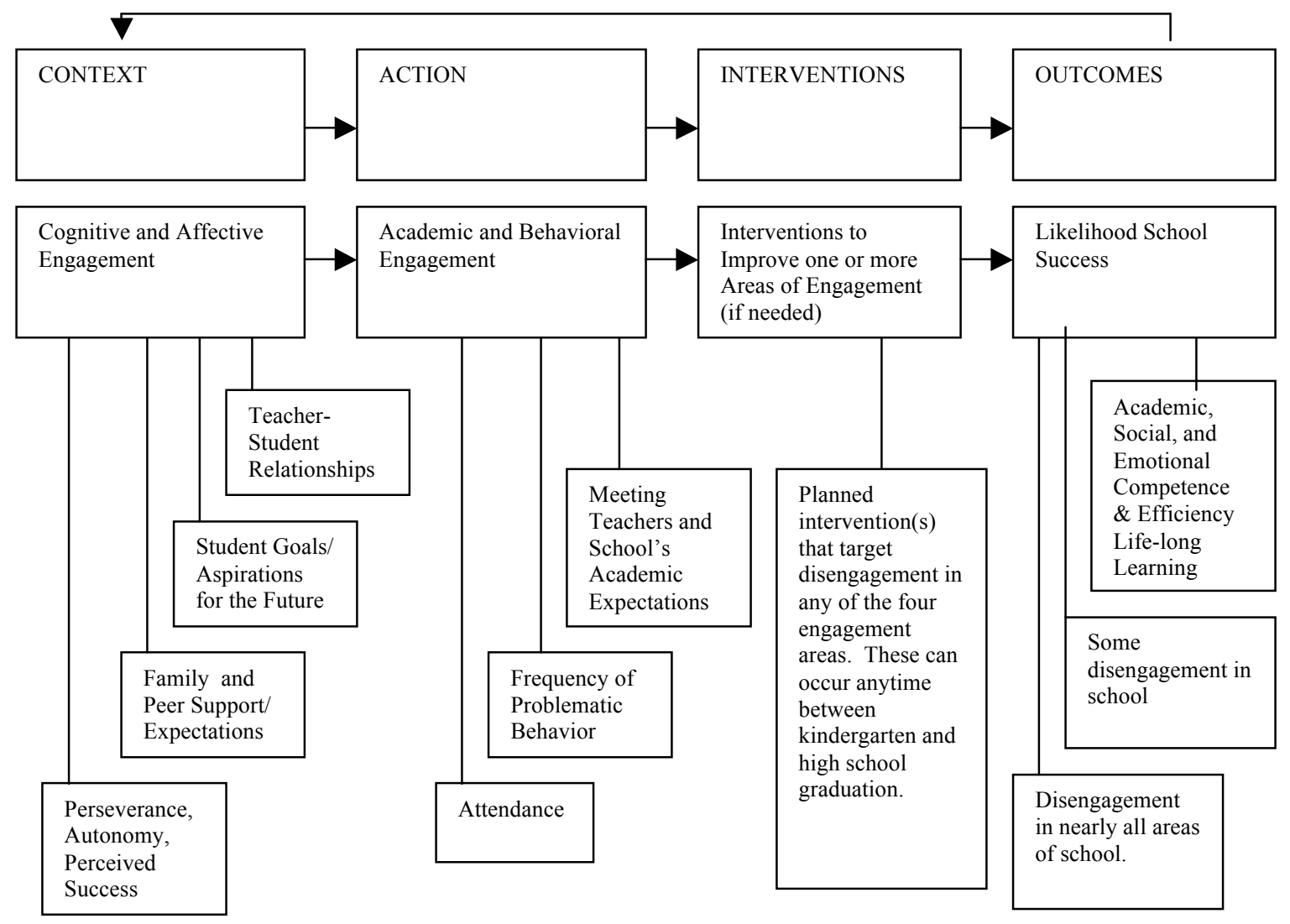

Figure 1.1. Concept Map (Adapted from The Reduced Self-System Process Model, Klem \& Connell, 2004)

Since motivation is needed for engagement, it makes sense that this conceptual framework includes both the idea of motivation (otherwise referred to as cognitive and affective engagement) as well as engagement (specifically academic and behavioral engagement) of students. Interventions have been added to the conceptual framework, but are not often seen in traditional motivational models (Hardre \& Reeve, 2003; Klem \& Connell, 2004). They have been included because interventions can change engagement 
levels and are a key component in the proposed research study (Appleton, 2012;

Christenson et al., 2008).

In Figure 1.1, the four main headings at the top include Context, Action, Interventions, and Outcomes. This cyclical pattern examines the relationship among student's experiences in the social context, their actions as a result of this context, the possible need for interventions to improve engagement levels, and then the outcomes of these actions, which are seen as school success or school difficulties. The division of the four engagement categories into those that are internal and those that are external is also deliberate. Since teachers do not know the internal engagement levels of their students, they must often make decisions based on their knowledge of students' academic abilities and behavior (Appleton, 2012; Christenson et al., 2008). Reschley and Christenson (2006) speculate, though, that cognitive and affective engagement (the internal components) are potential mediators of academic and behavioral engagement. This means that, "engaging or disengaging students cognitively and affectively precedes changes in students' behavior and academic engagement," (Reschley \& Christenson, 2012, p. 9) which is why this category is listed first in the motivational theory model. In general, most motivational theories tend to occur in a cyclical pattern, represented by the arrow at the bottom of the model. Students who have positive support both at school and at home, tend to behave in certain ways that help them become engaged in school, creating positive outcomes, and further promoting their sense of belonging and overall engagement (Finn, 1989; Hughes \& Kwok, 2005; Skinner, Wellborn, \& Connell, 1990). Disengaged students also enter a cyclical pattern where their thoughts about school and their actions in school result in negative outcomes, 
further promoting their sense of disengagement, and causing a decreased engagement trend throughout the years (Finn, 1989; Hughes \& Kwok, 2005; Skinner \& Belmont, 1993; Skinner, Wellborn, \& Connell, 1990). It is likely that students in the disengaged cycle are not receiving interventions or are receiving interventions that are targeting the wrong area of need. By missing this important part of the model, they are likely to become more disengaged with school as time goes by.

\section{Research Questions}

The following three questions are being proposed for this study:

1. For teachers at the same school, is knowledge of students' cognitive and affective engagement scores associated with increased student engagement?

2. Is teacher participation in the test group associated with meaningful changes in the classroom and increased student engagement scores? If so, what interventions are used?

3. How are student demographic and background characteristics associated with the amount of change students' show between their pre and post-survey results? (Specifically looking at school type, gender, and ethnicity).

\section{Purpose of the Study}

There are two main goals to this research study. The first goal is to see if teachers benefit from systematically collecting and reviewing the cognitive and affective engagement scores of their students, and the second is to explore interventions that increase students' cognitive and affective engagement scores at the fourth grade level. The study intentionally targets elementary students because this type of study has only been attempted at the high school level (Appleton, 2012; Appleton, Christenson, Kim \& 
Reschley, 2006). Knowing that student engagement levels tend to decrease over time, the study examines if early interventions can reverse this effect and re-engage students who have become disengaged in their learning. By creating a solid foundation and promoting high levels of engagement at the elementary level, these students will hopefully be more engaged learners as they enter middle school. 


\section{Chapter Two: A Review of the Literature}

The following chapter presents a review of the literature on student engagement. The chapter begins with a history of the student engagement concept, and identifies Finn's (1989) Participation-Identification Model as a seminal theory of engagement. The history ends with an expanded explanation and justification for the use of the four-part model in this paper.

The majority of this chapter focuses on the educational outcomes for elementary students who are engaged academically, behaviorally, cognitively, and affectively. Beginning with academic and behavioral engagement, a clear link connects these two engagement areas to student achievement (Bodovski \& Farkas, 2007; Caldas, 1993; Finn, Pannozzo, \& Voelk1, 1995; Finn \& Zimmer, 2012; Gottfried, 2009; Lamdin, 1996; Roby, 2004; Sutton \& Soderstrom, 1999). Affective engagement is discussed next, and is thought to be the foundation for engagement at the elementary level. The research points to a three-part process where students have a strong sense of belonging at school, when leads to increased engagement levels, and then results in higher achievement (Finn, 1989; Hamre \& Pianta, 2001; Furrer \& Skinner, 2003; Klem \& Connell, 2004; Voelk1, 2012). Cognitive engagement is the final component mentioned in this subsection, and the area with the least amount of research (Finn \& Zimmer, 2012; Howse, Lange, Farra, \& Boyles, 2003). Possible reasons for this lack of research are provided, as well as a few studies that focus on upper elementary students' cognitive engagement.

The chapter concludes with a section that articulates the purpose and significance of the study. The conclusion restates the need for elementary students to be engaged in all four areas and points out the difficulties that face researchers on measuring 
engagement - especially at the elementary level. The conclusion ends with the current trends of using data at the classroom, school, district, state, and federal levels to inform decisions that affect students on a daily basis. The data that is used tends to represent academic and behavioral engagement only, but this provides an incomplete picture of students' actual student engagement levels. The significance of this study is to determine if data on students' cognitive and affective engagement levels in fourth grade will prove beneficial for teachers' decision-making practices in their classrooms.

\section{The History of Student Engagement}

The idea of student engagement has continued to evolve since its conception in the 1980's (Finn, 1989; Fisher \& Berliner, 1985; Reschly \& Christenson, 2012). Two distinct areas of research lead to the idea of student engagement, but in many ways researchers were discussing the same issue from different perspectives. The first line of research looked into improving student achievement (Fisher \& Berliner, 1985). This research found that students who had more academic engaged time had higher achievement levels than those students who were less engaged in their learning (Fisher \& Berliner, 1985; Reschly \& Christenson, 2012). The other area of research focused on decreasing the number of students who were bored, unmotivated, uninvolved, or had a high likelihood of dropping out of school (Appleton, Christenson \& Furlong, 2008; Fredricks, Blumenfeld \& Paris, 2004; Finn, 1989; Reschly \& Christenson, 2012). In both of these cases, student engagement became the middle ground that promoted academic achievement and increased the likelihood of succeeding in school.

Early models of engagement fit into two different groups: those that focused on the educational context and those that focused on intrapersonal skills of students. (Finn \& 
Zimmer, 2012). These two concepts would later combine to create a more cohesive model for student engagement that is used today (Finn, 1989). Newmann (1981) looked at the context and argued that only school reform could increase student engagement and decrease the number of students who were dropping out. His guiding principles included ideas such as having clear consistent goals, keeping school sizes small, including students in the decision making process, and encouraging cooperative student-staff relationships (Finn \& Zimmer, 2012; Newmann, 1981).

Self-System Process model. In contrast to these context driven solutions, the self-system process model was presented as an intrapersonal explanation for disengagement (Connell, 1990; Connell \& Wellborn, 1991; Finn \& Zimmer, 2012; Klem \& Connell, 2004). The self-system process assumes that humans have the basic needs of competence, autonomy, and relatedness. This theory asserts that as people move through life, they are constantly assessing if these three needs are being met and making adjustments if they are not. Therefore, the self-system process model states that schools that support competence, autonomy and relatedness in their students have higher levels of student engagement and student achievement, regardless of other contextual factors (Connell, 1990; Connell \& Wellborn, 1991; Finn \& Zimmer, 2012).

The Participation-Identification model. In 1989, Finn presented the Participation-Identification Model as a different way to look at student engagement. This model became a seminal theory because it was the first to explain how both context and intrapersonal skills interacted to impact the likelihood of improved student engagement and achievement (Finn, 1989; Finn \& Zimmer, 2012). Up until this point, researchers believed that engagement was a result of one or the other, but the Participation- 
Identification Model asserted that both context and intrapersonal skills were necessary for student engagement to occur (Finn \& Zimmer, 2012).

According to the Participation-Identification Model, school outcomes were the result of students' active participation in school and classroom activities and a feeling of identification with the school (Finn, 1989). The arrow at the bottom of the model suggests that student engagement is the result of a cyclical pattern of participation and identification with school that is constantly in motion. There are two cycles that are presented in this model: the first, seen in Figure 2.1, is for students who are engaged and not likely to drop out of school.

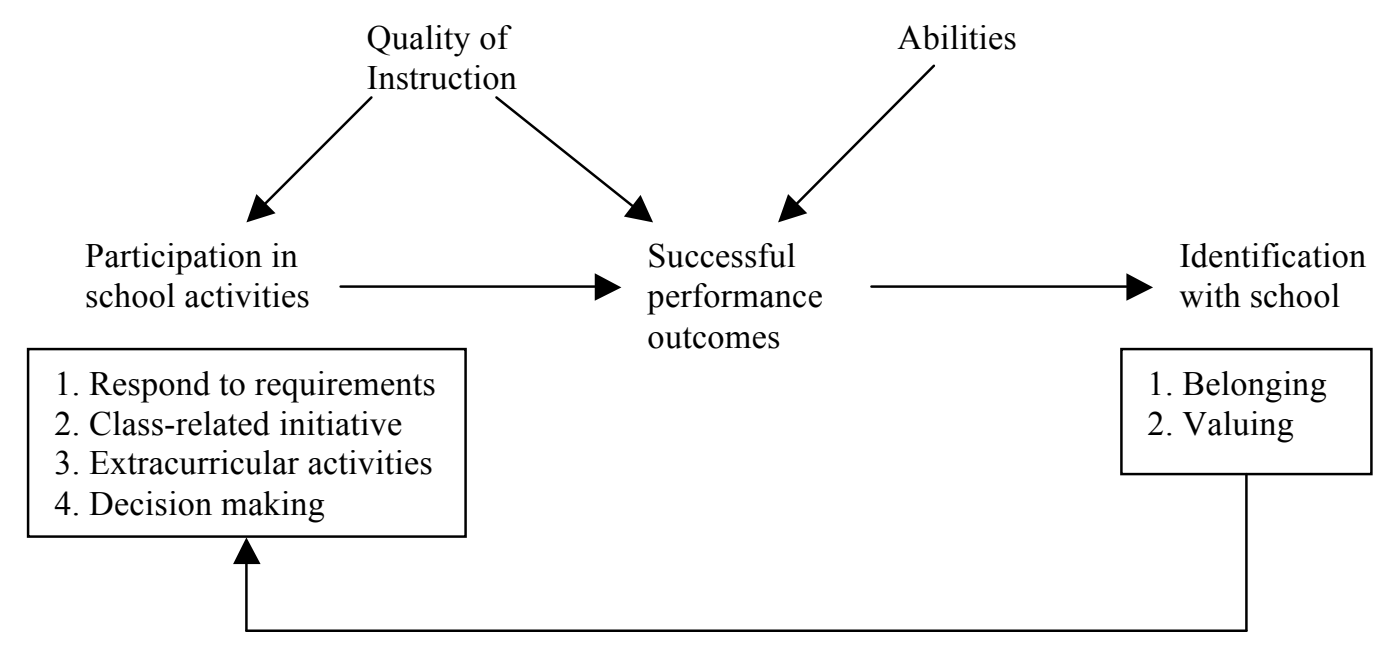

Figure 2.1. Participation-Identification Model; (Finn, 1989)

In Figure 2.1, Finn (1989) shows a cyclical process where students' participation in school is a prerequisite for academic success and a sense of belonging. It also shows that students who feel successful, and like they belong in school, are more likely to participate in school activities, further promoting a positive cycle of learning. Outside of this participation-identification cycle, Finn (1989) also points out that the quality of 
instruction, and students' innate abilities both contribute to the likelihood of students continuing in this positive engagement cycle, or become more disengaged with school.

Figure 2.2 shows Finn's second engagement cycle, which represents students who have withdrawn from school. This model developed from Rumberger's (1987) belief that dropping out of school may be the result of a long-term process of disengagement, rather than simply factors such as socioeconomic status and ethnicity. Instead, it was suggested that, "dropping out itself might better be viewed as a process of disengagement from school, perhaps for either social or academic reasons" (Rumberger, 1987, p. 111).

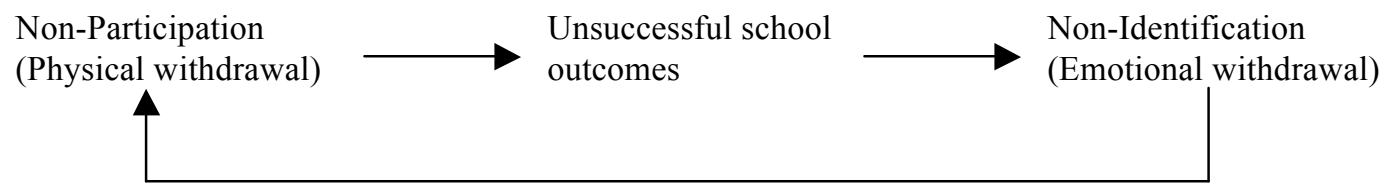

Figure 2.2. Participation-Identification Model: Withdrawal Cycle (Finn, 1989)

This model is one interpretation of disengagement over time. In this version of the model, students do not participate in the school environment, leading to unsuccessful school outcomes, and therefore causing students to feel emotionally detached from the learning environment. Of course, this is not thought to happen immediately when students enter school, but as a gradual process that takes place over many years. Finn (1989) openly admits that this model does not explain all reasons why students may drop out or become disengaged, but that it does portray the withdrawal of some individuals as a process of disengagement over time.

Three-part model of engagement. Between 1989 and 2004, the field of student engagement continued to develop based on the ideas set by the ParticipationIdentification Model (Finn, 1989; Fredricks, Blumenfeld, \& Paris, 2004). Newer models 
all contained the internal and external elements that were originally combined by Finn (1989); however, three engagement components (behavioral, emotional, and cognitive engagement) became the new norm in the field (Fredricks, Blumenfeld, \& Paris, 2004). While not all engagement researchers agreed on the names of these three terms, the ideas around these three engagement terms did overlap in a majority of the models (Appleton, 2012; Reschly \& Christenson, 2012). Fredricks, Blumenfeld, and Paris' (2004) review of the research on engagement defined these three key components as behavioral engagement, cognitive engagement, and emotional engagement.

According to Fredericks, Blumenfeld and Paris (2004), behavioral engagement is defined as following the rules, being involved in the lessons, and participating in schoolrelated activities. Emotional engagement refers to a student's affective reactions to the classroom, the teacher, and the other students. Cognitive engagement looks at a psychological investment in learning, a student's willingness to challenge themselves, and the desire to go beyond the requirements. While much of the research done in the field of engagement matched these three categories, Fredericks, Blumenfeld, and Paris (2004) openly acknowledge that a few researchers had their own ideas about how to categorize engagement, and others disagreed on the components that belonged into each group. No consensus has been agreed upon by the major researchers in student engagement (Appleton, Christenson, Kim \& Reschley, 2006; Fredricks, Blumenfeld, \& Paris, 2004).

Four-part model of student engagement. Since Fredericks, Blumenfeld, and Paris' (2004) review of the research, newer models of engagement have appeared with three, four, or more components (Appleton, Christenson, Kim \& Reschley, 2006; Libbey, 
2004; Rumberger \& Lim, 2008). The four-component model, seen in Table 2.1 is consistent with the latest research of Appleton and his colleagues (Appleton, 2012; Appleton et al., 2006). This model takes the three components from Fredericks, Blumenfeld, and Paris (emotional, cognitive, and behavioral engagement) and bifurcates the behavioral engagement domain — separating academic behaviors from other behavioral indicators (Appleton et al., 2006; Christenson et al., 2008; Reschly \& Christenson, 2006). By doing this, researchers can differentiate between students who have high social skills, but are less academic, from students who are more academic, but less social (Carter, Reschly, Lovelace, Appleton, \& Thompson, 2012). Without this division, these two types of students would look very similar in an engagement survey (each scoring high on half of the behavioral options).

Table 2.1. The Four Components of Engagement with Indicators

\begin{tabular}{|c|c|}
\hline \begin{tabular}{ll}
\multicolumn{2}{l}{ Academic Engagement (external) } \\
- & Time on task \\
- & Homework completion \\
- & Meeting teacher requirements in \\
class. &
\end{tabular} & \begin{tabular}{l}
\multicolumn{2}{l}{ Cognitive Engagement (internal) } \\
- \\
- \\
aspirations \\
Relevance of school to future \\
- $\quad$ Value of learning (goal setting) \\
$\quad$ Strategic thinking
\end{tabular} \\
\hline 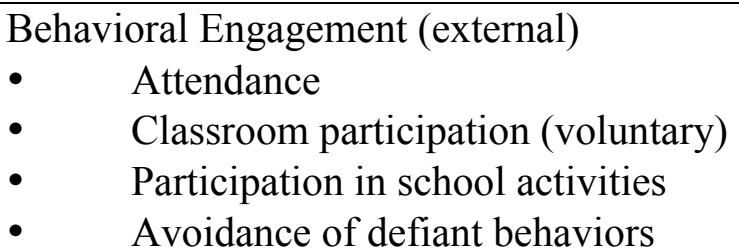 & $\begin{array}{l}\text { Affective Engagement (internal) } \\
\text { - } \quad \text { Belonging } \\
\text { - } \quad \text { Identification with staff, other } \\
\text { students, and school } \\
\text { - } \quad \text { School membership }\end{array}$ \\
\hline
\end{tabular}

In this model, it is understood that the four categories represent two internal engagement indicators and two external engagement indicators and that these four are interconnected to make up the larger engagement construct. (Appleton et al., 2006; Christenson et al., 2008). It is also thought that these internal and external components are constantly fluctuating and that a positive or negative engagement trend in one area 
can result in a change in one or more of the other engagement areas as well (Finn, 1989). For example, a student who has shown strong work habits in the past may begin to demonstrate lower quality work if he feels that his teacher does not like him or that his peers do not think that being smart is socially acceptable trait. In this case, low affective engagement may result in a decrease in academic engagement. In order to promote school success for all students, teachers must be aware of the engagement levels of their students in all four sub-groups, and be prepared to provide meaningful interventions when necessary.

Knowing that disengagement in any of the four areas can have lasting negative affects on a student's education, it is also important to know what results have been associated with high levels of engagement. The next section looks at the research that has been done at the elementary level in the areas of academic, behavioral, and affective engagement. When elementary students are engaged academically and behaviorally, they are more likely to be successful in school (Bodovski \& Farkas, 2007; Caldas, 1993; Finn, Pannozzo, \& Voelk1, 1995; Finn \& Zimmer, 2012; Gottfried, 2009; Lamdin, 1996; Roby, 2004; Sutton \& Soderstrom, 1999). Affective engagement appears to be part of a threepart process that indirectly promotes student achievement. It is thought that affective engagement is the foundation for elementary students, which promotes better behavioral engagement and higher academic achievement (Finn, 1989; Furrer \& Skinner, 2003; Hamre \& Pianta, 2001; Klem \& Connell, 2004; Voelk1, 2012). 


\section{The Outcomes of Student Engagement}

Schools are often focused on the most effective ways to promote academic achievement with their students. The research consistently shows that student engagement has been associated with academic achievement; however, these statements may be the result of an oversimplified definition of student engagement (Connell, Spencer, \& Aber, 1994; Dolezal, Welsh, Pressley, \& Vincent, 2003; Dunleavy \& Milton, 2008; Finn \& Zimmer, 2012; Fredricks, Blumenfeld, \& Paris, 2004; Hughes, Luo, Kwok, \& Loyd, 2008; Lutz, Gurthrie, \& Davis, 2006; Marks, 2000). In many cases, researchers analyze only a few of the overall engagement components, such as time on task, attendance, or student behavior, in order to say that engagement leads at achievement.

This section looks at the benefits for elementary students that have been researched in the four sub-groups of engagement. It begins with the achievement benefits associated with academic and behavioral engagement. The section then moves to the benefits of affective engagement, which research predicts is the foundation necessary for students to become engaged in the other areas, and eventually to achieve in schools (Finn, 1989; Furrer \& Skinner, 2003; Hamre \& Pianta, 2001; Klem \& Connell, 2004; Voelk1, 2012). The section concludes with an exploration into the limited research that has been done on cognitive engagement for elementary students. Possible reasons for this lack of research are provided as well as links from cognitive engagement to academic achievement.

Academic and behavioral engagement and student achievement. Academic and behavioral engagement components are both outwardly expressed and can therefore be observed or recorded by a third party (Appleton, 2012, Fredricks, Blumenfled, \& 
Paris, 2004). This is important because teachers, as well as outside researchers, can assess students' academic and behavioral engagement by observing the classroom and assessing the work of the students. While academic and behavioral engagement are two distinct categories in Appleton's four-part engagement model, many of the research studies combine elements from the two categories into their findings about student achievement. For this reason, the first section will look at the combination of academic and behavioral engagement. Some key indicators of these include time on task, attendance, homework completion, meeting the teacher's requirements, participating in school activities, attentiveness, and the avoidance of defiant behavior (Appleton et. al., 2006; Christenson et. al., 2008).

Time on task. Time on task is a concept that has been studied since the 1920's (Fisher \& Berliner, 1985; Washburne, Bogel, \& Gray, 1926). These studies began by assessing the amount of time students looked at books, or appeared to be paying attention to the teacher, but have increased in their complexity over the years (Fisher \& Berlinger, 1985, Washburne, Vogel, \& Gray, 1926). In the 1970's, research began to look at the time spent throughout the school day to try and make connections to student learning (Stallings, 1980). Stallings found that across the country, elementary school days varied in length by as much as an hour and a half, but that this extended school time had no association with increased student learning. Instead, it was found that the amount of time students spent for academic learning time, or time spent reading, writing, or doing math, was positively associated with academic gains (Stallings, 1980). Within that time, the percent of time the students were engaged in learning tasks was also of vital importance to student achievement (Bodovski \& Farkas, 2007). Evertson (1982) took these findings 
a step further and noted that low-achieving students were engaged in academic activities an average of $40 \%$ of the school day, while high-achieving students are engaged in academic activities on average, $85 \%$ of the time. Time spent engaged in academic learning appears to have a clear connection to student achievement, but it is not the only variable that can be tied to student learning (Stallings, 1980).

Attendance. Attendance is another indicator of engagement that has been shown to be moderately to strongly correlated with student achievement (Caldas, 1993; Finn \& Zimmer, 2012; Gottfried, 2009; Lamdin, 1996; Roby, 2004; Sutton \& Soderstrom, 1999). Studies began by analyzing these two factors at the school level and found a positive correlation between school attendance and overall student achievement (Caldas, 1993; Lamdin, 1996; Roby, 2004). Roby (2004) also found that student attendance was greater for students at the elementary level $(95.6 \%)$ and that this figure continued at the middle and high school levels, which follows the achievement trends of students that also deteriorates as students progress from elementary school to high school. Lastly, it was noted that the high school with the lowest achievement scores in the study, also had the lowest attendance rate of $89.6 \%$ : a highly statistically significant difference from the average attendance rate at the elementary level (Roby, 2004).

Gottfried (2009) also looked at the relationship between attendance and achievement with elementary and middle school students, but this time the analysis was done at the individual student level. This longitudinal study took place between the $1994 / 1995$ and 2000/2001 schools years and involved nearly 333,000 students in the Philadelphia School District. In the end, the results showed that individual student attendance was an important indicator of achievement as measured by GPA, math and 
reading test scores (Gottfried, 2009). This was consistent across all grade levels studied and is further evidence supporting the importance placed on the relationship between attendance and achievement.

Attention and defiant behavior. Besides attendance, behavioral engagement includes the voluntary participation in school and classroom activities as well as avoidance, resulting in defiant behavior. Rowe and Rowe (1992) studied over 5,000 students, ages 5-14, to see if there was a relationship between reading achievement and students' attentiveness in school. In this case, attentiveness is defined as paying attention to the teacher or task as deemed by a third- party observer. They found that, regardless of socioeconomic status, age, or gender, that students' inattentiveness in the classroom had a strong negative effect on reading achievement, as well as students' attitudes towards reading, and their reading activity at home (Rowe \& Rowe, 1992). They also found the opposite to be true. Students who scored higher in reading assessments also showed to have higher attentiveness in the classroom.

Three years later, Finn, Pannozzo, and Voelkl (1995) did a similar study, but added the variable of defiant behavior to see how this would affect inattention and achievement. Their study focused on the achievement levels of fourth grade students who were inattentive, and/or who displayed defiant behavior, compared to their average peers. Inattentive behavior was defined as students who were not focusing on the teacher or the content covered in class, while defiant behavior was seen as behavior that interrupted the learning in the classroom and often required teacher intervention. While students who were defiant had lower test scores than those students who were considered average by their teachers, the students who were inattentive had the lowest test scores of 
all (Finn, Pannozzo, \& Voelkl, 1995). Students who were both inattentive and disruptive showed no statistical different in their test scores from students who were simply inattentive. The results support the idea that teachers often overlooked inattentive students, and this non-participation over time was shown to have the strongest effect on student achievement scores compared to the average and defiant groups.

Moving from academic and behavioral engagement, the outcomes of affective engagement appear to be indirectly tied to student achievement. Instead a three part process is explained where affective engagement leads to academic and behavioral engagement, which in turn leads to achievement. The following section also explains the necessity for early elementary students to form strong bonds with their teachers and for older elementary students to associate with peers who are supportive and value educational success.

Affective engagement for elementary students. Affective engagement includes a student's sense of belonging, membership in the school community, and identification with school, staff, and peers. As children progress through school, the relationships they develop with others continue to affect their ability to actively engage in school (Lynch \& Cicchetti, 1997). School-aged childrens' feelings of connectedness to others in their school setting are related to the degree that they feel engaged with their social environment (Connell, 1990; Lynch \& Chicchetti, 1997; Lynch \& Wellborn, 1988). Researchers view affective engagement as the foundation, or a precursor, to a student becoming behaviorally and academically engaged in school (Finn, 1989; Furrer \& Skinner, 2003; Hamre \& Pianta, 2001; Klem \& Connell, 2004). Figure 2.3 outlines the causational pattern thought to be in play in all students (Hamre \& Pianta, 2001; Furrer \& 
Skinner, 2003). It is believed that students who are affectively engaged in schools (and feel a sense of belonging), are then able to behaviorally and academically engage in schools, which in turn allows students to achieve (Finn, 1989; Hamre \& Pianta, 2001; Furrer \& Skinner, 2003; Klem \& Connell, 2004; Voelkl, 2012).

One longitudinal study involving 805 students from fourth through eighth grade looked at the relationship between affective and behavioral engagement and found affectively engaged students to have more effortful participation in learning activities than their less affectively engaged peers (Skinner, Furrer, Marchand, \& Kindermann, 2008). When analyzed, it was found that students' engagement levels tended to decrease from fall to spring. The one group that did not follow this trend was the students with higher affective engagement in the fall. These students continued to have increases in behavioral engagement as the school year went on. Student relationships and affective engagement levels appear to predict behavior more than academics; however, since academics have been linked to student behavior, the three are tightly connected and play an important role in the success of a student (Hamre \& Pianta, 2001; Skinner, Furrer, Marchand, \& Kindermann, 2008).

\begin{tabular}{|c|c|c|}
\hline $\begin{array}{l}\text { Sense of } \\
\text { Belonging and } \\
\text { Quality } \\
\text { Relationships } \\
\text { (Affective }\end{array}$ & $\begin{array}{l}\text { Behavioral, and } \\
\text { Academic } \\
\text { Engagement. }\end{array}$ & $\begin{array}{l}\text { Student } \\
\text { Achievement }\end{array}$ \\
\hline Engagement) & & \\
\hline
\end{tabular}

Figure 2.3 Causational Relationships Among Belonging, Engagement, and Achievement. 
Affective engagement begins to develop the first time a child enters a school environment. Students who are able to successfully navigate early social environments in school get off to a better start and benefit from this knowledge as they progress through their years in education (Hamre \& Pianta, 2001). Students who are socially adjusted to school show emotional regulation, enjoy school, are able to make friends, are engaged, and demonstrate self-control (Hamre \& Pianta, 2001; Lynch \& Cicchetti, 1997). These students are also more likely to succeed than their less socially adjusted peers (Furrer \& Skinner, 2003; Goodenow \& Grady, 1993; Hamre \& Pianta, 2001; Hamre \& Pianta, 2005). One factor that has been shown to have a strong impact on student adjustment in the early years is the quality of teacher-student relationship.

Early teacher-student relationships. Studies with students as early as kindergarten have addressed the need for strong teacher-student relationships (Hamre \& Pianta, 2001; Hamre \& Pianta, 2005; Hughes \& Kwok, 2006; Lynch \& Cicchetti, 1997). Teachers have a much stronger impact on students than simply teaching academic skills. They are also responsible for regulating activity levels, providing behavioral support and teaching communication and coping skills; all of which are vital for success in later life (Doll, 1996; Entwisle \& Hayduk, 1988; Hamre \& Pianta, 2001). Teachers' feelings of closeness with individual students have proven to be good predictors of students' school liking, school performance, and motivation from kindergarten through middle school (Birch \& Ladd, 1997; Furrer \& Skinner, 2003; Hamre \& Pianta, 2001; Skinner \& Belmont, 1993). Teachers may serve as an attachment figure for young children, and when a close relationship is present, students may feel more supported in their ability to 
cope with social and academic challenges in the elementary years (Hughes \& Kwok, 2006; Pianta \& Steinberg, 1992).

On the other hand, teacher-student conflict has positively correlated with school avoidance, students' dislike of school, a lack of cooperation in the classroom, a decline in social behavior, and an increase in peer-perceived aggressive behavior (Birch \& Ladd, 1997; Hamre \& Pianta, 2001). Indeed even when controlling for cognitive abilities and problem behaviors at the kindergarten level, teacher's reports of closeness with students predicted academic success, disciplinary infractions, and school suspensions through eighth grade (Hughes \& Kwok, 2006). All of these correlations affect students' behavioral or academic engagement, which have lasting effects on student achievement. Knowing that early teacher-student relationships are an important precursor to student engagement and achievement, researchers have begun to study interventions that could alter the negative trajectory of students who have low affective engagement levels. Hamre and Pianta (2005) studied 910 five and six-year-old students who their teachers deemed to be at-risk based on behavior, attention, social, and/or academic factors. Half of these students were enrolled in regular first grade classrooms while the other half were enrolled in classrooms with a strong emphasis on structural and emotional support. The students who were given additional support ended the year with achievement scores and teacher-student relationships equal to their low-risk peers (Hamre \& Pianta, 2005; Hughes \& Kwok, 2006). The other students in regular classrooms continued to have poor relationships with their teachers and scored on average lower than their low-risk peers in the same classroom (Hamre \& Pianta, 2005). While this is just one study, it begins to build a case that low affective engagement is a serious concern for students at the 
elementary level, and that interventions need to be put in place to help students build positive teacher-student relationships early in their school career that can impact overall student success.

Peer relationships. While a student's relationship with their teachers plays an important role in the elementary years, the influence of peers has also been explored (Furrer \& Skinner, 2003; Goodenow \& Grady, 1993; Lynch \& Cicchetti, 1997). Research has shown that the power of peer influence grows as children progress through school — with upper elementary school and middle school marking the highest points of peer conformity (Goodenow \& Grady, 1993; Lynch \& Cicchetti, 1997). For students at this age range, an especially influential factor seems to be children's perceptions of the support they receive from peers (Furrer \& Skinner, 2003). A number of studies have reported a link between children's perceptions of peer support and their academic goals, engagement, and self-esteem (Furrer \& Skinner, 1997; Murdock, 1999; Wentzel, 1998). Since peer influence can be either positive or negative towards student engagement, this may prove difficult for students who choose to socialize with friends who have strong anti-academic norms (Goodenow \& Grady, 1993).

While relatively little research has been done on the importance of peers and its impact on affective engagement in the early elementary years, strong peer relationships appear to be important in making the transition from elementary to middle school easier on students (Furrer \& Skinner, 2003; Goodenow \& Grady, 1993; Lynch \& Cicchetti, 1997; McDougall \& Hymel, 1998; Wentzel, 1998). At this critical time, students usually need to adjust to a drastic decrease in teacher attention, which now comes from multiple teachers, rather than just one or two. Students with stronger peer relationships and whose 
friends value academic achievement have an easier time making this adjustment than students who are lonely or dissatisfied with school (Furrer \& Skinner, 2003; McDougall \& Hymel, 1998). Since the current engagement trends show the greatest decrease in engagement occurring at this transition time to middle school, it is important that students have strong peer relationships during their upper elementary years in preparation for this change. Ideally, these strong relationships will help support students and make the transition to middle school a bit easier to handle.

Although studies of student engagement exist for students from elementary school through college, not all grade levels have been equally explored (Appleton, Christenson, Kim, \& Reschly, 2006; Finn \& Zimmer, 2012; Fredricks, Blumenfeld, \& Paris, 2004; Linnenbrink \& Pintrich, 2003). At the elementary level, academic, behavioral, and affective engagement are the three areas that have been the most explored. The following section discusses the current lack in research on cognitive engagement at the elementary level. Developmental patterns of student cognitive development are also presented with research support to help explain why this gap may exist.

\section{A lack of research on cognitive engagement at the elementary level.}

Cognitive engagement at the elementary level is by far the least researched area of the four. Cognitive engagement includes components such as self-regulation, the value a student puts on education, the relevance of school to future aspirations, and strategic thinking. The current research at the elementary level appears to be split into studies that focus either on early elementary - kindergarten through third grade - or upper elementary — fourth through sixth grade — students. The few studies that do exist for early elementary students, their findings on association with academic achievement have been 
mixed (Finn \& Zimmer, 2012; Howse, Lange, Farra, \& Boyles, 2003). At the upper elementary age, a few studies have reported students' self-efficacy to be a major component related to cognitive engagement and achievement.

Measuring cognitive engagement. One underlying reason for the dearth of research in this area may be the difficulty researchers have had in accurately measuring cognitive engagement. In the past, researchers have observed or videotaped students for evidence of cognitive engagement, had students respond to questionnaires, asked students to write out their steps when solving difficult problems, or stopped students during their work to explain their thinking processes (Finn \& Zimmer, 2012; Peterson, Swing, Stark, \& Waas, 1984). Using these techniques, students at fourth grade and higher have shown a connection between cognitive engagement scores and achievement, but little correlation has been found for younger students (Finn \& Zimmer, 2012; Peterson, Swing, Stark, \& Waas, 1984).

In one of the rare studies of kindergarten students dealing with cognitive engagement, teachers measured students' ability to self-regulate, as one possible measure of cognitive engagement. The results of this study showed that students' inability to selfregulate in kindergarten was not correlated to lower reading scores (Howse, Lange, Farran, \& Boyles, 2003). It is possible that these measures do not accurately measure the important components of cognitive engagement for students at the elementary level. Alternatively, early elementary students are not developmentally ready to complete the required tasks being asked of them by researchers.

Developmental stages for elementary students. Students begin elementary school in what Newmann and Newmann (2003) refer to as the 'early school age stage.' 
This stage lasts until the students are around the age of seven. (Mahatmya, Lohman, Mtjasko, \& Farb, 2012). At the early school age stage, students begin to transition from externally to internally regulated actions. This means that students who are deemed cognitively engaged at this level are able to self-regulate their behaviors in order to participate in classroom activities, pay attention, and stay on task (Mahatmya, Lohman, Mtjasko, \& Farb, 2012; Newmann \& Newmann, 2003). Despite the age-appropriateness of these actions, they appear to the outside observer as a student who is behaviorally engaged much more than the results of cognitive engagement. Therefore, it is not surprising that research is inconsistent in its efforts to show a connection between cognitive engagement and achievement in early elementary students.

Between the ages of seven and twelve, the students enter into the 'upper elementary stage' (Newmann \& Newmann, 2003). The research shows that the connection between cognitive engagement and achievement also becomes more apparent in students during this stage of development (Mahatmya, Lohman, Mtjasko, \& Farb, 2012; Newmann \& Newmann, 2003; Sedaghat, Abedin, Hejazi, \& Hassanabadi, 2011). It is typical for students in this age range to develop concrete operational reasoning, acquire new skills, and gain the ability to self-evaluate their performances against the performances of others (Mahatmya, Lohman, Mtjasko, \& Farb, 2012; Newmann \& Newmann, 2003, Piaget, 1972). This is a time when students begin to think in a more logical way, develop their own beliefs and interests, and begin to figure out their place in a more complex society (Newmann \& Newmann, 2003). Unlike adolescents; however, students at this developmental stage have difficulty entertaining hypothetical situations, connecting ideas that are not logically related, or explaining in detail the thoughts behind 
their actions - a common request of researchers studying cognitive engagement (Newmann \& Newmann, 2003). These may not be possible for students until they reach high school or college.

Research that supports the developmental stages. Looking at the research that has been done throughout the elementary years, and thinking about the developmental stages that children go through during these years, some conclusions can be made about how cognitive engagement is developed and when it can be measured in students. When looking at a comparative study of high- and low-risk kindergarten and second grade students, researchers found that the only difference between the two groups was found at the second grade level (Howse, Lange, Farran, \& Boyles, 2003). It was noted that the most successful second grade students were able to self-regulate and focus their attention on the task at hand better than their lower achieving peers. For students at the early school age stage, this ability to focus and self-regulate may be the first developmentally appropriate signs of cognitive development.

Another study looked at cognitive engagement and achievement of students from first through fifth grade, but focused on the teachers' teaching strategies rather than the students' thinking processes (Taylor, Pearson, Peterson, \& Rodriguez, 2003). By analyzing students across such a wide age rage, some students were in the early school age stage, some were beginning to transition to the upper school age stage, and others still had firmly transitioned (Newmann \& Newmann, 2003). When looking at all the data, the most consistent finding was that the teachers who promoted higher-order thinking skills, either through their questions or the tasks they designed, had students who were more cognitively engaged in their learning and who made greater academic gains 
(Taylor, Pearson, Peterson, \& Rodriguez, 2003). Teacher scaffolding and modeling has also been linked to students' improved cognitive development (Lutz, Guthrie, and Davis, 2005). While students are going through these important cognitive stages, perhaps the most important variable to the development of strong cognitive engagement is the amount of exposure students have to teachers who promote and model strong thinking skills at the elementary level.

If students are exposed to teachers who encourage cognitive development throughout their elementary years, by the time they reach fourth or fifth grade, it is more likely that students will be developmentally ready for researchers to measure some aspects of cognitive engagement. Self-efficacy has been identified as a significant predictor of upper elementary students' cognitive engagement, motivation, self-regulation processes, and overall performance (Linnenbrink \& Pintrich, 2003; Metallidou and Vlachou, 2007). Bandura (1977) defines self-efficacy as a person's coping behavior and how much effort they will expend in the face of obstacles and aversive experiences. Those students with a strong self-efficacy will sustain a greater effort for a longer amount of time than those who have lower level of self-efficacy, and will learn more in the process (Bandura, 1977; Linnenbrink \& Pintrich, 2003; Metallidou and Vlachou, 2007). Another study of middle school students found very similar results (Sedaghat, Abedin, Hejazi, \& Hassanabadi, 2011). By this age a student's perceived ability, their belief that the work is meaningful and important for the future, and their desire to learn the task at hand were all positively correlated to cognitive engagement and student achievement. In both studies, students who were willing to work hard in the face of obstacles and who felt 
the work was meaningful had high cognitive engagement and high student achievement (Metallidou and Vlachou, 2007; Sedaghat, Abedin, Hejazi, \& Hassanabadi, 2011).

Motivation and cognitive engagement. While a desire to learn plays an important part in a student's cognitive engagement level, the motivation behind that desire is also equally important. Three separate studies, one of upper-elementary students, one of middle school students, and one of college students, reported that some students worked in order to master the task at hand, while other students wanted to please the teacher or impress their peers (Greene \& Miller, 1996; Meece, Blumenfeld, \& Hoyle, 1988; Sedaghat, Abedin, Hejazi, \& Hassanabadi, 2011). Greene and Miller (1996) refer to this more social motivation behind working as shallow engagement and in multiple studies this was found to negatively correlate to student achievement (Meece, Blumenfeld, \& Hoyle, 1988; Sedaghat, Abedin, Hejazi, \& Hassanabadi, 2011).

In one study, 275 fifth and sixth grade students answered a questionnaire about the motivation behind their work in science. Students' answers were then placed in one of three categories: students who work to master a task, students who work for social reasons, and students who try to avoid work. While it makes sense that students who avoid work have a lower cognitive engagement level, it is also interesting to note that students who worked for social reasons, such as pleasing a friend or teacher, also had lower cognitive engagement scores. It was the students who worked hard to master a task for themselves that had the highest level of cognitive engagement. In order for students learning to be meaningful for cognitive engagement, it needs to be self-driven and primarily for the purposes of academic growth or bettering ones own self. 
Keeping this in mind, teachers who are hoping to make a positive impact with their students in the area of cognitive engagement need to find a way to make the work they are doing in the classroom meaningful for the students. Students need to see a purpose for the work and believe that the assignment is going to help them find success in their future. While getting a student to complete an assignment is a good start, it appears that unless students are doing the work for their own self-improvement, and to enhance their futures, that the work is not as cognitively engaging as it could be.

\section{Synthesis}

After reviewing the research on engagement outcomes at the elementary level, there are a few conclusions that can be made. First, and most importantly, the research shows that students at the elementary level need to be engaged in all four areas of engagement in order to increase their likelihood of current and future school success. Students who are disengaged, even at the earliest stages of school, enter a cycle of disengagement that tends to get worse over time (Alexander, Entwisle, \& Horsey, 1997; Dunleavy \& Milton, 2008; Finn, 1989; Finn, Pannozzo, \& Voelkl, 1995; Lopez, 2011; Roeser, Strobel, \& Quihuis, 2002; Skinner et al., 2009). Lehr, Sinclair, and Christenson (2004) found that they could identify high school students at risk of dropping retrospectively as early as third grade based on their attendance, achievement, and behavior records. Ideally, these behavioral and academic indicators would have been seen as low engagement levels at the elementary level and interventions would have been put in place to try and get these students more engaged in school. While there is no guarantee that these interventions would have eliminated the chance of students dropping 
out in the future, the problem is expected to have been much more manageable at the elementary level, and it is possible the interventions could have made an impact.

The second conclusion that can be made from the data is that measuring engagement is a difficult task, especially at the elementary level. Engagement is never static, especially for elementary students who are going through many developmental changes as they progress from kindergarten through fifth grade. One student will develop skills much sooner than another, but this does not necessarily mean that a second student is disengaged; it just means that their engagement may need to be measured in a different way. Because of this challenge, and the initial focus on students who were at risk of dropping out of high school, it is understandable that the majority of the current studies involve older students who are more developmentally capable of complex thinking and self-reflection (Appleton, 2012; Fredricks, Blumenfeld, \& Paris, 2004; Newmann \& Newmann, 2003). Despite the challenges that are present when trying to measure the engagement levels of elementary students, the research presented in this chapter demonstrates the need for future work in this area.

The third conclusion involves the ways that teachers use data. Classroom teachers are relying more and more on data to help them make the best decisions for their students. Teachers use data gathered from test scores, attendance records, behavior records, student participation, homework scores, and class work to make important decisions that affect the lives of students on a daily basis. While all of these data points provide important pieces of information, in most cases, the data is only coming from the areas of academic and behavioral engagement and does not allow teachers to look at the whole engagement picture for each student in the classroom. 
It might be argued that teachers know the affective and cognitive engagement levels of their students, but some research is beginning to show otherwise (Furrer \& Skinner, 2003; Klem \& Connell, 2004; Linnenbrink \& Pintrich, 2003). Students’ affective and cognitive engagement levels are much more difficult for teachers to accurately assess because they include an internal, emotional element of which teachers are not fully aware. When one study compared the results of engagement surveys completed by the students' teacher and then the students themselves, a large discrepancy was found (Klem \& Connell, 2004). In this one case, $40 \%$ of middle school students reported themselves as disengaged with school, while teachers believed that only $17 \%$ of the same students were disengaged (Klem \& Connell, 2004). Furrer and Skinner (2003), also support the need for student input by stating that teachers were able to accurately report on students' efforts, persistence, and attitudes toward school; however, students' own accounts of their behaviors and emotions add vital information that would be otherwise unknown. Since research is beginning to show that teachers' intuition on students' affective and cognitive engagement is not always accurate, it is important that another method be put into place (Furrer \& Skinner, 2003; Klem \& Connell, 2004; Linnenbrink \& Pintrich, 2003). In order to more affectively promote high engagement trends for all students across time, it is necessary that schools begin to find a systematic way to gather data on the affective and cognitive engagement levels for all students. This information, along with the data teachers already have on academic and behavioral engagement, will allow teachers to see a more clear picture of each student's engagement trends, and to implement interventions when any of the four engagement areas begin to drop. 


\section{Purpose and Significance of the Study}

The primary purpose of this study is to build on the foundation of the current research in student engagement and to determine if cognitive and affective engagement scores are helpful when trying to encourage highly engaging fourth grade classrooms. As described in Chapter 3, half of the teachers will be provided with the cognitive and affective engagement scores of their students, and the other half will not know their students' scores. This second group is an important comparison group because they represent the current trend in elementary classrooms where teachers base their decisions on academic and behavior engagement information and their perceptions of the cognitive and affective engagement levels of their students. The study proposes to determine the extent to which student input on cognitive and affective engagement levels is meaningful for teachers in promoting high levels of student engagement.

The second goal of the study is to determine if any interventions are particularly helpful in increasing students' cognitive and engagement levels in fourth grade.

Interviews with teachers will be used to see if any connections can be made between teacher interventions and specific student engagement scores as recorded in pre- and post- student surveys.

This study is significant because it will contribute to Appleton's (2012) current literature on the benefits of cognitive and affective engagement data at the high school level, but will begin to explore the use of cognitive and affective engagement data with upper elementary students. As of 2012, the research revealed that only a few districts were using this type of data for their high schools students (Appleton, 2012). The data allowed teachers and administrators to track the engagement levels of each of their 
students in all four areas, and to identify students who were at high risk for disengagement. Interventions were put in place for students who were deemed at high risk, in order to try to improve the trajectories of those students. While the efforts at the high school level are still in the beginning stages, the additional cognitive and affective data appears to be beneficial for keeping track of and working towards increasing the engagement levels of all students (Appleton, 2012). Taking the foundation from the work being done at these high schools, this mixed-methods study presented in the following chapter will begin to explore if these same practices would be beneficial at the elementary level. 


\section{Chapter Three: Methodology}

This chapter begins with a description of pragmatism as a relevant research paradigm and a justification for a mixed-methods research approach, followed by a discussion of the sampling process and the timeline for research. A justification for the use of the Student Engagement Instrument-Elementary (SEI-E) version is given. The chapter continues with a detailed explanation of how the student surveys and teacher interviews were administered. Finally, the chapter concludes with a discussion on the data analysis approach that will be used in the study, including the use of t-tests and multiple linear regressions for the quantitative data, and coding schemes for the qualitative data.

\section{Paradigm}

Paradigms help to explain a researcher's general orientation about the world and the nature of research that should be done in order to further our knowledge about how the world works (Guba \& Lincoln, 2005). Pragmatism is the paradigm that is being used for this research proposal because it is, in many ways, a bridge between other paradigms that often lead to either quantitative or qualitative research in isolation (Johnson \& Onwuegbuzie, 2004). Classic pragmatists (i.e. Charles Sanders Peirce, William James, and John Dewey) saw pragmatism as a way to include the insights of both qualitative and quantitative research while still seeking workable solutions (Cherryholmes, 1992).

Pragmatism is different from nearly all other paradigms because it is focused on action rather than philosophy (Johnson \& Onwuegbuzie, 2004). The overall goal of Pragmatism is to focus on a problem and to use all available methods as a means to finding a solution (Cherryholmes, 1992; Johnson \& Onwuegbuzie, 2004). Pragmatism 
rejects common dualisms (quantitative vs. qualitative, or subjectivism vs. objectivism) and prefers to find more moderate and commonsense solutions. Knowledge, in this paradigm, is viewed as both constructed and based on the reality of the world we live in (Johnson \& Onwuegbuzie, 2004). Overall, truth and knowledge are both conceptualized as tentative. In other words, what is true today may be proved fallible tomorrow based on new insights provided by research (Johnson \& Onwuegbuzie, 2004).

For researchers who have a pragmatic philosophy, mixed-methods studies are often the most appropriate. They allow the researcher a wide variety of tools and strategies that can be used together to help find solutions that may otherwise be impossible if limited to either quantitative or qualitative methods (Johnson \& Onwuegbuzie, 2004). In this study, both quantitative and qualitative data were collected sequentially in order to answer the research questions. More specifically, the study used student self-surveys from quantitative research techniques, and open-ended teacher interviews from qualitative research techniques. Used in combination, the goal was to determine if it was beneficial for teachers to have cognitive and affective information about their students in order to increase student engagement levels. By using a mixedmethods approach, the data was triangulated to better ensure validity and reliability. The interviews informed the researcher of the teacher's thoughts about the study and any interventions that had been used as a result of the survey data, while the pre and postsurveys provided a numerical means to determine which classrooms were most successful at increasing student engagement scores. Without both pieces of data, it would be nearly impossible to gain a clear enough picture of what happened in the 
classrooms to determine if any interventions might be generalizable to other fourth grade learning environments.

\section{Research Questions}

The following three questions are being proposed for this study:

1. For teachers at the same school, is knowledge of students' cognitive and affective engagement scores associated with increased student engagement?

2. Is teacher participation in the test group associated with meaningful changes in the classroom and increased student engagement scores? If so, what interventions are used?

3. How are student demographic and background characteristics associated with the amount of change students' show between their pre and post-survey results? (Specifically looking at school type, gender, and ethnicity).

\section{Why Fourth Grade?}

The Student Engagement Instrument-Elementary (SEI-E) Version has shown initial evidence of its effectiveness for students between third and fifth grade (Carter et al., 2012). Of the potential age groups that could used to complete this study, third grade was eliminated as a possible target because the data on cognitive engagement is unclear about the readiness of third grade students for this type of measurement (Mahatmya, Lohman, Mtjasko, \& Farb, 2012; Newmann \& Newmann, 2003). Fourth and fifth grade students appear to be developmentally ready to accurately complete the survey; however, more cognitive studies have currently been done with students fifth grade and older (Mahatmya, Lohman, Mtjasko, \& Farb, 2012; Newmann \& Newmann, 2003; Sedaghat, Abedin, Hejazi, \& Hassanabadi, 2011). By choosing fourth grade, this study can help to 
fill this gap in the research and possibly broaden the age range for cognitive and affective engagement data.

\section{Setting}

The study took place in a large school district in the Pacific Northwest that serves over 20,000 students. The district is made up of nearly 50\% Title I schools, and class sizes vary between grades and schools, but most fourth grade classrooms have between 25-36 students. In 2012, 49\% of the student population was comprised of minority students (with the highest minority population being Latino/Hispanic, followed by Asian Americans), 52\% of students qualified for free and reduced lunch, $26 \%$ of the students were English Learners, and 13\% qualified for Special Education services, (Oregon Department of Education, 2012-2013). Three schools volunteered from this school district to participate in the research study.

While these numbers show that there is a diverse population that attends this public school district, the school specific ethnicity compositions vary drastically from one school to the next. For example, one elementary school in the district has a student population that is $69 \%$ Hispanic, $2 \%$ Black, $1 \%$ Asian, $27 \%$ White, and $1 \%$ Other, while another elementary school has a population that is 58\% White, 13\% Asian, 19\% Hispanic, 2\% Black, and 8\% Other. The same discrepancies can be found in the number of students who receive free and reduced lunch at various school sites ( $>95 \%$ at the first elementary school and $37 \%$ at the second). In both cases, the numbers of minority students and students who receive free and reduced lunch tend to be higher at Title I schools. In addition to different student populations, Title I schools also have increased funding from the government, additional staff support, and a more regimented curriculum 
that must be followed within the classroom (United States Department of Education, 2004). Generally, schools that do not receive Title I funding have a more limited staff and more flexibility in how teachers can choose to teach a curriculum that meets the state standards.

\section{Research Sites}

Since Title I and non-Title I schools have different resources and different school populations, it was important to have participants from both types of schools. While an even number of teachers in both settings was the goal, in reality, the study included six teacher volunteers: five of whom taught at a non-Title I school and only one who taught at a Title I school (see Figure 3.1). This unequal representation of teachers from both types of schools was not ideal, but it allowed for the beginning explorations of differences between the two groups and the teachers' strategies for engaging students.

Teachers in Control Group

Teachers in Test Group
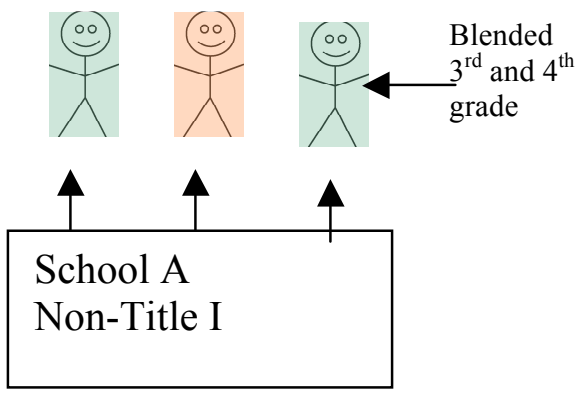

\section{School C} Title I
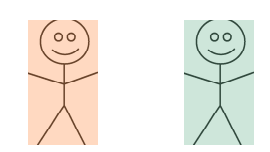

School B Non-Title I

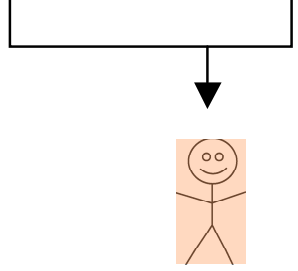

Figure 3.1: Visual of Classrooms at the Six Research Sites 


\section{Participants}

There were two major groups of participants in this research study: teachers and students. Six fourth grade teachers participated in this study, along with the students enrolled in these six classrooms. Assurance of confidentiality was given to all participants in this study. Names of people and places were changed in all written reports and in any presentations that may occur.

Teachers. Six teachers from three different schools volunteered to participate in this research study. At schools A and B, there were at least two fourth grade teachers that volunteered. This allowed both of these schools to have one teacher in the test group and one teacher in the control group, so that these two classrooms, with more similar parent involvement and student populations could be compared. All teachers in this study were required to participate in two interviews either in person or through the use of Skype. The use of Skype allowed face-to-face interviews to occur, but was often more convenient for both the teachers and the researcher. This was a helpful tool for two teachers during their first interview, but was not as helpful for the post interview. During this post interview, it was important to present the data to the teachers while the interview was in progress, so only face-to-face interviews were done.

Students. Students in this study were selected if their homeroom teacher volunteered for the study. Students and parents were given the choice to participate or not, but all students in the six classrooms were asked to participate. In order to maintain confidentiality, all students had the option to take the surveys regardless of parent permission. However, student data was only included in the study if the student received 
parent permission, and if they, themselves, agreed to participate. Students who did not have permission from their parents, but chose to complete the surveys in class, had their data shredded immediately following the surveys. These surveys served as a pre-and post-assessment to determine if teachers' knowledge of scores was beneficial in creating a statistically significant increase in students' engagement scores.

\section{Sampling}

When creating a study that involved a variety of teachers and students from across a school district, it was important to have a clear plan for selected participants. The recruitment and selection of the teachers for this study began at the district level. The second step was to ask principals for permission to use their school as a possible research site. After principal permission was granted, teachers were invited to participate in the study. The section concludes with student participants and the notification of parents.

District approval. Since research was done at multiple school sites across a school district, it was important to get permission before starting. The particular school district that was being used in this study required a formal paper including a summary overview, a description of the risks and benefits to all participants, and the inclusion of all appendices. This document was then submitted to District Office for its review and approval.

Principal permission. After permission for this research study was granted by the school district, the next step was to ask for permission from the elementary principals (Appendix A). All schools with at least two fourth grade teachers were asked to participate in this study, however, only six principals granted permission. Many of the principals that turned down the offer to participate in the study mentioned a lack of time 
and a feeling of an already full workload as reasons for not participating. These comments continued to be heard from even the teachers who did volunteer and will be looked at in greater detail later in the paper.

Institutional Review Board. The final approval for this research study came from Portland State's Institutional Review Board (IRB). The IRB specifically requested that both district and principal approval letters be included in the application for this study, so this step had to occur after the previous two steps had been completed successfully. Once approval was granted from IRB, then it was time to ask fourth grade teachers in the district if they would be interested in participating in this study.

Initial teacher contact. An initial teacher interest form (Appendix B) was sent to all fourth grade teachers who worked at a school where the principal has granted permission for the school to be involved in the research study. This one page document provided a short description of the importance of student engagement, explained that students become less engaged with school the longer they attended, and then provided the requirements for a teacher who would like to participate in the study. Teachers who were interested in the study returned the initial interest form (Appendix B) to the researcher. After a weeks time, a follow up email was sent to all teachers who had not responded to the initial letter. In the end, six teachers chose to volunteer for the study and all other possible participants requested not to participate. Once teachers had expressed an interest in the study, the researcher visited their school to answer any questions they had and to provide them with the teacher informed consent form (Appendix C). Teachers had a week to think about the decision and to let the researcher know. 
Once the teachers had volunteered, the final stage was choosing the control and test groups. Since there were six teachers participating in the study, three needed to be in the control group and the other three would be in the test group. Schools sites A and B both at two fourth grade teachers, so each of these schools had one teacher randomly assigned to each of the groups. The two final teachers were given a group more intentionally. The third teacher at School A was teaching a $3^{\text {rd }}$ and $4^{\text {th }}$ grade blended classroom and the only teacher from School C was teaching an all-fourth-grade class. Since School C was the only Title I school, it was important to put this teacher in to the test group. This would allow the researcher to begin to analyze the impact of cognitive and affective engagement data in Title I schools. In addition, the teacher with the $3^{\text {rd }}$ and $4^{\text {th }}$ grade blended classroom only had half of her kids eligible to participate in the study (since only $4^{\text {th }}$ grade students were allowed), so it was important to have this teacher as part of the control group.

Student participants and parent permission. Once the teachers had volunteered, the researcher visited all of the classrooms to explain the study to the students. Students had the opportunity to ask any questions that they wanted and to be able to meet the researcher before the study began. Students were given two forms during this visit. The first form was the parent permission form (Appendices D \& E). This form, written in both English and Spanish, explained the purpose of the study, what was being asked of the student, and the risks and benefits of participating. Parents could choose to contact the researcher at any time if they wanted further clarification, and were asked to either grant or refuse permission for their child to participate. 
The second form students were given was an assent form (Appendices F \& G) that explained in student friendly language what they were being asked to do and allowed the students to decide if they would like to participate in the study. Even if a child's parent has granted permission, the student was told that they could choose not to participate in the study at any time with no repercussions. This form was also available in both English and Spanish. Students were given a week to return their permission forms to school, should they choose to participate. The forms were returned in a sealed envelope, provided by the researcher, and dropped off in a box in a common area so that the teachers were unaware of which students were participating in the study. In order to further ensure confidentiality, all students in the classroom were given the option to complete the survey. Students who had not been granted permission to participate in this study, or who choose not to participate had their survey results shredded immediately after the surveys were given. The data for these students was not included in the study in any way.

The parent permission form and student assent form were the only two documents that were translated into Spanish for this study. All students in the district were provided instruction in English at least part of every school day, so it was assumed that the students could complete the forms in English. A large portion of the parent population, however, was Spanish speaking and so it was important that the two forms that parents received also be translated into Spanish. All parents were provided with two copies of the parent permission and student assent form so that one copy could be kept for their own records. The other study forms, such as the student survey, were not sent to parents, and were therefore, provided in only English. 


\section{Data Collection Timeline}

The following section provides the timeline for the study and reasons behind these decisions. Table 3.1 shows the dates when each step was completed. The entire study was completed within the 2013-2014 school year in order to ensure that teachers and students stayed together throughout the study.

Table 3.1: Data Collection Timeline

\begin{tabular}{|c|c|}
\hline Date & Action to be Completed \\
\hline November, 2013 & $\begin{array}{l}\text { Principals sent permission forms to allow their school } \\
\text { site to participate in the research study (Required } \\
\text { before IRB submission) }\end{array}$ \\
\hline December, 2013 & Application submitted for IRB approval. \\
\hline Early February, 2014 & $\begin{array}{l}\text { Interest forms given to fourth grade teachers from all } \\
\text { elementary schools with principal permission for } \\
\text { research (After receiving IRB approval) }\end{array}$ \\
\hline Early February, 2014 & $\begin{array}{l}\text { Teachers contacted with additional study information. } \\
\text { Teacher consent forms due. }\end{array}$ \\
\hline Mid February, 2014 & First interview of the six teacher participants. \\
\hline Mid February, 2014 & $\begin{array}{l}\text { Researcher visited six classrooms and provided } \\
\text { students with parent permission and assent forms. All } \\
\text { forms due in one week. }\end{array}$ \\
\hline End of February, 2014 & $\begin{array}{l}\text { Administer the first survey to the } 6 \text { fourth grade } \\
\text { classrooms. }\end{array}$ \\
\hline Early March, 2014 & $\begin{array}{l}\text { Provide the classroom summary of engagement results } \\
\text { to the teachers in the test group. }\end{array}$ \\
\hline Mid May, 2014 & $\begin{array}{l}\text { Administer the second survey to the six fourth grade } \\
\text { classrooms. }\end{array}$ \\
\hline End of May, 2014 & $\begin{array}{l}\text { Second interview of all six teachers. Pre-survey data } \\
\text { was given (or reviewed) and then all teachers received } \\
\text { their change data from the post-survey. }\end{array}$ \\
\hline
\end{tabular}

Table 3.1 was the result of wanting to provide the teachers as much time between pre- and post-surveys as possible, while still completing the study during one academic school year. Teachers had nine weeks of school instruction time (not including winter or 
spring break) between the pre and post surveys so that the test group teachers had time to receive their student data, and then make any meaningful classroom changes that they chose. Teachers were not required to implement any interventions in their classroom, but nine weeks was deemed by the researcher as an appropriate amount of time to see meaningful changes in the data of fourth grade students. This was deemed appropriate because teachers in the district already completed report cards for students at the end of every ten-week semester. If ten weeks was long enough to see changes in the data for fourth grade students in each subject area, then the engagement levels of students should also be able to change over nine weeks of school.

\section{Finding an Appropriate Student Engagement Measure}

In order to create the most effective study possible, it was necessary to review the current measures of student engagement that were being used with upper elementary students (grades 3-5). Fredricks, McColskey, Meli, Mordica, Montrosse, and Mooney (2011) analyzed twenty-one engagement measures that were currently being used for students in upper elementary school through high school. When eliminating all of the engagement instruments that were effective only for middle and/or high school participants, there were five that had been deemed to be valid and reliable for upper elementary students (Fredricks, Blumenfeld, Friedel, \& Paris, 2005; Juniper Gardens Children's Project, n.d.; Roehrig \& Christensen, 2010; Skinner, n.d.; Wigfield, Guthrie, Perenchevich, Taboaba, Klauda, McCrae \& Barbosa, 2008). Of those five, two of the instruments were teacher reports — where teachers mark the engagement levels based on a variety of questions for each of the students in their classroom (Skinner, n.d.; Wigfield et al., 2008). Another two instruments used with elementary students were observational 
measures — where an outside observer entered the classroom and provided an overall engagement score based on factors such as students' time on task, and the number of students who participated in the lesson (Juniper Gardens Children's Project, n.d.; Roehrig \& Christensen, 2010).

Since one of the goals of this study was to see if teachers changed their practices based on a deeper understanding of the cognitive and affective engagement levels of their students, it was vital to find a student self-report that focused on these two aspects of engagement. None of these previously mentioned four engagement instruments allowed for the teachers to understand the students' levels of engagement from the students' perspective, and therefore all four were eliminated as possible tools for this study. An instrument that was found to be effective for elementary students was the School Engagement Measure (SEM) (Fredricks et al., 2005; Fredricks et al., 2011); however, an examination of this instrument revealed that it focused on the overall engagement of students at the school level, rather than the classroom level (which was the focus of this study). The School Engagement Measure includes questions such as, "I like being at school," or "I try to watch tv shows about things we are doing in school." Fredricks et al. (2005) found that while these questions (and the others on the survey) did provide an overall engagement level for each student, they are not written with enough detail to provide insight into why a student was at a certain engagement or disengagement level in their school environment. It was because of these reasons, that the School Engagement Measure was also eliminated as an effective tool for this study and the search for another measurement tool was deemed necessary. 
After eliminating these other engagement measures, the Student Engagement Instrument-Elementary Version (SEI-E) was selected as the most appropriate measurement tool for this study. Additional information about the SEI-E is discussed in greater detail in the following section.

\section{Data Sources and Collection}

Two sources of data were collected for this study: student survey data and teacher interviews. This section begins by explaining why the Student Engagement InstrumentElementary Version was the best choice for this study. It is then followed by a detailed description of how the SEI-E was administered to students. Finally, the section concludes with a description of the teacher interviews that were conducted for all teacher participants.

Student Engagement Instrument-Elementary Version. This study needed an age appropriate student survey that systematically measured cognitive and affective engagement. After much research, the Student Engagement Instrument-Elementary Version (SEI-E) was found to be the most appropriate measurement tool for this study because it fit both of the required criteria. The SEI-E was a new version of Appleton, Christenson, Kim, and Reschly’s (2006) Student Engagement Instrument (SEI). The SEI was originally designed to assess the cognitive and affective engagement levels of middle and high school students, but the new SEI-E was specifically designed for students in third through fifth grade (Appleton et al., 2006; Fredricks et al., 2011). Using Croncach's alpha, the original version was shown to have an internal reliability of .72-.92, and has also passed tests on construct and criterion-related validity (Fredricks et al., 2011). The SEI (middle and high school version) was currently being used in many districts across 
the United States and data continued to show the utility of the instrument (Reschly, Betts, \& Appleton, 2012).

As indicated previously, there were very few self-report instruments that were valid at the elementary level (Fredricks, McColskey, Meli, Mordica, Montrosse, and Mooney, 2011). Because of this, the SEI-E was created and the first pilot test of its reliability and validity was done (Carter, Reschly, Lovelace, Appleton, \& Thompson, 2012). The SEI-E was created by Carter et al. (2012) then analyzed by an expert panel of engagement scholars. The researchers wanted to ensure that the wording of each question was developmentally appropriate and that the questions were accurately addressing either cognitive or affective engagement, which were the goals of the survey (Carter, et al., 2012).

The final product was then tested with third through fifth grade students at four elementary schools in a large urban school district in the Southeast. The sample population was 30\% African-American, 29\% Hispanic, 28\% White, 8\% Asian, and 4\% Multi-Racial. 59\% of the students in the study were eligible for free and reduced lunch, $14 \%$ were eligible for special education services, and 16\% were designated as English Language Learners. While this district as a whole had a higher minority population than the school district in this study, the Title I school's population was similar to that of the district in the Carter, et.al. study. The Title I school's population was 52\% Hispanic, 40\% White, 4\% Multi-Racial, 2\% Asian and 2\% African-American. Although the two districts are not identical, they are similar in many ways, and therefore warranted the use of the SEI-E in this study. If at the end of this study there is a large discrepancy between 
the Title I and non-Title I schools, this difference in student population may be a contributing factor that will need to be discussed.

Once the data was collected for all 1,943 students in the Carter et.al. pilot study, a confirmatory factor analysis was run (Carter et al., 2012). Unlike the original middle and high school version, that showed a 6-factor trend, the new elementary version showed a four-factor model was more sound (Carter et al., 2012). Each of these four factors, Teacher-Student Relationships (TSR), Peer Support for Learning (PSL), Future Goals and Aspirations, (FGA), and Family Support for Learning (FSL), met a variety of goodness of fit tests and each contained at least four questions on the survey (Carter et al., 2012). These factors were also the same as four of the original six factors from the middle and high school version. The other two factors that did not have high enough factor loadings at the elementary level were Control and Relevance of School Work, and Intrinsic Motivation. Developmentally, elementary students tend to think in much more concrete ways, so it was not surprising that the more abstract ideas, such as the relevance of school work and the students' feeling of control, did not provide consistent results with this age group (Carter et al., 2012; Newmann \& Newmann, 2003). The other factor, Intrinsic Motivation, was questioned before the creation of the SEI-E. On the original SEI survey, there were only two questions that provided the input for Intrinsic Motivation, so some researchers questioned the ability to make a reliable statement of engagement based on such limited data (Betts, Appleton, Reschly, Christenson, \& Huebner, 2010).

Carter, et al.'s (2012) study showed that the SEI-E and SEI could be used to measure the cognitive and affective engagement levels of students between third and 
twelfth grade. This study was, however, the first of its kind to test the validity and reliability of the SEI-E measure for elementary students. While the results from the SEIE show the expected results based on the engagement research, and there was preliminary evidence of internal and external validity, additional testing will need to be done to affirmatively state that the measure is valid and reliable in all situations (Carter et al., 2012). Despite this, the SEI-E was used as the measurement tool in this study because it was the only survey for elementary students that tests cognitive and affective engagement and has some proof of validity.

The SEI-E survey that was used in this study (Appendix H) consists of 24 questions that matched the four-factor model tested by Carter et al. (2012). Each question was answered on a 4-point Likert-type scale. The survey also included questions on student ethnicity and gender for later analysis.

\section{Student Implementation Process}

Including an introduction given before the survey was taken, the administration of the SEI-E in each classroom took between fifteen and twenty minutes. In order to ensure the integrity of the SEI-E administration, the researcher administered the surveys in all six classrooms and within one week of each other. This helped to create consistency in the administration process across all classrooms in the study.

Before the surveys began, the teachers were asked to leave the room and the students were reminded about their confidentiality in this process. This was important because students were asked questions about their relationship with their teacher and they needed to feel confident that they could answer these questions honestly. The students were reminded that when their teacher received a report from the class, that no names 
would be attached to that report. The teacher would have no way to know how any individual student answered the questions on the survey. Students had time to ask any questions they had before the survey was passed out and the process began.

Secondly, the questions were read out loud. This eliminated a possible barrier for some students who may struggle with reading, and reduced the risk that some students would rush through the survey and read questions incorrectly.

Lastly, the researcher purposefully walked around the classroom when giving the survey to make sure that students were following along. As they were responding, the researcher scanned the surveys to make sure that only one number was being circled for each question. All three of these steps helped improve the validity of the results and to create a situation where students felt safe to answer the questions accurately and honestly.

Teacher interviews. Teacher interviews were the one qualitative component to the study and were completed by all participating teachers (Appendices I, J, \& K). Interviewing teachers allowed for insight into questions like, "Why did certain changes occur in the data," "How did participating in this study affect teachers' practices in the classroom?", and "How could this study be improved?" Without the teacher interviews, these types of questions would be otherwise unanswerable, and instead left to researcher speculation.

A semi-structured approach was used for the interviews with each of the six teacher participants, in which the researcher posed open-ended questions that were preplanned and were the same for each participant. This structure allowed for an in depth conversation about the same topic with each of the six teachers, while still allowing some flexibility. The flexibility in this approach comes from the researcher's decision to either 
move on to the next question once the original open-ended question was answered, or to pose a probing question to gain more understanding. Probing questions helped to add detail to the original answer, provide further clarification, or allowed the person to elaborate on what had already been said. All interviews were recorded using an audiorecorder and each interview was later transcribed in its entirety for analysis.

All six teachers were interviewed in February and in May, 2014. Each interview took between ten and twenty minutes, and occurred either at the participant's school or through the use of Skype. If the interview took place at school, the teacher's classroom was used either before or after school to ensure a quiet environment. When using Skype, both the participant and the researcher agreed on an appropriate time when both could focus their complete attention on the interview.

The first interview (Appendix I) took place before the students' pre-survey in February 2014 (See also Table 3.1). The goal of this interview was to learn about each teacher's background, the number of years they had been teaching both in general, and in fourth grade, and their general teaching philosophy. Questions were asked about how the teacher planned their lessons, in what ways data impacted their teaching practices, and the level of autonomy they felt they have in their classroom each day. These questions allowed the researcher to gain important insight into the teacher and key components of their classroom that might be important as the study unfolded. During these interviews, it was important to answer any questions the teachers had about the study so that all participants were well informed.

The second interview took place in May 2014, after students had completed their post-survey. The three goals of this interview were to discover what, if any, changes 
were made after receiving the results of the SEI-E, to share the student data with the teachers, and to receive feedback on how to improve the study for the future. For teachers in the test group, the teacher had the chance to review their pre-survey data and then see their students' change data for the first time. The control group, who had not previously seen their results, had the chance to see both their pre-survey and post-survey scores for the very first time. It was possible that by simply being a part of the study, that the teachers in the control group had made mindful changes to their classroom practices in order to possibly increase their students' engagement scores on the second survey. If this was true, it was important to know what aspects of the process were affecting them and how they thought it might have changed the engagement results of their students. For teachers in the test group, this interview allowed the researcher to know if any mindful changes were made to the classroom as a direct result of the student engagement results. Lastly, all teachers were asked about their experiences in the study, and provided feedback about what went well and what could be improved for the future.

\section{Data Analysis}

This section discusses how the survey results were presented to the teachers in the test group during the study, and for all teachers once the study was completed. For the teachers in the test group, a summary results page for their students was presented within a week of administering the first survey. The second change summary sheet was presented to the teachers in the test group during their final interview. Next, this section explains the different analyses that were completed using the numerical survey data and SPSS. Finally, there is an explanation of the coding methods that were used to analyze the teacher interviews. 
First survey engagement summary. After the first SEI-E was given, each teacher in the test group received a summary result for their classroom (see Figure 3.2). This was done by first compiling the data into SPSS. The engagement summary contained a stacked horizontal bar graph showing the average scores for each of the students in each of the four factor areas (Teacher-Student Relationships [TSR], Peer Support for Learning [PSL], Future Goals and Aspirations, [FGA], and Family Support for Learning [FSL]). For example, if a child answered the four questions about family support and learning with the following Likert-type scores $(3,4,3,3)$ the average shown on the bar graph for that child in the FSL category would be $(3+4+3+3) / 4$, or 3.25 . To protect the students' confidentiality, the bar graph did not have student names and were instead listed from most to least engaged. The final item on the engagement summary was the class average in each of the four factor areas. These average numbers were provided to the teachers in the test group during the study, but all teachers in the control group had to wait until the study concluded to see the results for their students. 


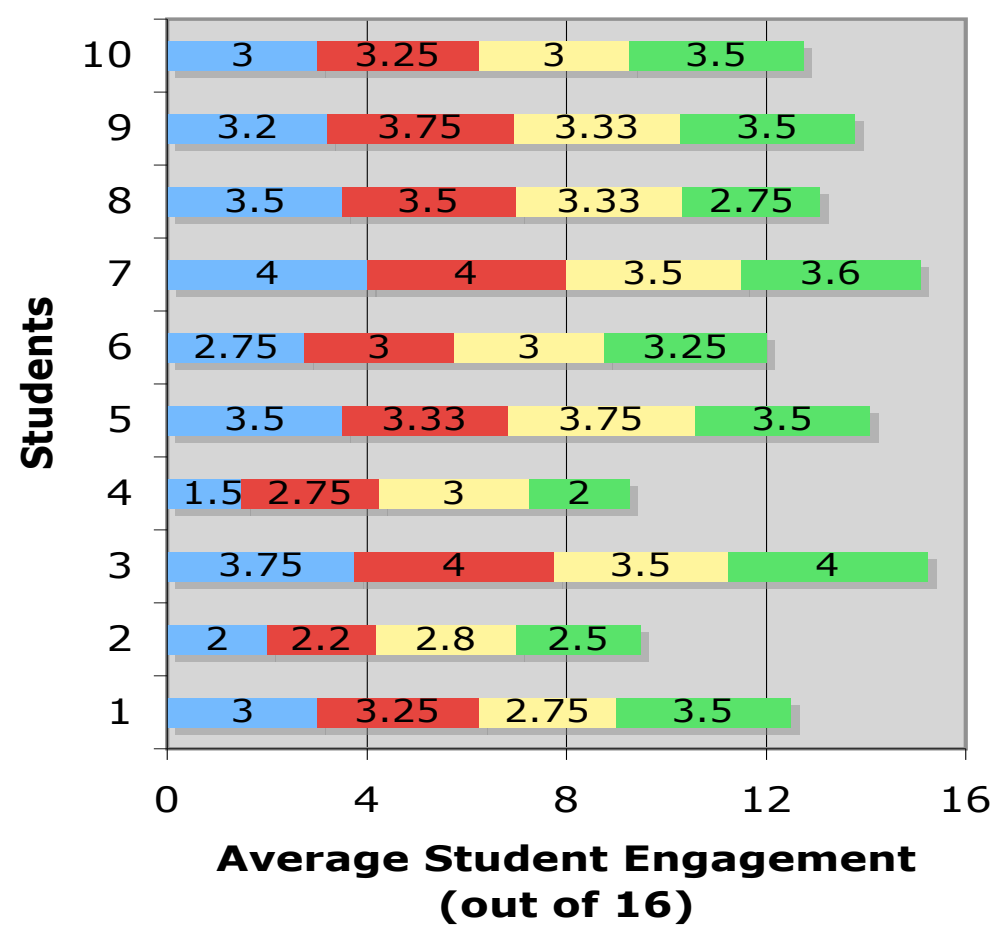

TeacherStudent Relationships Peer Support for Learing

Family Support for Learing

Future Goals and Aspirations

Figure 3.2. Student Engagement Results Summary Sample

Second survey change results summary. After the second survey was given to students in May of 2014, a change results summary was compiled for the teachers (see Figure 3.3). Within a week of the post-survey, control group teachers received their initial summary results page, and all teachers received their change results summary. 


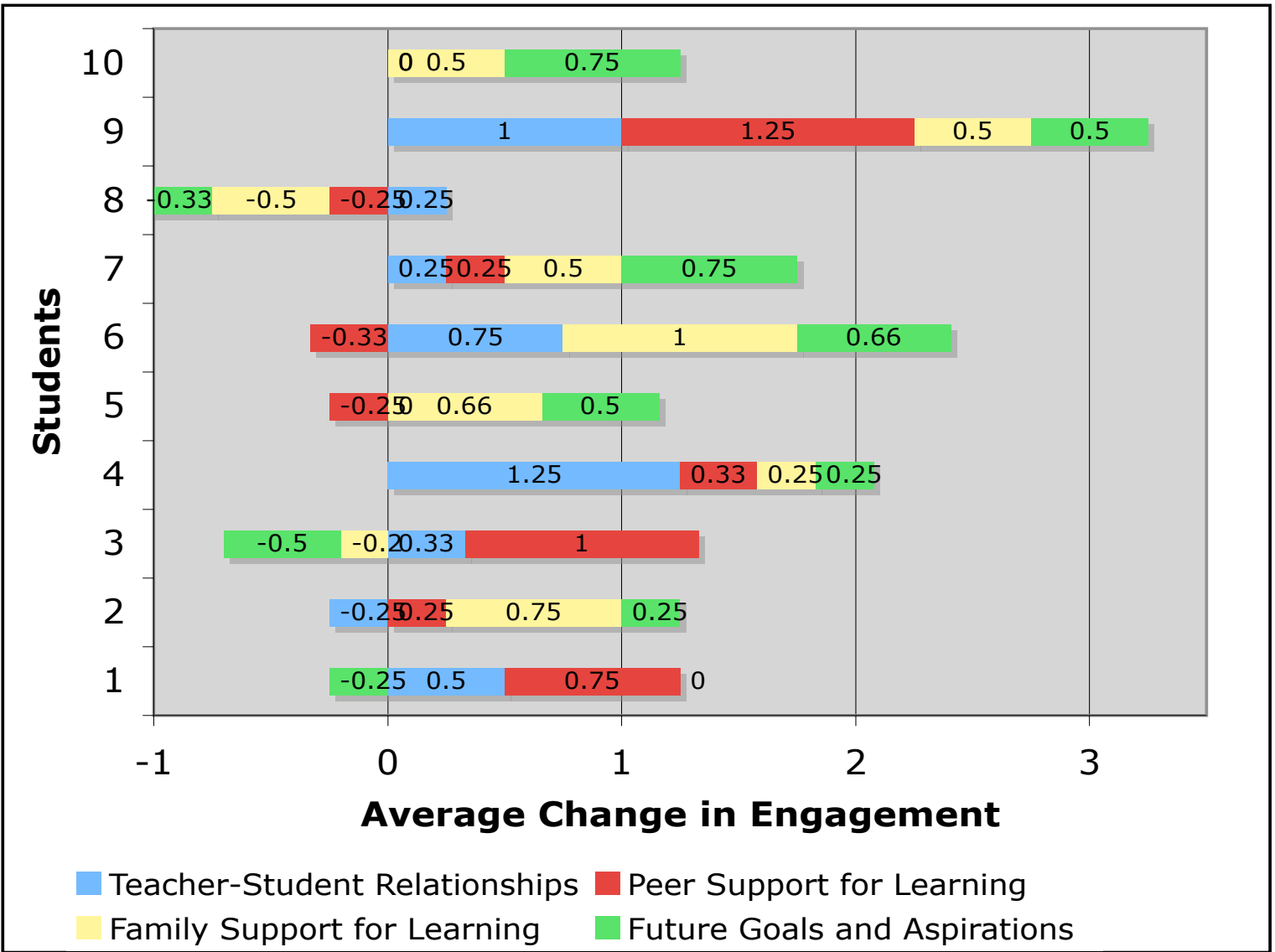

Figure 3.3. Classroom Change Results Summary Sample

On this change results summary, SPSS was used to calculate the difference between the second survey and the first survey in each of the four factor areas. In this case, the results of the first survey were subtracted from the second survey results in order to determine the overall change made. If the student's engagement score increased on the second survey, then the change score was positive; however, if a student recorded being less engaged in May, then the change score showed a negative difference. If student recorded the same engagement score on both surveys, then the resulting change score for that child in that one factor area was a zero. Students who were absent for the post-survey have no scores listed on the change score summary page. 
The change results summary was presented to teachers using a horizontal bar graph format. In the middle of the paper was a line for zero. The change scores that were positive (or show an increase in engagement from the first to the second survey) were shown to the right of the zero line. The factors where the survey recorded a decrease in engagement from the first to the second survey were found on the left side of the zero line. Each student had one horizontal row for the results of all four of their change scores. Student numbers from the first survey results correlated with the student numbers on this second summary sheet, however, the names were listed in the same order as on the initial summary report. If a row is left blank for a student, this means that that particular student's scores remained the same between the two surveys or that the student was absent. To tell the difference, a teacher would have to look at the bottom of the summary change page where there was a table showing the scores for each student participant. Students whose scores did not change have a zero in the bottom chart, while students who were absent have a blank next to their name.

Two-tailed, independent $t$-test. There were many different comparisons that were used to analyze the data in this study. In each case, a categorical, independent variable (control group vs. test group, or Title-1 schools vs. non-Title-1 schools) was tested with a continuous dependent variable (mean engagement survey scores). Table 3.2 outlines the variables and goals of each of the three research questions. In each of the ttests, the mean engagement scores in each of the four factor areas, as well as the total mean engagement score out of a possible 16 points was analyzed.

When testing for a categorical independent variable and a continuous dependent variable, researchers always run a $t$-test (Field, 2009). Since the two surveys in the 
proposed study were coming from the same sample of students and can be thought of as similar to a pre and post test, a dependent $t$-test was run using SPSS. It was a two-tailed $t$-test because you cannot assume that one of the independent variables will always score higher than the other on their mean engagement scores. Before a t-test can be run, though, it was important to check the assumptions of normality and homogeneity of variance. (Field, 2009). 
Table 3.2: Overview of SPSS Analysis to be Completed During this Research Study

\begin{tabular}{|c|c|c|c|}
\hline Type of Analysis & $\begin{array}{l}\text { Independent } \\
\text { Variable }\end{array}$ & Dependent Variable & Goal of the Test \\
\hline $\begin{array}{l}\text { 1. Site- } \\
\text { specific } \\
\text { independent } t- \\
\text { test }\end{array}$ & $\begin{array}{l}\text { Test group vs. } \\
\text { control group at } \\
\text { each school site }\end{array}$ & $\begin{array}{l}\text { Mean engagement } \\
\text { survey scores }\end{array}$ & $\begin{array}{l}\text { Determine at each } \\
\text { school location of } \\
\text { there is a } \\
\text { statistically } \\
\text { significant different } \\
\text { between the } \\
\text { teachers who know } \\
\text { their students' test } \\
\text { scores and those } \\
\text { that do not. }\end{array}$ \\
\hline $\begin{array}{l}\text { 2. Collective } \\
\text { independent t-test }\end{array}$ & $\begin{array}{l}\text { All test groups vs. } \\
\text { all control groups }\end{array}$ & $\begin{array}{l}\text { Mean engagement } \\
\text { survey scores }\end{array}$ & $\begin{array}{l}\text { When combining all } \\
\text { test group } \\
\text { participants and all } \\
\text { control group } \\
\text { participants, what } \\
\text { patterns emerge } \\
\text { with the mean } \\
\text { student engagement } \\
\text { scores. Do any } \\
\text { patterns emerge? }\end{array}$ \\
\hline $\begin{array}{l}\text { 3. Multiple linear } \\
\text { regression }\end{array}$ & $\begin{array}{l}\text { Students' gender, } \\
\text { ethnicity, and Title I } \\
\text { status }\end{array}$ & $\begin{array}{l}\text { Mean engagement } \\
\text { survey scores }\end{array}$ & $\begin{array}{l}\text { Do students have } \\
\text { statistically } \\
\text { significant mean } \\
\text { engagement scores } \\
\text { based on their } \\
\text { gender, ethnicity, or } \\
\text { the type of school } \\
\text { they attend? What } \\
\text { patterns emerge for } \\
\text { students in these } \\
\text { different categories. }\end{array}$ \\
\hline
\end{tabular}

The tests that were run have a telescopic effect. The first of many $t$-tests was school-specific and looked at that the changes in each of the two classrooms between the first and second survey. This $t$-test answered the first research question-For teachers at the same school, is knowledge of students' cognitive and affective engagement scores 
associated with increased student engagement? In this case, the independent variable was the test group vs. the control group within each specific school. This was an important comparison to start with because, while there were still external factors that contributed to slight differences in the results, these external factors were largely minimized when comparing two classrooms that were each a representative sample of the same school population. This allowed the researcher to look at the trends in each school site, and see if they were consistent across both School A and School B.

The second comparison combined the results of all classrooms in the control group and compared them to all the classrooms in the test group. This $t$-test answered the second research question - Is teacher participation in the test group associated with meaningful changes in the classroom and increased student engagement scores? If so, what interventions are used? This comparison was testing the effect of a teacher knowing versus not knowing their students' engagement scores. Are teachers who were aware of their students' engagement scores able to make more meaningful modifications to their classrooms that therefore caused a greater increase in engagement? Or, is the idea of knowing that your students' engagement scores will be analyzed, enough to create meaningful increases in engagement for the control classrooms?

Multiple regression. Multiple linear regressions were needed to determine if some student data could help predict expected engagement scores. For this part of the study, analysis determined if using a student's first mean score on the SEI-E, as well as their gender, ethnicity, and Title-1 status, could help me make an accurate prediction of their change score between the first and second survey. This multiple linear regression helped answer the third research question - How are student demographic and 
background characteristics associated with the amount of change students' show between their pre and post-survey results? (Specifically looking at school type, gender, and ethnicity). The outcome variable (students' change scores) was determined by taking the mean of their first engagement survey and subtracting this from the mean of their second engagement survey. This regression was run five times: one time for each of the factor analyses, and a fifth time for the total mean score for engagement.

Before a regression was done, there were three assumptions that first had to be met. These assumptions are in place in order to limit the chance that the outcomes found were from any unrelated factors. The first two assumptions, linearity and homogeneity of variance, were checked using a scatterplot of the data points. Scatterplots should have variables that are linearly associated and where the majority of the points are evenly dispersed within a band that is two standard deviations above and below the regression line. The third assumption is normality and was checked using a histogram. When looking at a histogram, a bell curve indicates that most of the points are close to the regression line and that the points get fewer the farther you move away. If all assumptions were met, then the outcomes that have been found are the result of the independent variables.

The next thing that needed to be done for a multiple linear regression was to be as parsimonious as possible. This means that the fewest variable predictors were used while still trying to acquire the highest $\mathrm{R}$ Square value possible. The R Square value is the amount of variance in the science score that is accounted for by the independent variables. The closer this number is to 1.0 , the better the independent variables are at predicting a person's probable dependent outcome. 
The last thing that needed to be done was to make the independent variables either continuous or dichotomous categorical variables. The only variable that currently did not meet this requirement was ethnicity, so it needed to be changed into dummy variables. This meant that instead of having ethnicity coded as the following, (Caucasian=1, African-American=2, Asian=3, Hispanic $=4$, Other $=5$ ), the researcher needed to create four new variables that represented ethnicity and each had a dichotomous coding scheme. The ethnicity with the largest student population, Caucasian, did not receive a new variable, but it was assumed that if a person did not receive a 1 for any of the other four ethnicity variables, that they belong to this final category. Once this has been done, the multiple regressions were run and determine if any of the predictor variables reduced the variance in a statistically significant way.

Teacher interviews. Once the interviews were completed, they were transcribed in order to allow a deeper level of analysis. Coding was used for the interviews to look for common themes amongst the different teachers. The initial codes that were used included key components of the SEI-E, and logical events that could be expected to come up in a teacher interview. These include modifications that a teacher made to any of the four factor areas (Teacher-Student Relationships [TSR], Peer Support for Learning [PSL], Future Goals and Aspirations, [FGA], and Family Support for Learning [FSL]). These were coded with their three letter abbreviations. Another code that was used was barriers, or challenges that teachers faced, during the study. When looking at these, they were divided into at least two categories: generic challenges, and challenged faced due to Title I criteria. The third code that was used was resources or supports that helped a teacher feel successful. For example, a principal may have been flexible, or a coworker 
may have helped rewrite a unit in order to make it more engaging. In these cases, a flexible teacher and a helpful coworker were supports that were needed in order to be successful, but may be barriers in other locations if these do not exist.

Once the transcripts were coded and common themes were noted, it was important to see if there were places where the qualitative data explained the numerical data collected in the student surveys. For example, if a teacher talked a lot about having students start to make goals for their future, it was important to see if the quantitative data for this teacher's classroom showed an increase in Future Goals and Aspirations. The same was true for a teacher who spoke a lot about finding new ways to incorporate families into the classroom. In this case, you might expect the scores for Family Support for Learning to increase more drastically in this one classroom than in the other classrooms where this may not have been a major focus. In the end, the qualitative data helped provide a more clear picture of the quantitative data so that researcher could begin to understand why certain changes were seen in different classrooms, and so that more meaningful next steps for improving student engagement levels in upper elementary classrooms could be provided.

\section{Synthesis}

This study looked into the possible need to add cognitive and affective engagement scores to the growing data that teachers use when informing their teaching practices. Teachers currently base many of their teaching decisions on the academic and behavioral indicators of their students. Things such as students' latest test scores, their attendance in school, or the inability to complete homework on time, provide teachers with meaningful insights into student engagement levels. These insights often spark the 
implementation of interventions to try to increase areas where students appear to be lacking engagement. While these practices can be effective, the research shows that they are not sufficient when trying to promote engagement for all students (Appleton, 2012; Christenson et al., 2008; Finn \& Zimmer, 2012). Teachers need to be aware of all four engagement areas in order to determine if students are fully engaged in school. This study begins to explore the impact of providing teachers with measurements of students' cognitive and affective engagement levels which are otherwise not fully known, but which both have lasting impacts on students' success at school.

After determining if this data is helpful for teachers, the study continued to provide information about interventions that could be used to improve the cognitive and affective engagement levels of fourth grade students. While it is unlikely that all interventions will show positive correlations to engagement, the ones that do are worthy of further exploration. It will also be important to explore the limitations of different interventions, or the environments where certain interventions appear to be more beneficial.

In the realm of current research on student engagement, this study was at the beginning exploration stage of cognitive and affective engagement for upper elementary students, but began to provide new insights and a stepping-stone for future research in this area. This study began to fill in the gaps about the importance of cognitive engagement levels for upper elementary students. This study also built on the knowledge that students needed to be affectively engaged in schools, but that teachers needed to be aware of these levels in order to promote overall engagement and achievement for all of their students. Lastly, teachers' reflections and comments collected in this study 
provided important insights into the benefits of SEI-E as a tool for elementary teachers in their goal to promote long-term engagement for the students that they teach. 


\section{Chapter Four: Findings}

The findings in this chapter are presented in three main sections. The first section focuses on descriptive statistics. In this section, the background characteristics of the sample are presented first, followed by summary statistics from the pre- and post-survey. The second section directly addresses the three research questions. For each research question, the quantitative research findings are presented first and then any relative qualitative findings are presented afterwards. The final section in this chapter presents a summary of the findings based on all data collected.

\section{Descriptive Statistics}

This section describes the participants of the study at the school level, the teacher level and the student level. Multiple forms of data are presented, including but not limited to: school type, classroom demographics, teacher experience and class size. Similarities and differences amongst the participating classrooms, such as a teacher's teaching philosophy, are also pointed out so that readers can more clearly understand the data that was later analyzed.

Teacher background characteristics. Table 4.1 shows key background information about each of the six participating teachers including school type, teacher number, teacher experience, and class size. An explanation about how teachers were assigned to each group has also been included.

Since teacher group, control versus test, was an important component of this study, the remainder of the chapter will label teachers in a way that allows them to be easily identified as part of either the control or the test group. For example, Teacher 1 is part of the control group, so for the remainder of this paper, teacher one will be written at 
CTR 1, which stands for Control Teacher 1. The other teachers in the control will be labeled similarly as CTR 3 and CTR 5. The test group will be labeled as TTR, which stands for Test Teacher, and then their number will follow. So teacher 2, who is part of the test group, will be referred to as TTR 2 for the remainder of this paper.

Table 4.1

Teacher Descriptive Statistics and Background Characteristics

\begin{tabular}{|c|c|c|c|c|c|c|}
\hline & \multicolumn{3}{|c|}{ Control Group } & \multicolumn{3}{|c|}{ Test Group } \\
\hline $\begin{array}{l}\text { Teacher } \\
\text { Numbers }\end{array}$ & 1 & 3 & 5 & 2 & 4 & 6 \\
\hline School & A & A & B & A & B & $\mathrm{C}$ \\
\hline $\begin{array}{l}\text { Title I } \\
\text { Status }\end{array}$ & Non-Title I & Non-Title I & Non-Title I & Non-Title I & Non-Title I & Title I \\
\hline $\begin{array}{c}\text { Teaching } \\
\text { Experience }\end{array}$ & 26 years & 1 year & 28 years & 26 years & 10 years & 17 years \\
\hline $\begin{array}{c}\text { Years } \\
\text { Teaching } \\
4^{\text {th }} \text { Grade }\end{array}$ & 3 years & First year & $\begin{array}{c}3 \text { years } \\
\text { (20 years } \\
\text { ago })\end{array}$ & 5 years & 7 years & 2 years \\
\hline $\begin{array}{c}\text { \# of } \\
\text { Students } \\
\text { in Class }\end{array}$ & 32 & $\begin{array}{c}29 \\
\left(14 \text { in } 3^{\text {rd }}\right. \\
\text { grade and } \\
15 \text { in } 4^{\text {th }} \\
\text { grade })\end{array}$ & 28 & 31 & 27 & 32 \\
\hline $\begin{array}{c}\text { \# of } \\
\text { Students } \\
\text { in Study }\end{array}$ & 27 & 9 & 15 & 24 & 26 & 18 \\
\hline
\end{tabular}

Table 4.1 shows which teachers were assigned to the control group and which teachers were assigned to the test group. For each school, one teacher was assigned to be a part of the test group. This teacher was given the pre-survey data for their students shortly after the survey was completed. This allowed the test group teachers to make changes, should they choose, based on the engagement data of their students. All other 
teachers were assigned to the control group. These teachers did not receive the engagement data for their students until after the study was completed.

Table 4.1 highlights two anomalies in the group of participants. The first anomaly was that while the study was focused on fourth graders, one of the teachers actually taught a blended classroom of $3^{\text {rd }}$ and $4^{\text {th }}$ grade students. This teacher was included in the study for two reasons. First, this teacher was a new teacher, which was a new variable that was worthy of exploration, and secondly, the inclusion of this classroom helped to increase the sample size of the study. As seen in the table, all other teachers in the study had between ten and twenty-eight years of teaching experience (Table 4.1). In order to try and keep the data both valid and reliable, data was collected only from the fourth grade students in this classroom. This classroom was also purposefully put into the control group since the additional variable of class format was an inconsistency compared to the other five classrooms.

The second anomaly seen in Table 4.1 was that five of the six participating teachers taught at Non-Title I schools. While the original research design was for two teachers at each school, the decision to include TTR 6 was made because it allowed the beginning explorations of cognitive and affective engagement levels at a Title I setting. The inclusion of both Title I and Non-Title I schools was an important component of the original research design, and while having only one classroom from a Title I school made for a very small comparison group, it did at least allow the beginning of a comparison to be made.

The bolded sections (in Table 4.1) indicate where the data stood out from the other participants and therefore requires a deeper look. The first bolded area of Title I 
has already been explored. The next bolded portion falls under teacher experience. CTR 3 is the teacher of the blended third and fourth grade classroom and was currently completing her first full year as a classroom teacher. This lack of experience, as well as the added challenge of teaching students at two grade levels, made this classroom unique from the other five classrooms.

The next bolded portion was under the category of experience teaching $4^{\text {th }}$ grade. For this question, there are three teachers who stood out as having less experience than the others (CTR 3, CTR 5 and TTR 6). CTR 3 was just mentioned as completing her first full year of teaching. CTR 5 has 28 years of overall teaching experience, but had not taught fourth grade for twenty years. This teacher openly admitted to feeling more comfortable in kindergarten (where she had most recently taught) and a bit nervous about the transition to fourth grade students. TTR 6 was the teacher from the Title I school, and had two previous years of fourth grade experience. This teacher did not report any apprehension about teaching fourth grade, but instead seemed excited about her grade level assignment.

There were no major discrepancies amongst the teachers when it came to class size. All classrooms had between twenty-seven and thirty-two students, which created similar challenges for the teachers to meet the engagement needs of all of their students. This similarity was likely due to the fact that all teachers were chosen from the same school district that had consistent procedures for determining class size. This consistency helped to create a more consistent comparison group for future data analysis.

Student demographics in each classroom. The students had the option of including their ethnicity when completing the pre-survey. Of the 109 students who 
participated in the study, 103 of them chose to answer the ethnicity question and six students chose to leave this item blank. Table 4.2 shows the student demographics for each of the six participating classrooms.

Table 4.2

Student Demographics Per Classroom

\begin{tabular}{|c|c|c|c|c|c|c|c|c|c|c|c|c|}
\hline & \multicolumn{6}{|c|}{ Control Group } & \multicolumn{6}{|c|}{ Test Group } \\
\hline $\begin{array}{l}\text { Teacher } \\
\text { Number }\end{array}$ & \multicolumn{2}{|c|}{1} & \multicolumn{2}{|c|}{3} & \multicolumn{2}{|c|}{5} & \multicolumn{2}{|r|}{2} & \multicolumn{2}{|c|}{4} & \multicolumn{2}{|r|}{6} \\
\hline $\begin{array}{l}\text { Total Student } \\
\text { Participants } \\
(\mathrm{N})\end{array}$ & \multicolumn{2}{|c|}{27} & \multicolumn{2}{|r|}{9} & \multicolumn{2}{|c|}{14} & \multicolumn{2}{|c|}{24} & \multicolumn{2}{|c|}{14} & \multicolumn{2}{|r|}{15} \\
\hline $\begin{array}{c}\text { Caucasian } \\
\text { (N) } \%\end{array}$ & 12 & $44 \%$ & 6 & $67 \%$ & 10 & $71 \%$ & 11 & $46 \%$ & 6 & $43 \%$ & 3 & $20 \%$ \\
\hline $\begin{array}{c}\text { African } \\
\text { American }\end{array}$ & 1 & $4 \%$ & 0 & $0 \%$ & 1 & $7 \%$ & 1 & $4 \%$ & 0 & $0 \%$ & 1 & $7 \%$ \\
\hline $\begin{array}{c}\text { Asian/Pacific } \\
\text { Islander }\end{array}$ & 3 & $11 \%$ & 0 & $0 \%$ & 0 & $0 \%$ & 5 & $21 \%$ & 0 & $0 \%$ & 1 & $7 \%$ \\
\hline Hispanic & 4 & $15 \%$ & 1 & $11 \%$ & 1 & $7 \%$ & 0 & $0 \%$ & 3 & $21 \%$ & 7 & $47 \%$ \\
\hline $\begin{array}{c}\text { Other/Multiple } \\
\text { Selected }\end{array}$ & 7 & $26 \%$ & 2 & $22 \%$ & 2 & $14 \%$ & 7 & $30 \%$ & 5 & $36 \%$ & 3 & $20 \%$ \\
\hline
\end{tabular}

Overall, the first five classrooms, which were all Non-Title I schools, had similar student demographics while classroom six, the only Title I classroom, had a distinct student population. In all of the Non-Title I classrooms, the highest percentage of students reported their ethnicity as Caucasian, with the second most common student group of Other/Multiple Selected. A small minority of students in these five classes noted their ethnicity to be African American, Asian/Pacific Islander or Hispanic.

The student demographics for TTR 6 were different in a few ways. First, the largest percentage of students (47\%) reported Hispanic as their ethnicity. Caucasian and Other/Multiple Selected were both the second most common group with $20 \%$ of the 
students in each. As with the other five classrooms, Asian/Pacific Islander and African American made up only a small percentage of the class population with $7 \%$ each.

\section{Summary Statistics: Pre and Post-Survey Reports}

When teachers volunteered for this research study, one of the key benefits was their receiving pre and post-survey summary reports to see the engagement results of their students. These summary results were created using the data acquired from the students' engagement surveys. As described in Chapter 3, students' engagement scores were determined using the Student Engagement Instrument-Elementary Version (Appendix H).

Each question on the survey specifically addressed one of the four factor areas for this study: Teacher Relationship, Peer Support for Learning, Family Support for Learning, and Future Goals and Aspirations. Students' scores ranged from a 1 to a 4, where 4 represented the most engaged student.

Once the survey was completed, the researcher used the data to create the pre and/or post-survey summary report. Three pieces of information were provided on this summary sheet. The first piece of information was an average score (out of a possible 4 points) in each of the four factor areas. The second was an overall engagement score for each student, which was the combined average of the four factor area scores. The overall engagement score was out of a possible 16 points. Finally, the summary report showed the average engagement for the class in each of the four factor areas. This summary sheet was presented to teachers in the test group within a week of giving the pre-survey and at the end of the study for teachers in the control group. 
At the end of the study, a post-survey was given to the students to reassess engagement levels. This post-survey was identical to the pre-survey in every way and was once again administered by the researcher while the teacher was out of the classroom. The main difference between the pre- and post-survey was the summary report given to teachers. For the post-survey, the graph given to teachers represented the change in engagement levels when compared to the pre-survey scores. This means that the post-survey summary report had students' scores that were both positive and negative. Positive scores meant that students were more engaged in a particular area as compared to their pre-survey scores. Negative scores meant that students engagement levels had dropped compared to their pre-survey scores. Class averages were once again reported on the summary report; however, these numbers represented the average change scores rather than average engagement scores, so they were both positive and negative and closer to zero (which would mean no change).

Pre-survey summary reports. Table 4.3 shows a summary of the pre-survey engagement scores for each of the six participating teachers, as well as a combined average of all participants. Rows 3-6 in the table show the average factor scores out of a possible four points. The bottom row in Table 4.3 shows the average overall engagement, which is a combination of the previous four factor scores, and therefore out of a possible 16 points. Table 4.3 also provides information about the minimum and maximum engagement scores from each classroom and the standard deviation. These scores let you know the range of engagement levels that existed in each classroom and the amount the scores varied in each classroom. 
Table 4.3

Pre-Survey Summary Statistics by Teacher

\begin{tabular}{|c|c|c|c|c|c|c|c|}
\hline & \multicolumn{3}{|c|}{ Control Group } & \multicolumn{3}{|c|}{ Test Group } & Total \\
\hline $\begin{array}{l}\text { Teacher } \\
\text { Number }\end{array}$ & 1 & 3 & 5 & 2 & 4 & 6 & $\begin{array}{c}\text { All } \\
\text { Teachers }\end{array}$ \\
\hline $\begin{array}{c}\text { Average } \\
\text { Engagement } \\
\text { in Teacher } \\
\text { Relationship }\end{array}$ & 3.63 & 3.54 & 2.97 & 3.58 & 3.33 & 3.38 & 3.44 \\
\hline $\begin{array}{c}\text { Average } \\
\text { Engagement } \\
\text { in Peer } \\
\text { Support for } \\
\text { Learning }\end{array}$ & 3.59 & 3.31 & 3.33 & 3.50 & 3.14 & 3.16 & 3.37 \\
\hline $\begin{array}{c}\text { Average } \\
\text { Engagement } \\
\text { in Family } \\
\text { Support for } \\
\text { Learning }\end{array}$ & 3.71 & 3.78 & 3.67 & 3.71 & 3.48 & 3.72 & 3.68 \\
\hline $\begin{array}{c}\text { Average } \\
\text { Engagement } \\
\text { in Future } \\
\text { Goals and } \\
\text { Aspirations }\end{array}$ & 3.73 & 3.58 & 3.70 & 3.78 & 3.76 & 3.72 & 3.73 \\
\hline $\begin{array}{c}\text { Range } \\
\text { (Minimum, } \\
\text { Maximum) }\end{array}$ & $\begin{array}{l}10.38 \\
16.00\end{array}$ & $\begin{array}{r}9.94, \\
15.78\end{array}$ & $\begin{array}{l}10.83 \\
15.56\end{array}$ & $\begin{array}{l}11.44, \\
16.00\end{array}$ & $\begin{array}{l}10.59 \\
15.50\end{array}$ & $\begin{array}{l}10.05 \\
15.89\end{array}$ & $\begin{array}{l}9.94 \\
16.00\end{array}$ \\
\hline $\begin{array}{c}\text { Standard } \\
\text { Deviation }\end{array}$ & 1.18 & 1.77 & 1.59 & 1.28 & 1.48 & 1.62 & 1.46 \\
\hline $\begin{array}{c}\text { Average } \\
\text { Overall } \\
\text { Engagement }\end{array}$ & 14.67 & 14.21 & 13.67 & 14.56 & 13.72 & 13.99 & 14.22 \\
\hline
\end{tabular}

From all six classes, 109 students volunteered to participate in the study. When looking at the data for each teacher, the majority of students in each classroom reported a three or higher in each of the factor areas, showing that most students felt that they were affectively and cognitively engaged in school. It can also be noted that the average in 
each factor area was at least a three in all classrooms except for CTR 5 in the area of Teacher Relationship. This class average was a 2.97 , which was nearly a half a point below the study average of 3.44 .

Looking more closely at the four factor scores, an interesting pattern can be noted. In all six classrooms, the two highest engagement averages were reported in the areas of future goals and aspirations, and family support for learning, while the two lowest engagement averages were consistently reported in the areas of peer support for learning and teacher relationship. While it is true that the averages in all four factor areas were above a 3.0, which is a good score on a 4-point scale, it is still concerning that the two categories that are based on interpersonal relationships at school were consistently listed as the two lowest engagement areas. In these two factor areas, students answered questions such as, I have friends at school, Other students respect what I have to stay, Adults know me as a person and not just a student, and My teachers are there for me when I need them. These types of questions allowed teachers to take note of a student's sense of belonging at school, which was an important component if students were to reach their full academic potential (Goodenow \& Grady, 1993).

Looking at the last three rows in Table 4.3, you can find data on the minimum engagement score, the maximum engagement score, the standard deviation and the average total engagement for each of the six classrooms. CTR 1 had both the highest average engagement score (14.67) and the lowest standard deviation (1.18). This meant that in this particular classroom, the students felt the most engaged and the students' scores varied less than in the other five classrooms. Classrooms, such as TTR 2, also had a fairly high average engagement score of 14. 21, but their standard deviation of 1.77 
meant that the individual students scores varied more in TTR 2's classroom than they did in CTR 1's classroom.

Data on the minimum and maximum engagement scores showed that at least one student was disengaged in each classroom. The lowest average engagement scores in each classroom ranged between 9.94 and 11.44 , but it is impossible to tell from Table 4.3 exactly how many students felt disengaged. In order to look more closely at the individual student level, it is necessary to look at the pre-survey summary report. These reports list the individual student results from most engaged to least engaged. In all six of the classrooms, the pre-survey summary reports looked fairly consistent, with most of the students reporting high levels of engagement and only a few reporting lower levels. Because of this, we will look closely at only the pre-survey summary report for CTR 1. All six pre-survey summary reports can be found in the Appendix.

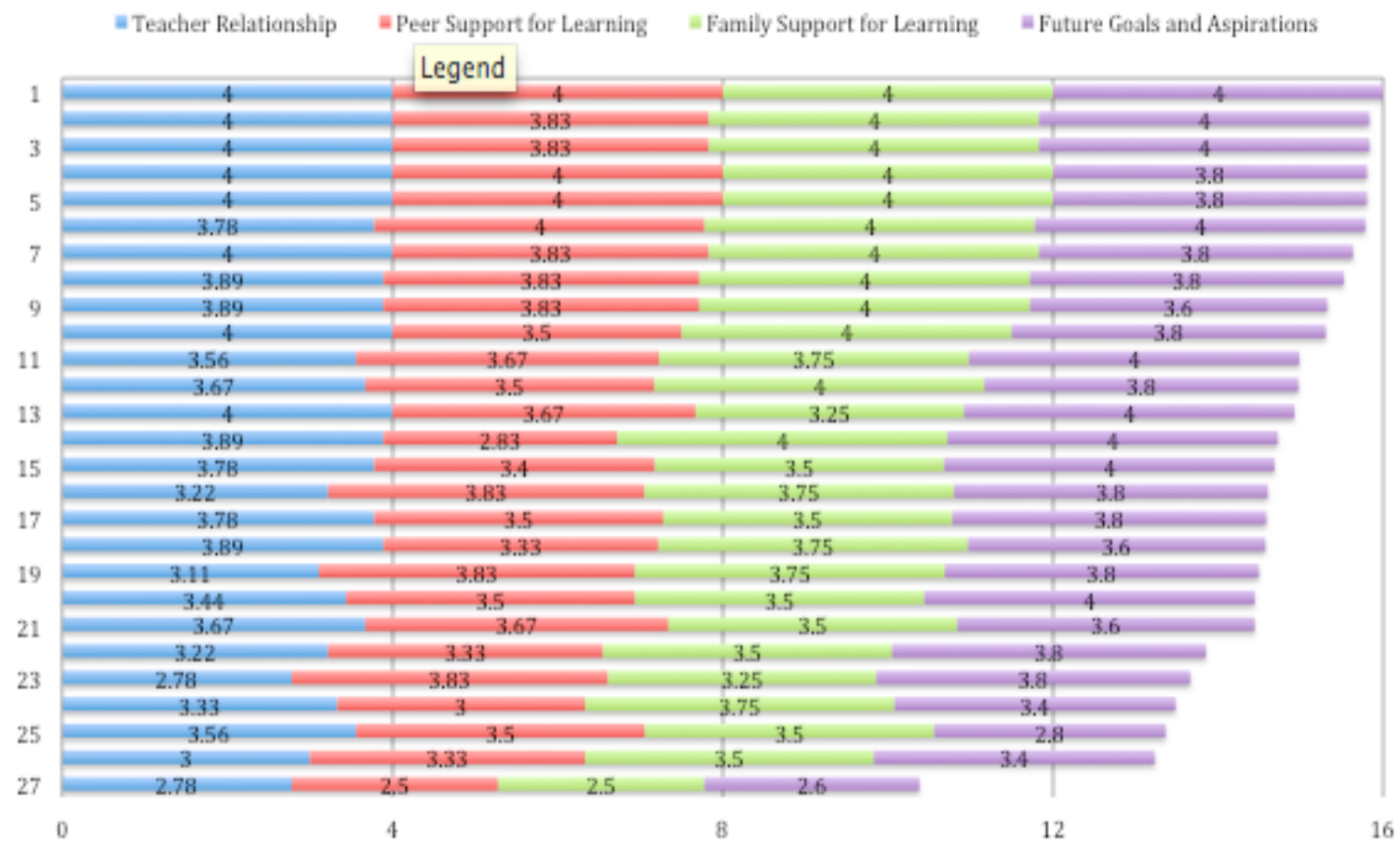

Figure 4.1. Control Teacher 1 Pre-Survey Engagement Summary Report 
The pre-survey report for CTR 1 shows the average student engagement scores in each of the four factor areas. The bar graph was put on a 16-point scale since the score of 16 meant a student reported the highest level of engagement on every question in all four factor areas. In this particular summary report, one student had an overall engagement score of 16. Out of the six classrooms, two of them had one student with a perfect engagement score of 16 and the other four classrooms had their highest engagement score of at least 15.50. Another common occurrence in all of the summary reports was that one or two of the students reported being significantly less engaged than the majority of their peers. In this case, the lowest engagement score was a 10.38 , while the next lowest engagement score was 13.33. Even though the teachers did not know which students went with which test scores, it gave them an overall picture of the engagement levels in their classroom.

Post-survey summary reports. Table 4.4 presents the post-survey findings in each factor area for each participating classroom. While in the pre-survey there were 109 student participants, 95 of this original group (87\%) were present to take the post-survey administered in May 2014. This discrepancy in student participants was caused by students who either moved away from the classroom or were absent on the day that the post-survey was administered.

There are two important differences that must be pointed out, between this summary statistics table and Table 4.3 , which was previously discussed and represented the pre-survey data. First, the data in Table 4.4 is presented as change data rather than overall engagement scores. The data was found by taking the post-engagement score in a particular area and then subtracting it from the original pre-survey engagement score. 
This means that if a student had an average pre-survey score of 3.0 in teacher relationships, and then had an average post-survey score of 3.5 in teacher relationships, the post-survey graph would should a change score of +0.5 in the area of teacher relationships. This was done so that teachers could easily see if a student had become more or less engaged in any of the four areas without having to refer to any other graph. With a quick glance, you can determine if a student reported being more or less engaged in any factor area by determining if they have a bar to the right or the left of the vertical $y$-axis. Bars to the right of the $y$-axis show an increase in engagement, while bars to the left of the y-axis show a decrease in engagement. Many students have bars on both the left and right of the y-axis showing that in some areas their engagement increased, while in other areas, their engagement decreased.

The second important point is the inclusion of a new row called "Modified Average Pre-Survey Engagement." This row (third from the bottom of Table 4.4) was added to address the fact that fewer students took the post-survey than took the pre-survey $(\mathrm{N}=109$ for the pre-survey and $\mathrm{N}=95$ for the post-survey). The row, "Original Average PreSurvey Engagement" was the original engagement score out of a possible 16 points for all students who took the pre-survey. For example, in CTR 1's classroom, 27 students originally took the pre-survey and together their average engagement score was 14.67. However, only 24 of those students were present to take the post-survey. In order to accurately find the average change in engagement, it was important to find the average pre-survey engagement score for only the 24 students who were also present for the postsurvey. This number has been called the "Modified Average Pre-Survey Engagement" and for CTR 1's classroom, the new pre-survey engagement score was 14.80. This 
means that when eliminating the three students who were not present for the post-survey, the average pre-survey scores actually went up. For some classrooms, the modified presurvey average went up and for other classrooms the average went down; it was completely dependent on the scores of the students who were eliminated.

The final change in average engagement was based on the difference between the post-survey score and the modified pre-survey engagement so that only the twenty-four students were taken into account. For CTR 1's classroom, the average post-survey engagement was 14.26 and the modified average pre-survey engagement was 14.80 . $14.26-14.80=-0.54$, which means that the average change in engagement went down by a little over half a point. 
Table 4.4

Post-Survey Summary Statistics by Teacher

\begin{tabular}{|c|c|c|c|c|c|c|c|}
\hline & \multicolumn{3}{|c|}{ Control Group } & \multicolumn{3}{|c|}{ Test Group } & Total \\
\hline $\begin{array}{l}\text { Teacher } \\
\text { Number }\end{array}$ & 1 & 3 & 5 & 2 & 4 & 6 & $\begin{array}{c}\text { All } \\
\text { Teachers }\end{array}$ \\
\hline $\begin{array}{c}\text { Average } \\
\text { Change in } \\
\text { Teacher } \\
\text { Relationship }\end{array}$ & -0.21 & -0.35 & -0.16 & -0.28 & -0.22 & +0.13 & -0.18 \\
\hline $\begin{array}{c}\text { Average } \\
\text { Change in } \\
\text { Peer } \\
\text { Support for } \\
\text { Learning }\end{array}$ & -0.15 & -0.24 & -0.51 & -0.25 & +0.17 & +0.29 & -0.12 \\
\hline $\begin{array}{l}\text { Average } \\
\text { Change in } \\
\text { Family } \\
\text { Support for } \\
\text { Learning }\end{array}$ & -0.05 & -0.25 & -0.11 & -0.13 & -0.08 & +0.08 & -0.08 \\
\hline $\begin{array}{c}\text { Average } \\
\text { Change in } \\
\text { Future } \\
\text { Goals and } \\
\text { Aspirations }\end{array}$ & -0.13 & +0.07 & -0.10 & -0.03 & -0.06 & +0.15 & -0.03 \\
\hline $\begin{array}{c}\text { Original } \\
\text { Average } \\
\text { Pre-Survey } \\
\text { Engagement }\end{array}$ & 14.67 & 14.21 & 13.67 & 14.56 & 13.72 & 13.99 & 14.22 \\
\hline $\begin{array}{c}\text { Modified } \\
\text { Average } \\
\text { Pre-Survey } \\
\text { Engagement }\end{array}$ & 14.80 & 14.47 & 13.87 & 14.52 & 13.42 & 13.88 & 14.26 \\
\hline $\begin{array}{c}\text { Average } \\
\text { Post-Survey } \\
\text { Engagement }\end{array}$ & 14.26 & 13.87 & 12.99 & 13.83 & 13.23 & 14.54 & 13.85 \\
\hline $\begin{array}{c}\text { Change in } \\
\text { Average } \\
\text { Engagement }\end{array}$ & -0.54 & -0.87 & -0.89 & -0.68 & -0.19 & +0.65 & -0.42 \\
\hline
\end{tabular}

After looking at the change result summary graphs, there were many things that stood out. First, the bold numbers were the only change numbers that were positive, 
meaning that students reported an increase in engagement over time. Even though most of the data was negative, TTR 6 was the only teacher who had an increase in average post-survey engagement in all four factor areas. This was an interesting finding because TTR 6 was also the only teacher in the study who taught at a Title I school. With such a small same size and only one teacher in this group, it is not possible to make a generalization about this finding, but this will be discussed in further detail when addressing research question three.

The only other teachers who had an increase in any factor area were CTR 3 and TTR 4. CTR 3 had an increase of 0.07 in the factor area of future goals and aspirations, and TTR 4 had an increase of 0.17 in the factor area of peer support for learning.

When looking at all the results of all 95 students together, the following change scores were observed: Teacher relationship (-0.18), peer support for learning (-0.12), family support for learning (-0.08) and future goals and aspirations, (-0.03). In all four areas, the average engagement levels went down, but the two largest drops were noticed in the area of teacher relationship and peer support for learning. This is important to note, because the pre-survey scores showed that these two areas started with the lowest engagement scores, and now the post-survey scores show that these areas have dropped to even lower levels.

Just like with the pre-survey results, the summary table only provided information at the classroom level. In order to look at individual student change scores, you must look at the post-survey summary reports. Figures $4.2-4.4$ are the post-survey summary results for CTR1, CTR 3 and TTR 6. CTR 1's summary report was chosen because it was a representative sample of the fourth grade classrooms in Non-Title I schools and 
also because the same teacher's pre-survey summary report was analyzed earlier in the chapter. CTR 3's summary chart was selected because this teacher teaches a blended $3^{\text {rd }}$ and $4^{\text {th }}$ grade classroom, which is a unique situation to this study. Finally, TTR 6's summary report was chosen because it representd the only fourth grade teacher at a Title I school. All six post-survey summary reports can be found in the Appendix.

For the post-survey results graphs, students were listed in the same order as they were in the pre-survey graphs. This means that a student who was listed as student one in the pre-survey was still listed as student one on the post-survey regardless of their postsurvey scores. This also means that the students at the top of the post-survey results graphs were the most highly engagement students and the students at the bottom were the least engaged students in that particular classroom based on their pre-survey results. Because of this, students at the top of the graph did not have much, if any, room for increasing their engagement, but only the opportunity to maintain their score or become less engaged. In an ideal case where students maintained or increase their engagement, the post-survey graph would have very little change at the top of the graph while the bottom of the graph would have bars to the right of the y-axis. 


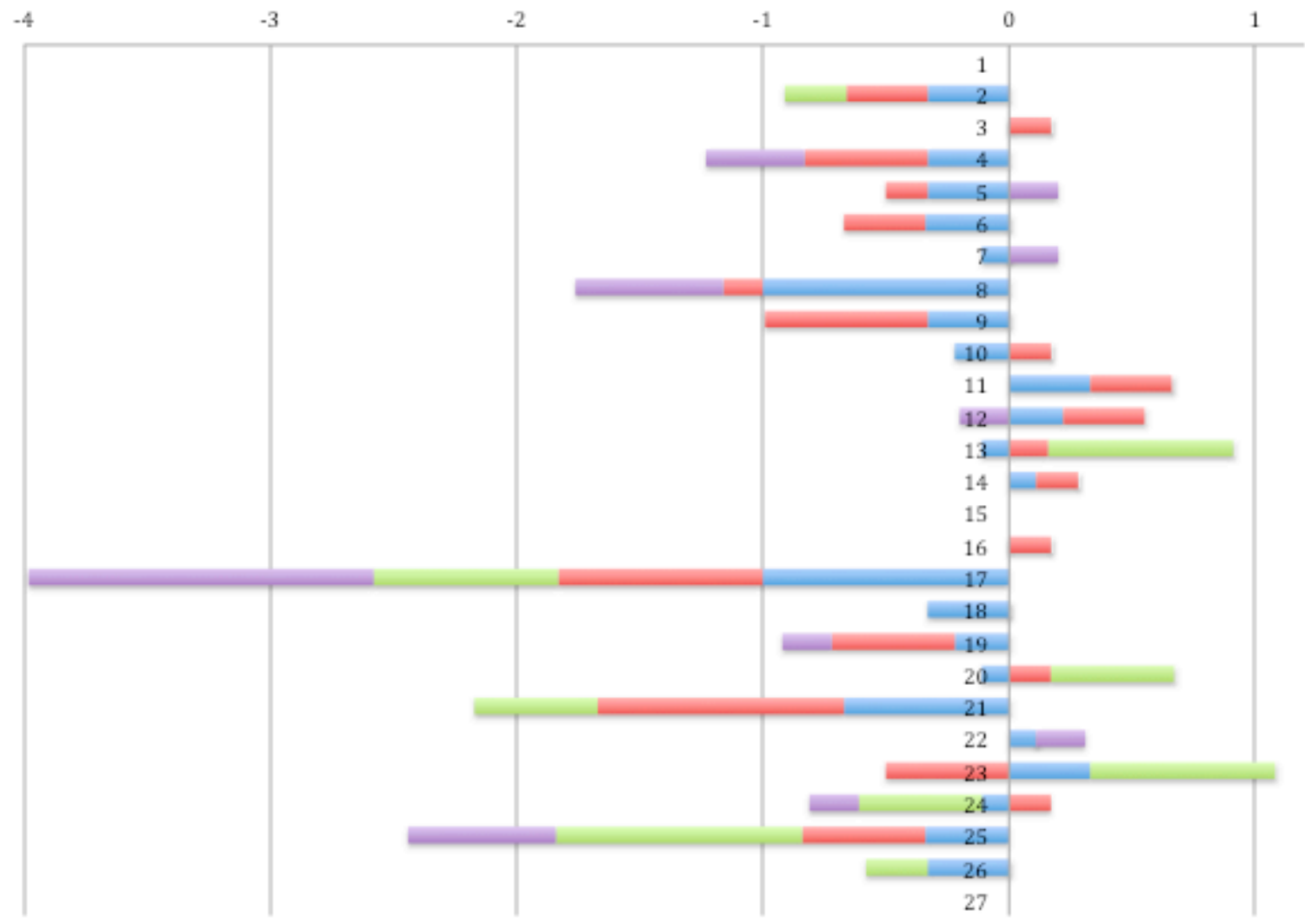

\begin{tabular}{|l|l|l|l|l|l|l|l|l|l|l|l|l|l|l|}
\hline Student \# & $\mathbf{2 7}$ & $\mathbf{2 6}$ & $\mathbf{2 5}$ & $\mathbf{2 4}$ & $\mathbf{2 3}$ & $\mathbf{2 2}$ & $\mathbf{2 1}$ & $\mathbf{2 0}$ & $\mathbf{1 9}$ & $\mathbf{1 8}$ & $\mathbf{1 7}$ & $\mathbf{1 6}$ & $\mathbf{1 5}$ & $\mathbf{1 4}$ \\
\hline $\begin{array}{l}\text { Teacher } \\
\text { Relationship }\end{array}$ & & -0.33 & -0.34 & -0.11 & 0.33 & 0.11 & -0.67 & -0.11 & -0.22 & -0.33 & -1 & 0 & & 0.11 \\
\hline $\begin{array}{l}\text { Peer Support } \\
\text { for Learning }\end{array}$ & & 0 & -0.5 & 0.17 & -0.5 & 0 & -1 & 0.17 & -0.5 & 0 & -0.83 & 0.17 & & 0.17 \\
\hline $\begin{array}{l}\text { Family } \\
\text { Support for } \\
\text { Learning }\end{array}$ & & -0.25 & -1 & -0.5 & 0.75 & 0 & -0.5 & 0.5 & 0 & 0 & -0.75 & 0 & & 0 \\
\hline $\begin{array}{l}\text { Future Goals } \\
\text { and } \\
\text { Aspirations }\end{array}$ & & 0 & -0.6 & -0.2 & 0 & 0.2 & 0 & 0 & -0.2 & 0 & -1.4 & 0 & & 0 \\
\hline
\end{tabular}

\begin{tabular}{|l|l|l|l|l|l|l|l|l|l|l|l|l|l|}
\hline Student \# & $\mathbf{1 3}$ & $\mathbf{1 2}$ & $\mathbf{1 1}$ & $\mathbf{1 0}$ & $\mathbf{9}$ & $\mathbf{8}$ & $\mathbf{7}$ & $\mathbf{6}$ & $\mathbf{5}$ & $\mathbf{4}$ & $\mathbf{3}$ & $\mathbf{2}$ & $\mathbf{1}$ \\
\hline $\begin{array}{l}\text { Teacher } \\
\text { Relationship }\end{array}$ & -0.11 & 0.22 & 0.33 & -0.22 & -0.33 & -1 & -0.11 & -0.34 & -0.33 & -0.33 & 0 & -0.33 & \\
\hline $\begin{array}{l}\text { Peer Support } \\
\text { for Learning }\end{array}$ & 0.16 & 0.33 & 0.33 & 0.17 & -0.66 & -0.16 & 0 & -0.33 & -0.17 & -0.5 & 0.17 & -0.33 & \\
\hline $\begin{array}{l}\text { Family Support } \\
\text { for Learning }\end{array}$ & 0.75 & 0 & 0 & 0 & 0 & 0 & 0 & 0 & 0 & 0 & 0 & -0.25 & \\
\hline $\begin{array}{l}\text { Future Goals } \\
\text { and Aspirations }\end{array}$ & 0 & -0.2 & 0 & 0 & 0 & -0.6 & 0.2 & 0 & 0.2 & -0.4 & 0 & 0 & \\
\hline
\end{tabular}

Figure 4.2. Control Teacher 1 Post-Survey Engagement Summary Report

When looking CTR 1's post-survey summary report, one can identify the students who were absent by looking at the results tables at the bottom of each figure. If a student 
has a score of 0 , then the student was present for the post-survey but their average score did not change from when they took the pre-survey. If the student has no numbers in their column, such as students 1,15 and 27 , then those students did not take the postsurvey in May.

Looking more closely at CTR 1's summary report, you can see that there is more data to the left side of the $y$-axis than on the right side. The bars on the left side show a decrease in engagement scores for those particular factor areas compared to that particular student's pre-survey engagement scores. This finding is similar with the other three fourth grade teachers at a Non-Title I school (TTR 2, TTR 4, and CTR 5).

The next thing that stood out in CTR 1's summary report was student 17. By being listed as student 17 , I know that this student reported an overall pre-survey engagement score that was lower than sixteen of their classmates, but higher than ten of them. This means that the student originally reported feeling fairly engaged in school. Now looking at the change data in their post-survey summary report, all four factor areas were listed to the left of the $y$-axis, and the area of future goals and aspirations appears to have decreased by 1.5 points when compared to the original pre-survey score. This data immediately lets the teacher know that this student felt a drastic decrease in engagement, and if the student's name were listed, it would have been a good idea to look further into this situation. It is possible that a major change had happened at home or school that the teacher was previously unaware of, and that this student could benefit from a targeted intervention.

The last thing that stood out was that the students toward the bottom of the bar graph did not reported an increased feeling of engagement compared to the pre-survey. 
Student 27 was not present for the post-survey, so this data cannot be taken into account, but the other students all reported the lowest engagement levels in the class. This meant that these students had the greatest possibility for increased engagement in the postsurvey. Instead, student 24 reported a slight increase in the area of peer support for learning, and a decrease in future goals and aspirations and family support for learning. Students 25 and 26 reported only decreases in overall engagement. In general, the increases in student engagement seemed to appear with some of the student who were towards the middle of the engagement spectrum, and were most often minor increases of less than half a point.

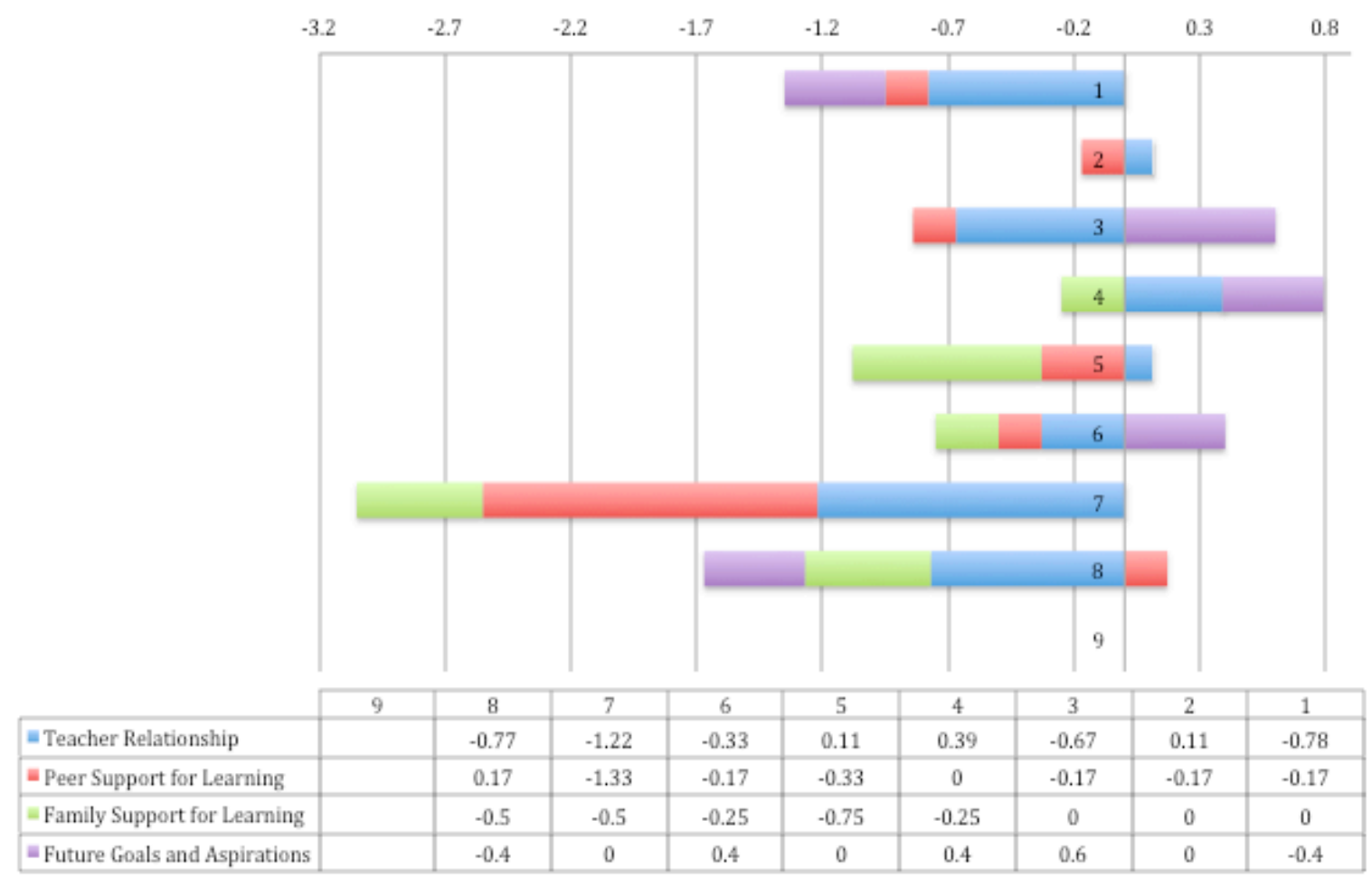

Figure 4.3. Control Teacher 3 Post-Survey Engagement Summary Report

CTR 3's post-survey summary report was very similar to that of CTR 1's summary in Figure 4.2, only there were fewer students since only fourth grade students could be 
considered for the study. Once again, there was a decrease in engagement for the students who were at the bottom of the graph. These students originally reported feeling the lowest engagement levels in the classroom, and instead of these numbers increasing, they continued to decrease as the year went on.

Another similarity was that the students whose data did increase originally reported engagement scores near the class average. This allowed them some room for improvement, but often not more than 0.5 in any factor area since the original engagement scores were fairly high.

The final two similarities were that the overall trend for the class was a decrease in engagement and that there was one student (student 7) who appeared to have a larger decrease than the other students. Again, if student names were attached to the data, it would be important to check in with this student and see if there was a reason for the drop in engagement scores and a way to help increase student engagement for the remainder of the school year. 


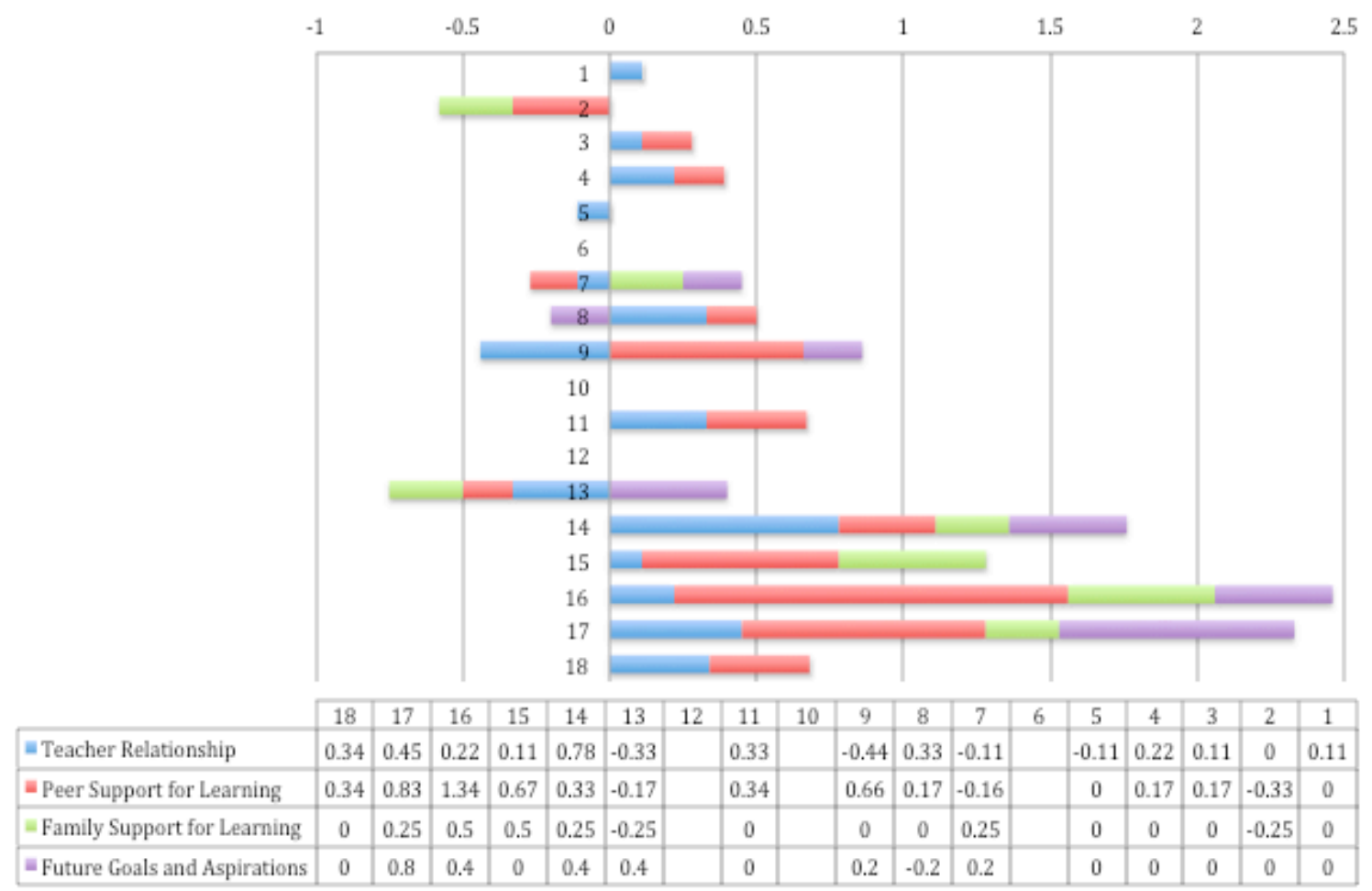

Figure 4.4. Test Teacher 6 Post-Survey Engagement Summary Report

Figure 4.4 shows the post-survey results for TTR 6 , and unlike the other five summary reports, this one stood out for a number of reasons. First, it was evident that more of the data was located on the right side of the y-axis, showing an overall increase in engagement from the time of the pre-survey. This was the only classroom where there was an increase in student engagement in all four-factor areas.

Secondly, as one would hope, the students who were at the bottom of the table and who originally reported feeling the least engaged at school now showed the greatest increase in overall engagement levels. In fact, the five least engaged students, as determined by the pre-survey scores, reported an overall engagement increase of between 0.5 and 2.5 points, and none of them reported a decrease of engagement in even a single factor area. 
Lastly, while there are a few students who did report a decrease in student engagement from pre- to post-survey, these decreases were small (less than a point) when compared to the other five classes. There was no individual student who stood out as needing immediate attention due to a drastic decrease in post-engagement scores.

\section{Inferential Statistics}

Once the pre- and post-survey reports, as well as the teacher interviews were completed, it was possible to answer the three research questions. The research questions were initially explored using quantitative research methods and then additional information was gathered using the qualitative teacher interviews. This section will present the data in a similar way, with the quantitative findings first and then the qualitative findings afterwards. During the teacher interviews, the themes of awareness, teaching philosophy, and workload appeared to play a critical role for some or all of the teacher participants. These themes are discussed in the findings of the three research questions.

The study was guided by the following three research questions:

1. For teachers at the same school, is knowledge of students' cognitive and affective engagement scores associated with increased student engagement?

2. Is teacher participation in the test group associated with meaningful changes in the classroom and increased student engagement scores? If so, what interventions are used?

3. How are student demographic and background characteristics associated with the amount of change students' show between their pre and post-survey results? (Specifically looking at school type, gender, and ethnicity). 
Research question one. The first research question was: For teachers at the same school, is knowledge of students' cognitive and affective engagement scores associated with increased student engagement? This research question compared two classrooms from School A and two classrooms from School B. By focusing in on pairs of classrooms from the same school, factors such as principal leadership, family support, financial support, extra curricular activities offered, etc., could be assumed to be similar for both of the classrooms, therefore minimizing the outside variables that could come into play when looking at the engagement data. Of the six teachers, CTR1 and TTR2 were compared from School A and TTR 4 and CTR 5 were compared at School B. In both of these pairs the teachers had at least ten years of teaching experience and the comparison groups had similar sample sizes. The sample sizes for each comparison group were CTR $1(\mathrm{~N}=24)$, TTR $2(\mathrm{~N}=21)$ and then TTR $4(\mathrm{~N}=13)$, and CTR $5(\mathrm{~N}=14)$.

CTR 3 was not included in this portion of the study for two main reasons. First, CTR 3 was currently completing her first year of teaching, while CTR and TTR 2 (who were also at School A) were both veteran teachers with twenty-six years of experience. This lack of teaching experience made for a drastic difference that did not create equal comparison groups. More importantly than teaching experience; though, CTR 3 was in charge of a blended third and fourth grade classroom. This presented CTR 3 with a unique challenge of needing to meet the needs of students across a wider age and ability level and eliminated the possibility of inclusion for research question one.

TTR 6 was not included in this portion of the research study because they were the only teacher from School C. Since the purpose of this question is to make sure teachers came from the same school, it did not make sense to include TTR 6 for this research 
question. Table 4.5 below shows the comparison results for Teachers 1-Control and 2-

Test in each of the four factor areas.

Table 4.5

T-test of Average Change Scores for Teachers 1 and 2 in Each Factor Area

\begin{tabular}{llllc}
\hline Factor Area & $\begin{array}{l}\text { Teacher 1 } \\
\text { Average } \\
\text { (Control) }\end{array}$ & $\begin{array}{l}\text { Teacher 2 } \\
\text { Average } \\
\text { (Test) }\end{array}$ & $\begin{array}{l}\text { Levene's Test } \\
\text { for Equality of } \\
\text { Variances Sig. }\end{array}$ & $\begin{array}{l}\text { t-test for Equality } \\
\text { of Means Sig. } \\
\text { (2-tailed) }\end{array}$ \\
\hline $\begin{array}{l}\text { Teacher } \\
\text { Relationship }\end{array}$ & -0.21 & -0.28 & 0.87 & 0.55 \\
$\begin{array}{l}\text { Peer Support } \\
\text { For Learning }\end{array}$ & -0.15 & -0.25 & 0.24 & 0.44 \\
$\begin{array}{l}\text { Family Support } \\
\text { For Learning }\end{array}$ & -0.05 & -0.13 & & 0.52 \\
$\begin{array}{l}\text { Future Goals } \\
\text { and Aspirations }\end{array}$ & -0.13 & -0.03 & 0.84 & 0.29 \\
\hline
\end{tabular}

In this case, CTR 1 did not know about their pre-survey scores until after the study was completed, and TTR 2 had a copy of their students' pre-survey scores within a week of the pre-survey being administered. A decrease of engagement was noted in all fourfactor areas, but none of the differences were found to be statistically significant based on prior knowledge of the students' engagement scores.

Table 4.6 shows the differences between change scores for Teachers 4-Test and 5Control. In this comparison, both of the teachers taught at School B. 
Table 4.6

T-test of Average Change Scores for Teachers 4 and 5 in Each Factor Area

\begin{tabular}{llllc}
\hline Factor Area & $\begin{array}{l}\text { Teacher } 5 \\
\text { Average } \\
\text { (Control) }\end{array}$ & $\begin{array}{l}\text { Teacher 4 } \\
\text { Average } \\
\text { (Test) }\end{array}$ & $\begin{array}{l}\text { Levene's Test } \\
\text { for Equality of } \\
\text { Variances Sig. }\end{array}$ & $\begin{array}{l}\text { t-test for Equality } \\
\text { of Means Sig. } \\
\text { (2-tailed) }\end{array}$ \\
\hline $\begin{array}{l}\text { Teacher } \\
\text { Relationship }\end{array}$ & -0.16 & -0.22 & 0.25 & 0.70 \\
$\begin{array}{l}\text { Peer Support } \\
\text { For Learning }\end{array}$ & -0.51 & +0.17 & 0.30 & 0.01 \\
$\begin{array}{l}\text { Family Support } \\
\text { For Learning }\end{array}$ & -0.11 & -0.08 & 0.81 & 0.86 \\
$\begin{array}{l}\text { Future Goals } \\
\text { and Aspirations }\end{array}$ & -0.10 & -0.06 & 0.39 & 0.78 \\
\hline
\end{tabular}

Three factor areas, teacher relationships, family support for learning, and future goals and aspirations, did not show a statistically significant change based on knowledge of the students pre-survey scores; however, peer support for learning did show a statistically significant difference. TTR 4 , had an increase in peer engagement by +0.17 while CTR 5 , had a decrease of -0.51 . This decrease was the largest recorded in the study and means that of the fourteen students who participated in the study from Teacher 5's classroom, they averaged a half a point lower on every question related to peer support for learning.

Unlike the prior comparison with CTR1 and TTR2, this comparison showed that the teacher with knowledge of their students' engagement scores was able to increase their peer engagement score a significant amount more than the teacher without this information. 
Qualitative findings around awareness. In the quantitative data, both CTR 1 and TTR 2 had statistically similar student engagement data. When completing the teacher interviews, however, both CTR 1 and TTR 2 reported an increased sense of awareness about their students' engagement levels due to participating in the study. This theme, and the fact that the two teachers taught similar student populations at the same school location, may help to explain the similarities in their data despite TTR 2's previous knowledge of his students' test scores. When asked to describe their experience in the study so far, CTR 1 said:

The study has made me more aware of developing those connections with kids. Even those kids you don't think you're having a huge impact on, you're really impacting. I found myself looking for and seeing those connections happening in little ways all the time. Even though we may have rough days, there is still that feeling of connection and the love that we build for each other.

TTR 2 initially reported looking at the data, seeing that the average engagement level in his classroom was fairly high and then not doing anything else. He stated that he felt overwhelmed with all of the things he needed to do in the classroom, and so he did not feel as if he had taken the time to look closely at the initial pre-survey data. Despite his feelings of doing little based on the data, when he continued to talk, he described an increased feeing of awareness about his students' engagement levels.

I thought it was cool that the kids knew they could write down anything they wanted to and I think that's what the study is all about. I think it is 
good for the kids to express their feelings because sometimes [teachers]

think that everything is going well and then little things pop up, and you go, oh, I wasn't aware of that. [The study] helped me to be more aware.

Peer support for learning for TTR 4 and CTR 5. When comparing these two classrooms, a statistically significant difference was found in the area of peer support for learning. TTR 4 had an average change score of +0.17 while CTR 5's change in the area of peer support for learning was -0.51 . When asked about these numbers in their teacher interviews, neither teacher was surprised by the data. TTR 4 said:

I feel like I've grown closer to them just naturally. Actually, I know what has helped a lot. I've had a couple really troublesome kids move to another school and so I've actually had more energy to spend with the students.

While TTR 4 reflected on positivity within her classroom at the end of the school year, CTR 5 described greater conflict. When CTR 5 was initially asked to describe her experience in the study, she replied, "To be honest with you, I forgot about it because we had so much going on." She then went on to tell me about the following situation:

We had some issues with students feeling like I was mean and yelling. I said that it was because they were not listening and how can I show them respect if they don't show the same respect to me? So then we had a long conversation and we created a silent zone and we started to move clips and it seems to have started to get better. 
TTR 4 and CTR 5 had different classroom situations at the end of the school year, but it was interesting to note that the difference in data was observed in the area of peer support for learning and not teacher relationships. From the teachers' interviews, it appears as if the teachers were reflecting on their own relationships with the students, but perhaps these classroom experiences also affected the students' relationships with one another. It is also possible that the teachers were reporting on their own feelings about the classroom, and that the students' positive, or negative, reports in the area of peer support for learning were completely unrelated to the teachers' descriptions. Without hearing from the students themselves, it is impossible to tell the real thoughts behind the students' scores, however, the data does provide the teacher with a general idea of how students are feeling in the classroom.

Research question two. The second research question was: Is teacher participation in the test group associated with meaningful changes in the classroom and increased student engagement scores? If so, what interventions were used?

Quantitative findings. For this research question, two t-tests were completed. The first t-test combined the results of CT1 and CT5 and compared them to the results of TT2 and TT4. This comparison combined the two test teachers and the two control teachers so that each comparison group had one teacher from School A and one teacher from School B.

The second t-test included all three of the teachers in the test group compared to all three of the teachers in the control group. By including CT3 and TT6 in this t-test, the comparison added teachers who do not have a comparative opposite. For example, CT3 
taught a split grade level classroom, but there was no other split grade level teacher to add to the test group to even out this variable. The same was true for TT6. This teacher was the only teacher at a Title I school and there was no other Title I teacher to put in the control group. Since it was possible that being part of a split level classroom or teaching at a Title I school may influence the data in a unique way, by only having one of these representative groups in the data, it may cause the second t-test to appear a bit differently than the first t-test. That being said, it was still important to look at the data with all six of the teacher participants to see if any drastic differences were noticed that might require additional investigation.

Since this comparison was once again looking at the difference in change scores from pre to post-survey, only the 95 students who completed both the pre-survey and post-survey could be included. The sample sizes for these two groups were once again similar, making the weight of each student's answers relatively equal. For the first t-test, the Control group, $\mathrm{N}=38$, and the Test group, $\mathrm{N}=34$. For the second t-test, the Control group, $\mathrm{N}=46$, and the Test group, $\mathrm{N}=49$. Table 4.7 shows the change results for $\mathrm{CT} 1$ and CT5 versus TT2 and TT4 in all four factor areas. 
Table 4.7

\begin{tabular}{llllc}
\multicolumn{5}{l}{ T-test of Average Change Scores for Control vs. Test Groups Excluding Teachers 3 \& 6 } \\
\hline Factor Area & $\begin{array}{l}\text { Control } \\
\text { Group } \\
(1,5)\end{array}$ & $\begin{array}{l}\text { Test } \\
\text { Group } \\
(2,4)\end{array}$ & $\begin{array}{l}\text { Levene's Test } \\
\text { for Equality of } \\
\text { Variances Sig. }\end{array}$ & $\begin{array}{l}\text { t-test for Equality } \\
\text { of Means Sig. } \\
\text { (2-tailed) }\end{array}$ \\
$\begin{array}{l}\text { Teacher } \\
\text { Relationship }\end{array}$ & -0.19 & -0.26 & 0.39 & 0.48 \\
$\begin{array}{l}\text { Peer Support } \\
\text { For Learning }\end{array}$ & -0.29 & -0.09 & 0.91 & 0.14 \\
$\begin{array}{l}\text { Family Support } \\
\text { For Learning }\end{array}$ & -0.07 & -0.11 & 0.98 & 0.71 \\
$\begin{array}{l}\text { Future Goals } \\
\text { and Aspirations }\end{array}$ & -0.12 & -0.04 & 0.16 & 0.33 \\
\hline
\end{tabular}

The data in Table 4.7 showed that on average, students were less engaged in May than they were in in February for the pre-survey. This was represented in the first two columns, where all of the average change scores were a negative number. In two of the four factor areas, the control group had a larger decrease in engagement and in the other two factor areas, the test group had a larger decrease; however, none of the differences were shown to be statistically significant. This meant that the data did not show that there was a statistically significant difference between the engagement scores of students in the test group, where teachers knew students pre-survey engagement scores, versus in the control group, where teachers did not have this information. 
Table 4.8

T-test of Average Change Scores for Control vs. Test Groups in Each Factor Area

\begin{tabular}{|c|c|c|c|c|}
\hline Factor Area & $\begin{array}{l}\text { Control } \\
\text { Group }\end{array}$ & $\begin{array}{l}\text { Test } \\
\text { Group }\end{array}$ & $\begin{array}{l}\text { Levene's|Test } \\
\text { for Equality of } \\
\text { Variances Sig. }\end{array}$ & $\begin{array}{l}\text { t-test for Equality } \\
\text { of Means Sig. } \\
\text { (2-tailed) }\end{array}$ \\
\hline \multicolumn{5}{|l|}{ Teacher } \\
\hline Relationship & -0.23 & -0.14 & 0.75 & 0.27 \\
\hline \multicolumn{5}{|l|}{ Peer Support } \\
\hline For Learning & -0.28 & -0.03 & 0.99 & 0.06 \\
\hline \multicolumn{5}{|l|}{ Family Support } \\
\hline For Learning & -0.11 & -0.05 & 0.35 & 0.43 \\
\hline $\begin{array}{l}\text { Future Goals } \\
\text { and Aspirations }\end{array}$ & -0.08 & -0.02 & 0.09 & 0.14 \\
\hline
\end{tabular}

When adding in the data for CT3 and TT6, the data changed slightly. Once again, the students indicated that their engagement levels had decreased from their original survey scores in February, and the data showed that there was no statistically significant difference between the scores of students in the control group versus those in the test group. This time, though, the engagement scores of the students in the control group dropped more than the students in the test group in each of the four areas. Also, this t-test showed that the area of peer support for learning was nearly statistically significant (pvalue $=0.06)$. In order to be considered statistically significant, the $p$-value would need to be less than 0.05 , but the current p-value of 0.06 was close which meant that something might have been going on and it was worthy of additional attention. The quantitative findings below provided some insight into the results of teachers in the control and test groups, and the question about interventions was addressed. Based on 
the data, all other factor areas do not appear to be affected by prior knowledge of students' engagement levels.

Qualitative findings about control versus test groups. One of the most important comparisons done in this study was the comparison between the control group and the test group. This comparison was especially important because it began to tell us if knowledge of students' engagement scores was an important factor when trying to maintain high levels of engagement throughout the year. Using the quantitative data, we found that there was not a statistically significant difference between the average change scores for teachers in the control group versus those in the test group. The qualitative data helped to support the quantitative findings and to provide some possible explanations for the findings.

First we will look at Teacher 3 who was part of the control group and did not receive data on her students' engagement levels until after the study was complete. CTR 3 reported that when she initially signed up for the study, she thought that she would make some changes based on her students' data. After the study was completed, she was asked about the changes that she had made and she reported that in fact, she had not made any changes and had instead continued with what she naturally would have done.

This initial conversation would have you believe Teacher 3 implemented no interventions in her classroom to help improve engagement, however, a bit later in the interview, she remarked that she, "needed to try some new stuff [in her classroom] because the kids were fading at the end of the school year." She then went on to explain that she had tried to incorporate more technology into the classroom, had gotten some iPads for her students and had started to work on using Brain Breaks (taking a short break 
between lessons to allow the students' brains to rest) to help keep the students motivated. Despite CTR 3's initial feeling that she had not made any changes, she in fact did make changes to help increase the overall engagement levels in her classroom. She did this without the knowledge of her students' pre-survey engagement scores.

CT5 reported a similar event in her final interview. Even without receiving her students' pre-engagement scores, CTR 5 knew that the engagement levels of her students in regards to the factor areas of teacher relationship and peer support for learning had decreased and she came up with interventions to try to bring it back up. She reported having a class meeting and implementing an intervention that used clips to mark students' behavior in order to try and bring engagement levels up in her classrooms.

When we looked at the quantitative data, it was evident that the interventions had not brought the engagement levels back to their original pre-survey levels (Average Change in Teacher Relationship = -.16 and Average Change in Peer Support for Learning $=-.51$ ), but the situation was being addressed and the post-engagement findings supported the feeling the teacher had in the classroom.

Overall, no interventions stood out as consistent across the classrooms or as having a statistically significant change on engagement scores. It appears that teachers need to adapt their interventions to the specific setting and the specific group of students, so they are not easily taken from one situation to another.

Looking at the teachers in the test group, there were many similarities noted amongst their three interviews. When these teachers were asked if they had made any mindful changes to their classroom based on their pre-survey engagement results, all three of them said "no" and they all pointed to the same two reasons. The first reason 
they said that they did not make any changes was that the pre-survey engagement results showed that the majority of their students were engaged in their classroom. The teachers used the summary sheet as a quick snapshot of their students and since the majority of the students were all reporting an average engagement of 3.0 or higher, the teachers took this as a sign to continue on the same path they were on.

The second reason that the teachers reported for not making any changes was due to an already demanding workload. In fact, this was reported by five of the six of the teachers in the study. From one initial interview to the next, I kept hearing similar stories of having too much work to do and not enough time. When asked how he plans for upcoming lessons, TTR 2 reported:

[I plan using] the Common Core, there are a lot of new things coming down the line. It's way too much work, and when you ask the district for help, they are so overwhelmed right now, so it's kind of a free-forall.

When answering the same question, CTR 1, also reported a feeling of having a difficult year when it comes to workload.

It's a challenging year. I work hard. I've always worked hard, but this is my hardest year. We have all of the Common Core to teach. Math is the only subject with a curriculum. All the other subjects are totally brand new. We've taught these things before, but everything is new and not having a curriculum [is really hard]. We don't have any curriculum (said with emphasis). I have no textbooks to teach out of 
for my reading program. That can be a good and a bad thing. It gives me the freedom, but yet I miss having a textbook when I can pull out a lesson and teach it with five minutes prep time. I've been doing this long enough that I know what needs to be done, but this year is just really hard.

CTR 1 and TTR 2 were both veteran teachers who reported feeling overwhelmed by the amount of work that needed to be done to prepare for class each day. CTR 3 and CTR 5, had to try and make ends meet with even less experience. CTR 3 was currently completing her first full year of teaching and had a $3^{\text {rd }}$ and $4^{\text {th }}$ grade blended classroom to try and plan for. CTR 5 was a veteran teacher, but had spent the last many years in Kindergarten and felt overwhelmed by the transition to fourth grade. When I asked how they planned for lessons, CTR 3 said that she, "usually relies on one teacher in $3^{\text {rd }}$ grade to help her, but that teacher was on maternity leave. Then she works as a team with the other fourth grade teachers to try and get everything done. It's juggling. It's just crazy." CTR5 also reported relying on her teammate to help plan out the lessons each week.

When asked to look at the data, though, the teachers in the test group were not surprised by their post-survey results, and could often point reasons in the classroom or school environment that they felt caused the changes.

Research question three. The third research question was: How are student demographic and background characteristics associated with the amount of change students' show between their pre and post-survey results? (Specifically looking at school type, gender, and ethnicity). This research question looked to see if certain characteristics could predict engagement levels for a specific group of students. In this 
study, the three variables that were tested were school type (Title I vs. Non-Title I), gender and ethnicity. Pre-survey scores were also added as a predictor of post-survey scores.

Assumptions. In order to answer this research question, a multiple linear regression needed to be run using SPSS. Before this could happen, it was important to address the assumptions of linearity, homogeneity of variance, and normality. These three assumptions helped to make sure that a multiple linear regression was the most appropriate method of analysis for the data set and that results we got could be accurately applied to the population of interest (Field, 2009).

The first assumption that was addressed was normality. In order for the data to meet the normality assumption, the histogram of the data must for a normal bell curve. Figure 4.14 shows the histogram for the average change data (the dependent variable used for the multiple linear regressions) and met the first normality assumption. 


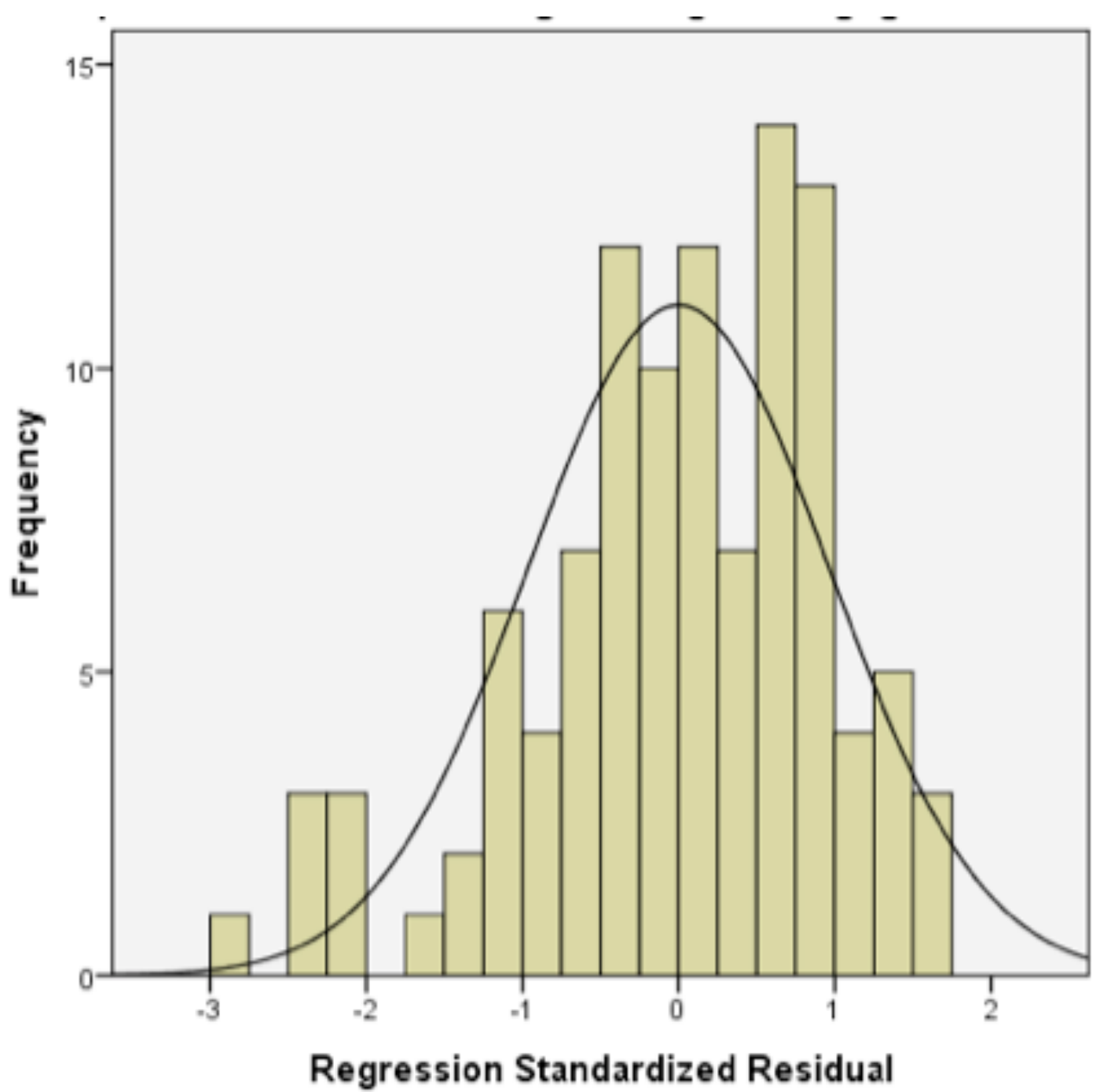

Figure 4.5. Histogram of normally distributed residuals

The second and third assumptions were linearity and homogeneity of variance.

Linearity means that the variables were linearly associated to one another and homogeneity of variance means that the majority of the data points fall within specific band. Both of these assumptions were checked using the scatterplot seen in Figure 4.15. The scatterplot showed a slightly downward linear trend for the data, and the majority of the data points fell within two standard deviations above or below the residual line, so both of these final assumptions were also met. This meant that the multiple linear 
regression was the appropriate analysis tool to help answer research question three.

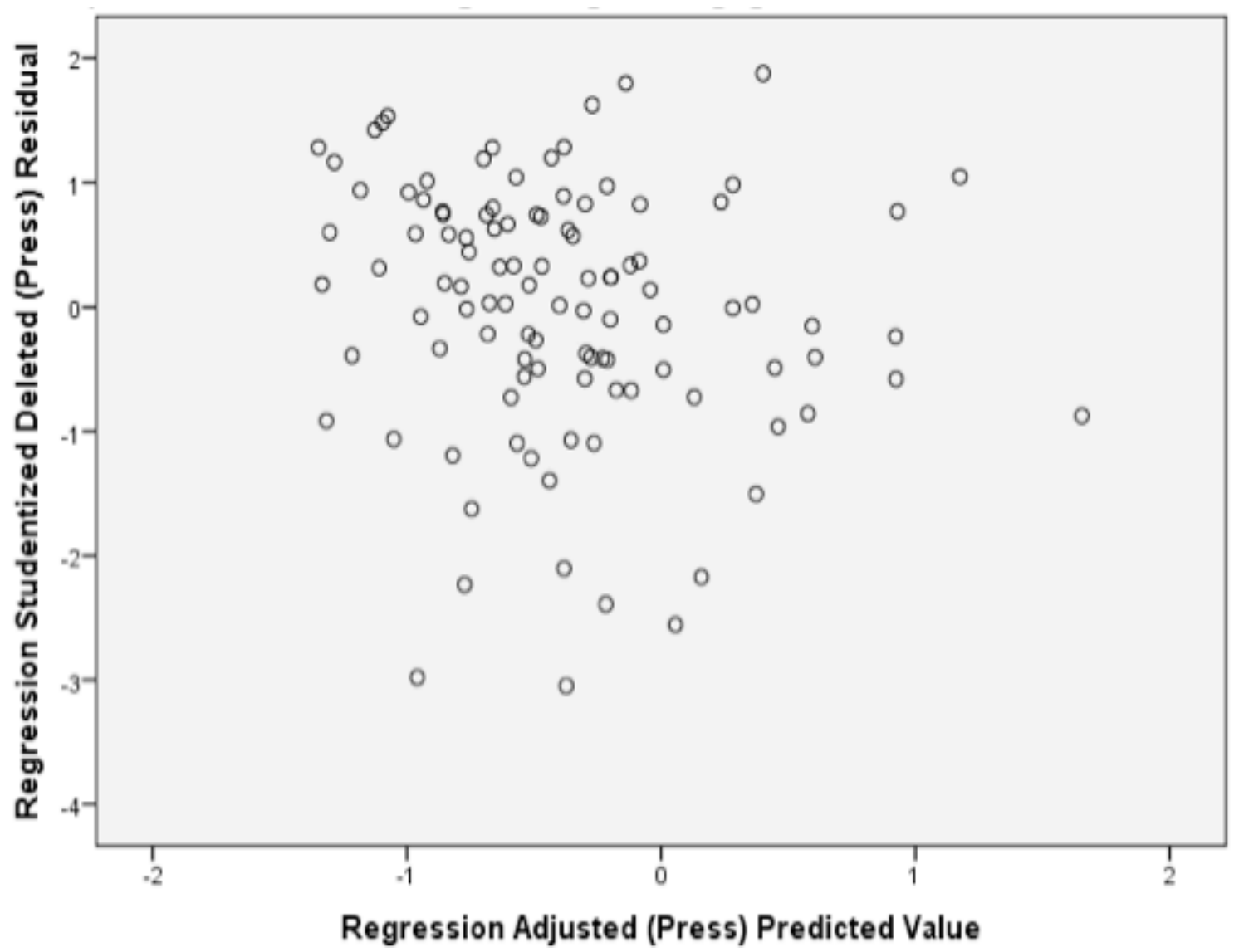

Figure 4.6. Scatterplot of standardized residuals against standardized predicted values.

Quantitative findings. Having addressed the three main assumptions of linearity, normality, and homogeneity of variance, a multiple linear regression was conducted to address the third research question. The initial four independent variables that were used in the multiple linear regression were average pre-survey scores, ethnicity, gender and school type (Title I vs. Non-Title I). Table 4.9 shows the coefficients that were found for this multiple linear regression. 
Table 4.9

Coefficients for Average Pre-Survey Score, Title Status, Ethnicity and Gender

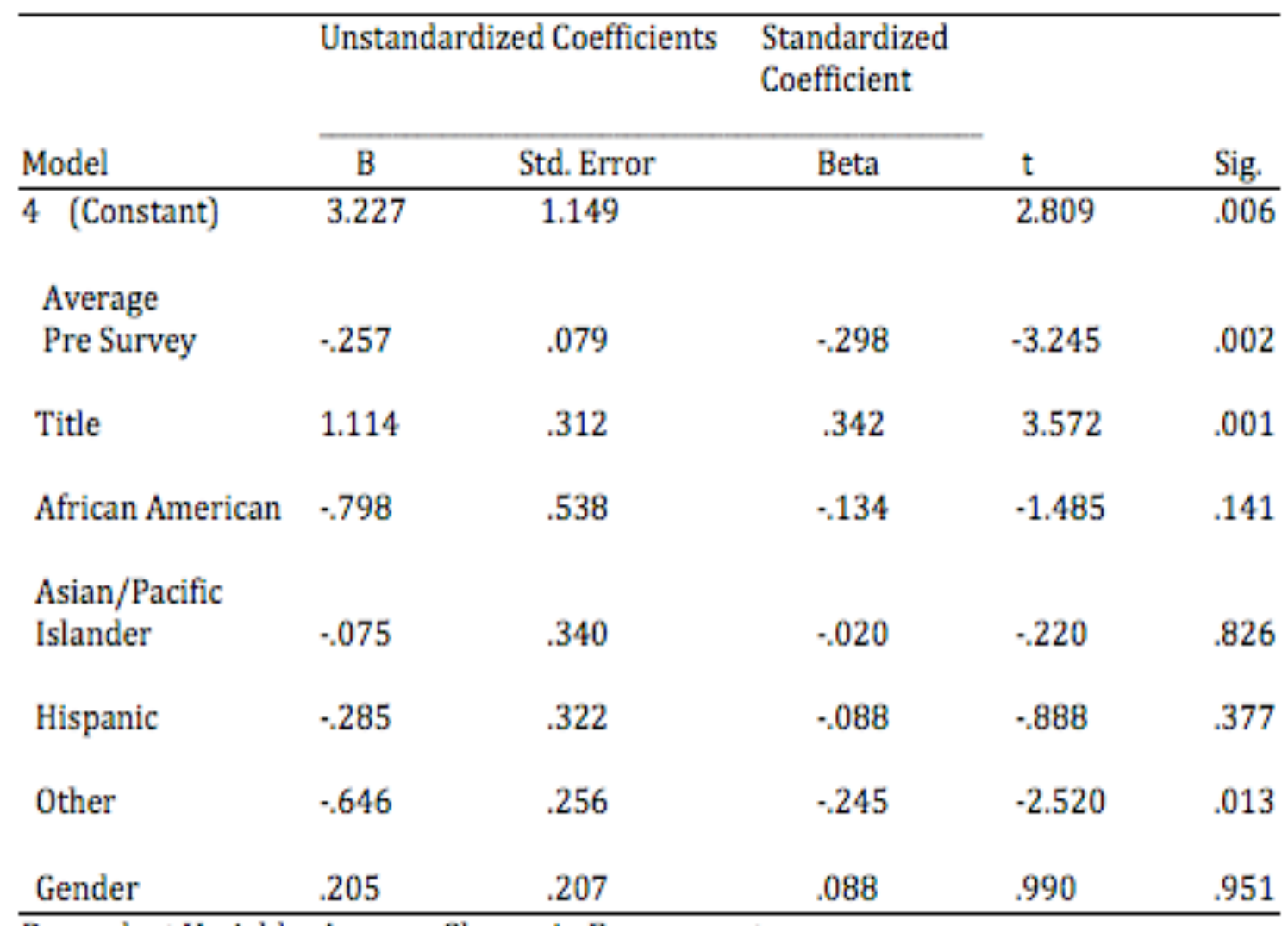

Dependent Variable: Average Change in Engagement

Looking first at the variables, average pre-survey referred to a student's initial presurvey engagement score, Title referred to whether or not a student attended a Title I school, and Other (in the category of ethnicity) was selected for a student who chose multiple ethnicities or for a student who did not identify with the other ethnicity choices of Caucasian, African American, Asian/Pacific Islands or Hispanic. For this particular regression, the reference group was a student who scored a zero on the average presurvey, did not attend a Title I school, was Caucasian, and male. For this particular student, their engagement score was expected to increase by 3.227 points. Since a student representing the constant had previously scored a zero on the pre-survey, their 
expected post-survey score would equal only 3.227 points out of the possible 16 for a student who reported being at the highest engagement level in all four factor areas.

The majority of the students did not, however, meet the exact description of the constant student. In order to find the expected change score for any other student, you would need to start with the constant and then include any other row for which the students who received a 1 (or a yes) in SPSS. The only exception to this rule was for the average pre-survey score. The -.257 represented the expected decrease in a students' engagement score for every point they marked on their pre-survey. So, if a student had a pre-survey score of 1 , then their expected post-survey score would decrease by -.257 , but a student who had a pre-survey score of 2, would be expected to decrease by -.514 (or $2 \mathrm{x}$ -.257). In other words, the higher the students' pre-survey score, the greater decrease was expected in their post-engagement score.

To look at this a bit closer, a hypothetical student named Sarah was a Caucasian female who did not attend a Title I school and reported a pre-engagement score of 10. This meant that Sarah differed from the constant in two ways (gender and preengagement score). To find Sarah's expected post-survey score, you would need to start with the base expected score of 3.227. Sarah would then be expected to get an increase of .205 based on being a female (rather than a male which is the gender used in the constant). Lastly, Sarah would be expected to decrease by -2.57 based on her preengagement score of $10(10 x-.257=-2.57)$. Putting these all together, Sarah's new change in engagement score would be $.862(3.222+.205-2.57=.862)$. Since her presurvey score was 10 , and her expected change in engagement score was .862, Sarah's post-engagement score would be expected to be 10.862 . 
Looking at the far right column, there were four categories that were statistically significant $(\mathrm{p}<.05)$. These four areas were the constant, pre-survey scores, Title I status and students who considered their ethnicity to be "Other." In order to create the most parsimonious model possible, it was important to remove the predictor variable of gender since it did not have a statistically significant effect on a student's change in engagement. This meant that the expected increase of .205 for females was not far enough from zero to meet the $95 \%$ confidence interval and therefore the current data shows us that there appeared to be no statistically significant difference between the change in engagement scores for males versus females. Even though the categories of African American, Asian/Pacific Islander and Hispanic all have p-values $>.05$, making them not statistically significant, these three categories could not be removed from the final model. This was because African American, Asian/Pacific Islander and Hispanic were all part of the overall model for ethnicity, and since one of the categories (Other) was statistically significant, all of the components of this predictor variable must remain. Table 4.10 showed the final multiple linear regression model for this study. This more parsimonious version of the multiple linear regression was identical to the previous table discussed (Table 4.9), but simply removed the final row that included gender as a predictor variable. 
Table 4.10

Coefficients for Average Pre-Survey Score, Title Status and Ethnicity

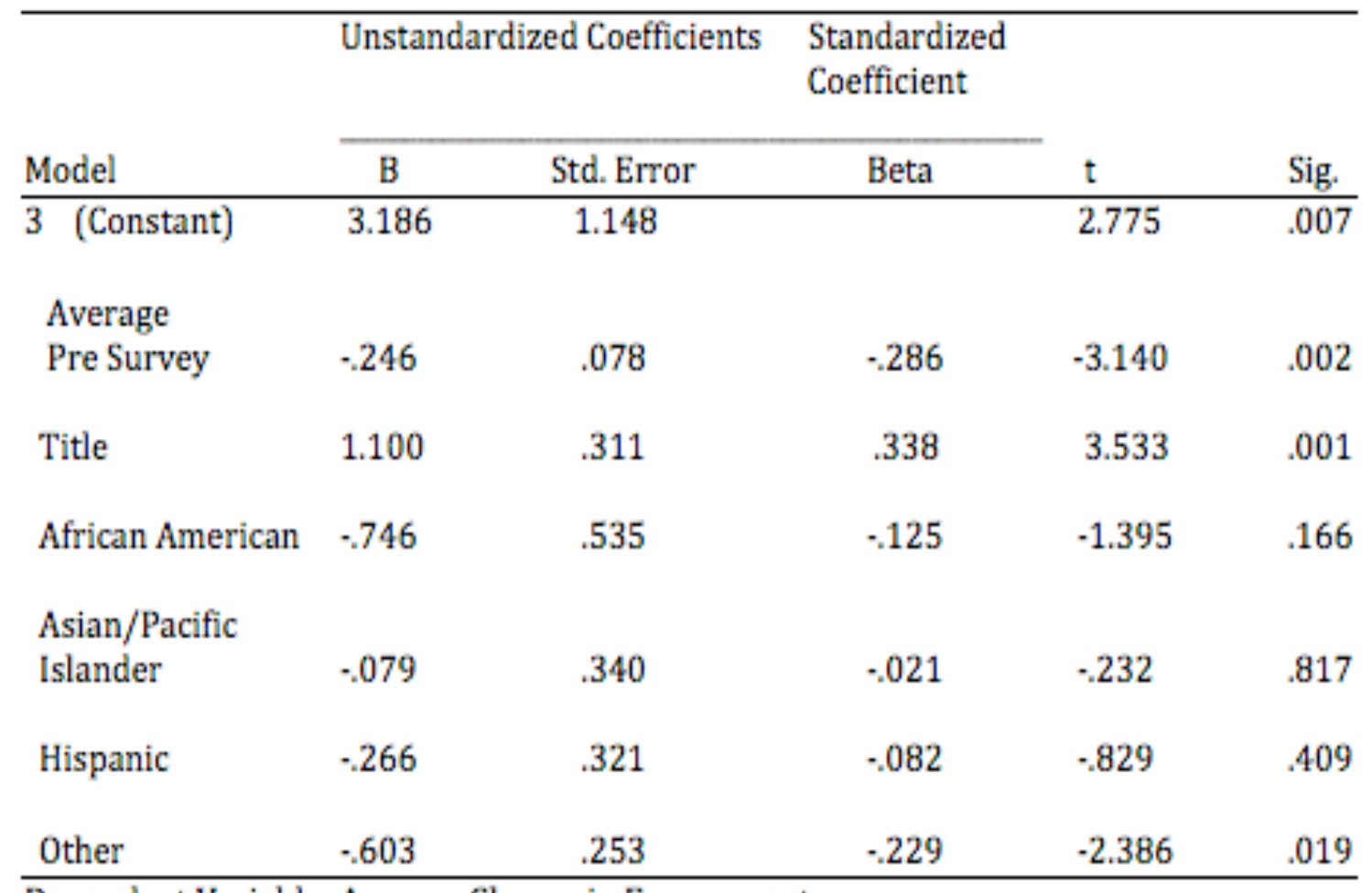

Dependent Variable: Average Change in Engagement

The values in the coefficients table (Table 4.10) have slightly changed due to the removal of gender as a predictor variable and can be seen in the table above. What did not change were the predictors that were found to statistically significant. In this final model, the data showed a $\mathrm{p}$-value $<.05$ for students represented by the constant, as well as a statistically significant difference between students who attended a Title I school and students who identified themselves as "Other" in the category of ethnicity. Students who attended a Title I school were expected to score 1.1 points higher on their postengagement scores than students who did not attend a Title I school, and students who identified as Other in the category of ethnicity, were expected to decrease in their postsurvey engagement by .603 . 
The final statistically significant category was pre-survey scores. This meant that students' pre-survey scores could be used to help predict students' post-survey scores, and because this value was a negative number (-.246), it was expected that the higher students' indicated their engagement levels on the pre-survey, the greater they were expected to decrease on the post-survey.

Qualitative findings about TTR 6. It has already been mentioned that TTR 6 was a unique case in this research study first, because she was the only teacher who taught at a Title I school, and second because she was the only teacher whose average engagement levels increased in all four of the factor areas. With such a small sample size in the Title I category, it was impossible to make a generalization that the same increase in engagement would be found in all Title I classrooms if they participated in the study. In order to gain as much insight from this case as possible, it was important to look closely at the teacher interviews.

When analyzing the two teacher interviews for TTR 6, there were a few differences that stood out from the other five teachers. The first difference was her reaction to the question about how she planned her lessons. The previous five teachers responded to this question with phrases such as, "It's just crazy", "It's the hardest year", "It's way too much work", "It's juggling", and "It's a free-for-all," when discussing the need to come up with new curriculum in all subject areas to meet the new Common Core standards.

TTR 6 responded to the same question about planning lessons in the following way: We have the Common Core State Standards now, but really you can call them the Common Core State Standards, or focal points, or learning targets. We have to teach the standards and keep pushing [the 
students to learn]. That hasn't changed. We had an adopted reading program, but now the district says that we don't need to teach it anymore. I found that [the reading curriculum] was effective for many years, so why would I throw it out? I just make modifications. I like the freedom that I can enhance [the curriculum]. For a while it was all about fidelity, and we taught our math curriculum exactly as it was written. But now, I can look at the big idea. I find that I am always looking for new ideas and new ways to teach [the students] what they need to know.

While TTR 6 did admit to being a bit overwhelmed by all of the data they were required to collect, overall, her reaction was much calmer when it came to the implementation of the new Common Core State Standards in all content areas.

Another subtle difference that was noted in the interviews was how far the teachers went to create a student-centered classroom. It was clear in nearly all of the interviews that the teachers cared for their students and wanted to make sure that they learned a lot during the school year. CTR 1 discussed the importance of building trust with her students and that she always lets them know that they could come to her with any question or concern and that she will always be there to help. She continued by stating that anything was open for conversation in the classroom and that it was a safe place where the conversations stayed amongst the group. Similar conversations were heard from a few of the other teachers as well, but none of the teachers went as far as TTR 6 to make sure her students were cared and challenged every day. 
TTR 6 made comments such as,

Each day I come into class completely prepared, but some mornings by $8: 45$, I realize that my plan isn't going to work. I would come up with another plan on the spot, but sometimes the students would come up with an idea, and I couldn't help but think, "Wow, that's better than what I thought, so let's run with it." Once the students hit their own ideas, they run with them, and running with [the students] is so much fun. I have a couple of boys writing a book series, Red and Joe, and they are two hamsters. They have been working on it all year, and we have lots of little Red and Joe stories. We are trying to figure out a way to publish them.

Modifying the curriculum and publishing stories may not make TTR 6 stand out amongst the other amazing teachers in this study, but it was the comments she would make as we spoke in the hallways that let me know that this was just the beginning. When I walked into her classroom at the end of the school year for the final interview, I commented on all of the office chairs that were scattered at student desks. I had not remembered them from the first interview and she laughed and said,

Oh no, these are new additions. Every time one of my students makes it to grade level on our online math program and passes the final end of the year assessment, I change their chair from a regular one to a special office chair. I spend hours each weekend looking at garage 
sales and Goodwill trying to find them, but I have to make sure I have them ready when the students arrive on Monday. They have worked hard to earn it and it's the least I can do.

And as I finish up the final interview that day, I hand the teacher her $\$ 25$ gift card. While other teachers chose to treat themselves to coffee or a dinner out, TTR 6 beamed and let me know that her Amazon gift card would help to add apps to the few iPads that the school had just raised money to buy. These were the first iPads many of these students had experienced using and she commented on how excited the students would be to know that they had some new apps to use when they got to school.

When asked to describe a good teacher, TTR 6 simply said, "A good teacher is someone who believes in her students." I believe that the data showed this teaching philosophy in action. For students at this Title I school, it seemed as if it took longer to build the relationship of trust with their teacher. TTR 6 reported that many of the families of students in her class had not had positive experiences in school themselves, so for some students, this may have created an even stronger barrier for engagement. Nonetheless, through consistent support and encouragement and with signs of success in the classroom, the data showed that the students gradually became more engaged in all factor areas. It is possible that TTR 6's dedication to go above and beyond was exactly what these students needed to have them start to believe in themselves as well.

\section{Summary of the Findings}

After collecting and analyzing the results of the research study, there were a few areas that stood out in the data. First, it appeared that that factor area of Peer Support for Learning was most influenced by teachers' knowledge of the students' pre-survey 
engagement scores. There was found to be a statistically significant difference in peer support for learning $(\mathrm{p}$-value $=0.01)$ when comparing the two teachers at School B and it was found to be nearly statistically significant $(\mathrm{p}$-value $=0.06)$ when comparing all teachers in the control versus all teachers in the test group.

Peer support for learning was also the factor area where teachers were most likely to request the addition of student names. In four of the six teacher interviews, the teachers said that the study could have been improved if individual students names were included for all of the factor areas except for teacher relationship. Teachers felt that the inclusion of student names was important because often peer interactions took place outside of the classroom, but the repercussions of these interactions affected the school experience without the teacher's knowledge. Teachers felt that if they had consistent data on students' engagement with peers, then they could more easily identify changes in a students' engagement, either positive or negative, and investigate the reasons behind the change. For students who were experiencing bullying or for other students who felt the social pressure to fit in regardless of academic success, there may have been a dip in engagement that was noted on the engagement survey. By making teachers aware of these changes, they could instigate a conversation and see if any interventions needed to be put in place to help re-engage that student in school.

The other main findings came out of the teacher interviews. First, it was reported that an increased sense of awareness was felt by two of the six teachers in the study. By simply participating in the study and knowing that students would eventually have the chance to report their engagement scores to the teacher, the two teachers said that they were more aware of how their students were feeling and interacting in the classroom. 
This increased sense of awareness could be considered a positive result, however, it was not a consistent one, as increased sense of awareness was not reported by all participating teachers.

The second finding was that no interventions were used in more than one classroom, and in fact, most teachers reported that they did not implement any interventions at all. When looking a bit deeper at their interviews; however, it appears that nearly all teachers did actually implement interventions in their classroom that could have had an effect on student engagement. The implementation of interventions was such an ingrained part of being a teacher, that many of the teachers sensed a need for a change and made that change without connecting their actions to the study.

So if interventions were happening regardless of whether or not a teacher received their students' engagement data, then it could be perceived that the data was not important in increasing student engagement. It is possible, however, that the way the data was presented limited the potential effect it had on increasing student engagement scores. When the study was designed, the decision was made to increase confidentiality and the validity of the student answers by removing all of the students' names. Since no student names were given, the data only provided teachers with a quick summary of their classroom engagement levels and the knowledge that someone in the classroom was not engaged. It is possible that the data could have been organized in a different, and more effective manner to help promote increased engagement at both the classroom and the individual level. Possible organizations for the data will be presented in the next steps section in the following chapter.

The final finding has to do with the different between Title I and non-Title I 
schools. In this study, it appeared that Title I schools had a much higher success rate than non-Title I school at increasing their engagement scores from pre-survey to post-survey. As previously stated, though, it is impossible to make this generalization on such a small sample size. Further exploration is needed to determine if the trend continues with larger and more varied student populations.

In the end, it appeared that this initial exploratory study of the Student Engagement Instrument-Elementary Version provided a few insights into the affective and cognitive engagement levels of fourth grade students, but that further exploration was warranted.

\section{Limitations of the Study}

There were two main limitations to this research study, and both of them had to do with the sample. The first limitation was the small sample size. In quantitative research it is helpful to have a large sample size for a variety of reasons. First, a large sample size makes it easier to notice trends and outliers within the data, and secondly, a large sample sizes allow for generalizations to be made for specific situations.

In this research study, ninety-five students and six teachers participated in all of the components. This number was large enough to show statistically significant differences, but it was not large enough to begin making generalizations about the findings. Instead, the findings allowed the researcher to know that further investigation was needed to see if the initial findings were also found true for a larger sample population.

The second limitation to this research study was that it was fairly homogeneous. All six of the classrooms came from the same school district, and five of the six had very similar student populations. The only classroom that was a bit different was Teacher 6- 
Test because she was the only teacher who taught at a Title I school and whose student population was largely Hispanic rather than Caucasian, which was found in all five other classrooms. The study provided some strong data about students at non-Title I schools in this particular school district, but only a small glimpse into the world of Title I education and the use of student engagement data. 


\section{Chapter Five: Discussion}

This chapter begins with a short synopsis of the research problem, the research study and the findings. The chapter then applies what has been learned in the study to Klem and Connell's (2004) Reduced Self-System Process Model, which was the original conceptual framework presented in Chapter 1. Next, three main suggestions are given for future research in the area of cognitive and affective engagement for fourth grade students. The chapter ends with final reflections and suggestions for administrators and teachers who wish to increase student engagement in their school or classroom.

\section{Summary of the Study}

Since its introduction in the 1980 's, student engagement has been a popular topic in educational research. In the beginning, engagement was thought of as a simple construct; however, it is now believed that student engagement involves four separate, but equally important components (Appleton, 2012; Christenson, Reschly, Appleton, Berman, Spanjers, \& Varro, 2008). The components of academic, behavioral, affective and cognitive engagement are each vital to the ongoing educational success of students, and ideally, these would remain high throughout all of the years students are in school. Unfortunately, research shows that most students' engagement levels continuously decrease from elementary school until high school graduation (or dropout), with the biggest drops occurring when students transition to middle school and high school (Alexander, Entwisle, \& Horsey, 1997; Dunleavy \& Milton, 2008; Finn, Pannozzo, \& Voelk1, 1995; Lopez, 2011; Roeser, Strobel, \& Quihuis, 2002; Skinner et al., 2009). Much of the research is currently being done at the middle school and high school levels to try and re-engage students in their learning (Appleton, 2012; Appleton, Christenson, 
Kim \& Reschley, 2006; Fredricks, Blumenfeld, \& Paris, 2004). This study was designed to address the issue of decreasing engagement trends for fourth grade students in order to increase the likelihood that students would be able to maintain high engagement levels as they made the transition to middle school.

This research study took a mixed-methods approach and had two main goals. The first goal of the study was to determine the benefits of providing teachers with systematically collected data on students' affective and cognitive engagement levels. This was important because, unlike academic and behavioral engagement, the areas of affective and cognitive engagement are more internal in nature and are therefore not fully known by the teachers. The second goal of the study was to begin to explore interventions that appeared to increase fourth grade students' affective and cognitive engagement levels.

Six teachers from a suburban school district in the Pacific Northwest participated in this research study. Of the six teachers, five of them taught at Non-Title I schools and one taught at a Title I school. Half of the teachers were part of the control group, and did not receive their students' data until the end of the study, while the other half of the teachers made up the test group and were provided with their students' engagement scores shortly after the pre-survey was administered.

\section{Summary of the Findings}

The findings presented in Chapter Four have been summarized into the follow five main statements.

1. Of the four factor areas, students consistently reported the lowest engagement scores in the areas of teacher relationships and peer support for learning. These were also 
the two areas with the largest decrease in engagement from pre to post-survey. School relationships appear to be an area where student engagement could be improved using student data.

2. There were no statistically significant differences between teachers in the test group versus the teachers in the control group.

3. Teachers did not report the use of interventions based on the student engagement data, however, in the teacher interviews, multiple teachers discussed interventions they had put in place in their classroom during the time of the study. It can therefore be concluded that teachers often know which whole-class interventions are needed, but not necessary which interventions need to be implemented for individual students.

4. The Title I school was the only school where students' engagement levels increased in all four-factor areas from pre to post-survey. This is something that needs to be explored further.

5. Two of the six teachers reported an increased sense of awareness by participating in the study.

\section{Returning to the Conceptual Framework}

After looking at the findings of this research study, it is important to step back and to reflect on how this study impacts our current understanding of student engagement in education. Klem and Connell's (2004) Reduced Self-System Process Model (Figure 5.1) was the framework for this research study. This conceptual framework has four main components: context, actions, interventions, and outcomes, and shows a visual representation of the ongoing, cyclical process that students are in from initial school 
enrollment to graduation (or dropout). This study specifically looked at three of the four components of the Reduced Self-System Model (context, interventions and outcome).

The study looked to see if data on students' cognitive and affective engagement (context) could promote the implementation of interventions, which would then cause an increase in students' overall engagement scores (outcomes).

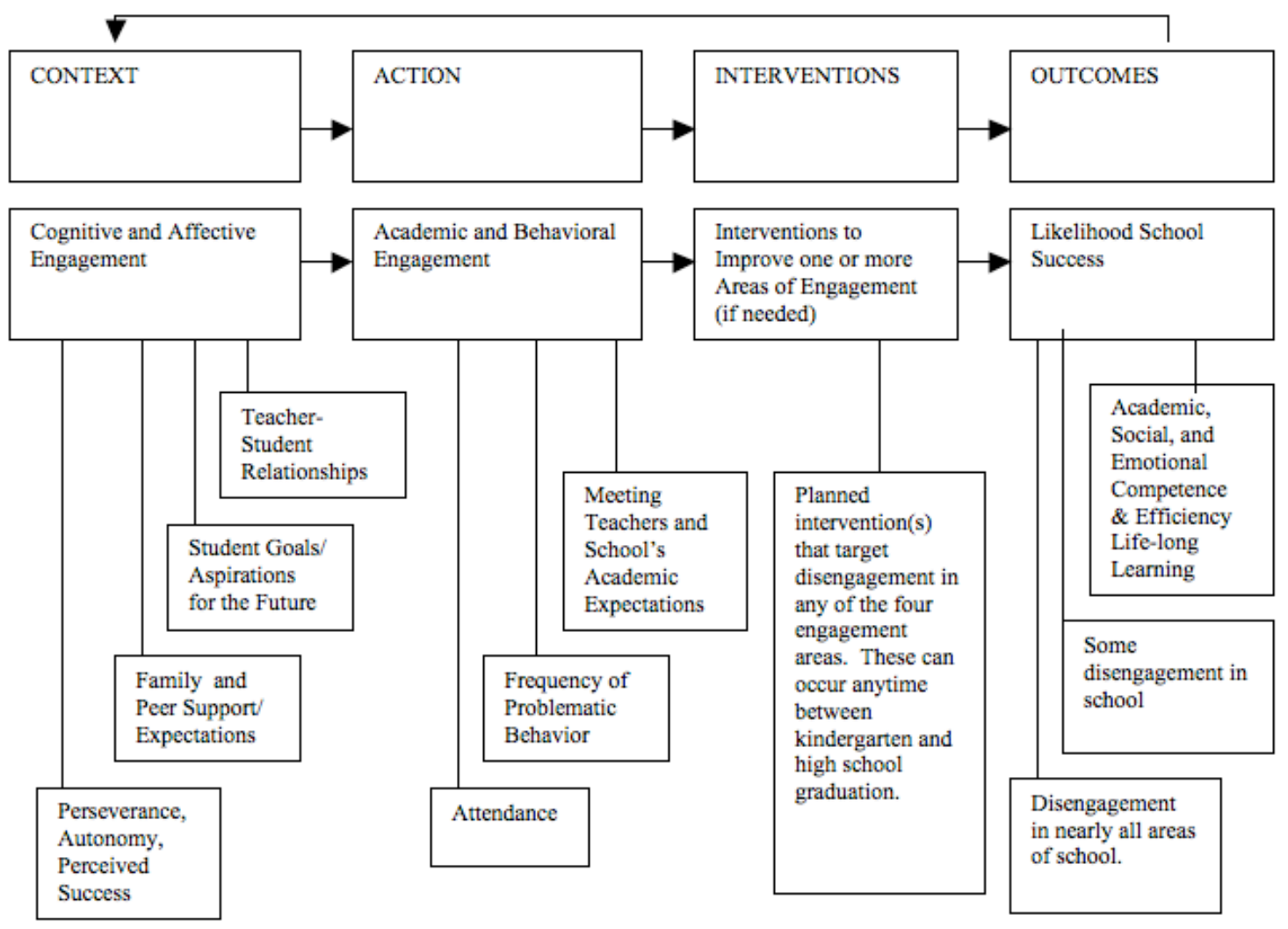

Figure 5.1. Concept Map (Adapted from The Reduced Self-System Process Model, Klem \& Connell, 2004)

Since cognitive and affective engagement is more internal in nature, it is difficult for teachers to know concretely about how each student is feeling in regards to school. By systematically collecting data in these areas using the Student Engagement Instrument-Elementary Version, this study was hoping to determine if cognitive and 
affective engagement data was helpful for teachers in promoting high levels of engagement throughout the year. What the study ended up showing was that this type of data has the potential to be a powerful tool that helps to make sure individual students are not overlooked.

The overall data showed that in most cases, there was not a statistically significant difference between teachers in the test group versus teachers in the control group. In fact, the teachers in both groups reported that they did not implement any interventions based on the student engagement data they received. When looking a bit deeper, though, nearly all of the teachers discussed whole class interventions they had implemented in their classrooms to try and promote engagement. These interventions ranged from increasing technology, purposefully choosing books to read aloud in class that would promote deep levels of thinking and increased empathy towards others, having class meetings to discuss classroom expectations, and implementing a new system for encouraging positive behavior in the classroom. These interventions were not prompted by the survey data, but came from the teachers' sense that there was a need or an opportunity available to increase student engagement. Teachers appear to be able to promote engagement for the majority of the students in the classroom without receiving additional data.

What the data also showed, though, was that there were students in each classroom who were less engaged than the average and in some cases, students who reported being highly disengaged in an otherwise engaging school environment. It is these students who are risk of becoming disengaged with school for a prolonged period of time, and these individual students who could most benefit from targeted interventions. 
During the interviews, teachers often said that they knew their students well enough to guess which ones were at the bottom of the student summary report (indicating that they had the lowest engagement in the classroom), however, four of the six teacher admitted that they would have liked to have the students' names next to the student survey just to make sure they were right. There was a chance in their mind that their assumptions were wrong and that a student who the teacher thought was engaged was in fact not. Teachers admitted that if they knew of specific students who were disengaged, that they would immediately try to find ways to increase their engagement in which every factor area appeared to be low.

\section{Suggestions for Future Research}

While the study provided some key insights into student engagement, there are three main suggestions to improve the study for future research. The first directly addresses the limitations around sample size, the second addresses the timing of the study, and the third directly addresses the suggestions of the six teacher participants around modifications to the survey structure.

First, in an ideal situation, this research study would be repeated with an even number of Title I and non-Title I schools and across a variety of different school districts. It would still be important for two teachers in each school to participate so that test and control groups could be compared, but a larger and more varied sample size would help to provide more clear data that could begin to be generalized to a wider group of fourth grade classrooms.

The second suggestion looks at the timing of the two student surveys. In the current study, the pre-survey was given to student in early March and the post-survey was 
administered in mid-May. The March date was chosen because it was the earliest possible administration date after getting permission from the Institutional Review Board, principals, teachers, students, and parents. The May date was chosen because it was only a few weeks away from the school year. This provided teachers nine instructional weeks to make modifications in their classroom, while still allowing time for the data to be collected, analyzed, and presented to the participating teachers before the school year ended.

In future research studies, it would be ideal to give three engagement surveys to the students to allow engagement to be tracked throughout the year. The first survey should be given about a month into the school year. This provides enough time for a student-teacher relationship to be built, but not too much time that changes could not be made. The other two surveys should be given in the middle of the school year and again at the end of the school year. This would allow enough time in the middle for modifications to be made, but frequent enough checks to ensure that the modifications were working and that no additional modifications needed to be put in place.

The third suggestion for future research modifies the structure of the survey slightly. Out of the six teacher participants, four directly suggested that students' names be added to part of the survey, and the other two hinted to the idea when they mentioned being curious about which students in their data had lower engagement scores than the rest of the students. The addition of student names would need to be done in a strategic way in order to continue to promote students' honesty.

In the original study design, student names were left off to help promote the students to provide honest answers to the engagement questions. After further 
consideration, this concern was directly centered around only the questions for the factor area of Teacher Relationship. It was thought that if students knew the teachers would know their answers, that they might not be honest in how they answered these particular questions, and therefore, the data would not provide an accurate overview of the student engagement in a classroom. In future research, it would be suggested that the first part of the survey included only questions from the Teacher Relationship factor area and students would once again answer these questions without providing their name to the teacher.

The second portion of the survey would contain questions from the other three factor areas of Peer Support for Learning, Family Support for Learning and Future Goals and Aspirations. In these three areas, teachers felt that knowing which answers went with which particular student would be helpful in order to monitor engagement trends over time and to create individualized interventions for the students whose engagement data was lower than ideal.

The next modification to the data would be the addition of a text box to both the anonymous portion of the survey and the second portion of the survey where the students provided their name. This text box on both surveys would say the same thing, "Is there anything else you would like your teacher to know?" and students would have the opportunity to write any additional comments they would like. This text box would be optional and students would have the opportunity to leave them both blank should they choose. If a student chose to write a comment on the first survey, the comment would be anonymous, and if they chose to write a comment on the second part of the survey, their name would be included. This would give the students the choice to either let their 
teacher know the comment was from them, or to simply say what they would like without having to worry about the teacher knowing that they wrote it.

The final change to the study would be the use of the computer as a way to gather the student data. This would allow students to type their comments on the anonymous portion of the survey and not have to worry that the teacher will know their handwriting and know that the comment was from them.

With the addition of text boxes, as well as names next to three of the four factor areas, it is the hope that future studies will continue to be able to provide students with a sense of security they need to be able to answer the questions honestly, while also adding additional meaningful information for the teachers.

\section{Some Final Suggestions on Lessons Learned}

So now that the study is complete, it is possible to step back and think about what this study tells us about engagement for fourth grade students. Some of these reflections go beyond the findings of the study itself, but are suggested by this work. Three main ideas emerge from the research and are worthy of a deeper discussion. These three ideas are:

- Promoting teacher's awareness of student engagement.

- The power needed to increase student engagement throughout the year.

- The feeling of "we" in a classroom and its role in student engagement.

All three of these ideas were important concepts in this study, but more importantly, they can be applied to other classrooms, schools and school districts that are also hoping to promote student engagement. By using the lessons learned in this study, the study can 
provide insight for others and help make positive changes in the field of education. First, I will discuss the idea of awareness.

Ideally, one would hope that participating in a study that was centered on improving student engagement would also increase the awareness teachers had about their students. While two teachers did mention an increased sense of awareness with their students, it was interesting to note that some of the teachers in the test group had the complete opposite reaction. These teachers in the test group actually mentioned that they stopped worrying about finding new ways to engage their students as soon as they saw their students' data. For these teachers, the data showed that the majority of the students in the classroom were already highly engaged, and as a result, the teachers took the data as evidence that they were already doing the "right" thing.

Instead of using the data to motivate change for increased engagement, teachers seemed to use the data as proof that they were already engaging their students enough. From the perspective of those teachers, the data seemed to give them permission to remain the same rather than motivating them to try something new. In this case, it appeared that the teachers in the control group, who did not receive their students' data, actually had a higher motivation to try new things and to keep engagement levels high for their students.

Taking this into consideration, it is perhaps best to limit the amount of data teachers receive about their students' engagement levels in order to promote increased awareness and the on-going pursuit of increased student engagement trends. I would propose that instead of receiving a complete report for each student in the class, that teachers would receive their class averages in each of the four factor areas and only 
specific information about the few students who are outliers from the average data. By providing the final teacher report in this way, it would allow teachers to have a general idea of the engagement level of their class and the ability to identify the few students who reported drastically different scores from the norm. These individual student scores could be either positively or negatively different from the class average, allowing teachers a better understand of the engagement levels of their students. Teachers could then determine what they are doing well and which, if any, students need to be targeted for individualized interventions.

The next major take away is about power and the ability to create a feeling of "we" in the classroom. In the study, the one classroom that had the most success in increasing student engagement levels was Test Teacher 6 (TTR 6). The main difference between this classroom and the other five classrooms was a strong feeling of "we" that the teacher created. What I mean by a strong feeling of "we" is that together, the students and the teacher worked to create an environment where the students were at the center of the learning. In a classroom with a strong feeling of "we," the teacher allows the students to have a greater voice and choice in the classroom activities, and the whole class works together to promote high levels of comprehension and engagement.

It is my contention that in order for this type of classroom to exist the teacher needs to feel that he/she has power over the curriculum and the environment so that changes can be made to match the students in the classroom. The idea of power is vital to the "we" classroom, and administrators need to think about this each time they implement something new. In order for teachers to feel powerful in their classroom, they 
need to be experienced and confident in their craft and they need to continue to grow through small amounts of change.

In this study, the school district adopted the Common Core State Standards and asked teachers to implement a new curriculum in each of the subject areas. The school district did not provide a curriculum to follow, but instead asked teachers to follow an implementation schedule and to figure it out on their own. This was a major change from the previous years, and as a result, it took away some of the teachers' power in the classroom in terms of the pace of change and strategies for implementing changes. Instead of teachers holding the power and sharing it with the students, the power was instead being held by the administrators who were mandating such drastic change.

The five teachers who attempted to meet all of the requirements of the administration felt stressed and overworked in their effort to create new units for the entire year. They worked with their teammates to divide the workload, but in the end, once they had created a unit that matched the common core state standards, the teachers did not have a great amount of motivation to ask for students' input. This created a classroom that was most often run by the teacher rather than created together with the students.

TTR 6, however, decided to maintain her power and to only make small changes to the curriculum that she had been using for years. She made only minor changes to her familiar curriculum, which incorporated student input, to help it more closely match the common core state standards, and which in the end allowed her to be successful in engaging her students. By maintaining more of her power and autonomy, TTR 6 was able to create a "we" classroom where students worked with the teacher to create 
meaningful and motivating lessons. TTR 6 worried less about the administrators' timetable and instead focused on meeting the needs of her students.

The data showed that this was a good choice for the engagement levels of her students, but this is also a very difficult decision to face as a teacher. It is difficult for a teacher to have to choose between creating a classroom environment that values the passions and the goals of the students and following the mandated and rigid guidelines that have been set by the district.

Ideally, district administrators who are hoping to promote high levels of student engagement would remember to:

- Make sure school and/or district initiatives require only a small amount of incremental change for the teachers.

- Ensure that all initiatives are presented with the necessary supports to help ensure success.

- Promote at least some teacher autonomy in the classroom so teachers have the power to meet the needs and individual desires of their students.

Ideally, fourth grade teachers who were hoping to promote on-going engagement for their students would remember to:

- Be willing to make small changes throughout the year to follow district initiatives and/or to promote continued growth as a teacher.

- Create a classroom that focuses on the "we."

- Continually be aware of the students in the classroom. 
- Create safe and caring classrooms that promote high levels of learning for all.

- Ask students meaningful questions and to be open to making classroom changes based on their input.

- Provide individualized interventions for students who are disengaged in at least one area.

In the end, the classroom that did the best job at promoting high levels of engagement for all students throughout the year focused on creating a safe and caring classroom environment. This classroom did not begin the year with the highest engagement levels, but the goal of engagement was seen as an on-going pursuit throughout the year. The teacher was open to trying new things and the students were willing to work hard to meet the standards. In the most engaging classrooms, it is necessary for the students and the teacher to work together and for all voices to be heard. In conclusion, this study shows that providing teachers with data has the potential to have an impact on student engagement as long as some modifications are made to the methods employed in the study. The study also provokes some reflections on those elements of a classroom, particularly in terms of creating a safe and caring environment with shared power, that can improve the engagement of all students in our classrooms. 


\section{References}

Alexander, K. L., Entwisle, D. R., \& Horsey, C. S. (1997). From first grade forward: Early foundations of high school dropout. Sociology of Education, 70, 87-107.

Appleton, J. J. (2012). Systems consultation: Developing the assessment-to-intervention link with the student engagement instrument. In S. Christenson, A. Reschly, \& C. Wylie, (Eds.) The handbook of research on student engagement (pp. 725-741) New York, NY: Springer.

Appleton, J. J., Christenson, S. L., \& Furlong, M. J. (2008). Student engagement with school: Critical conceptual and methodological issues of the construct.

Psychology in the Schools, 45(5), 369-386.

Appleton, J. J., Christenson, S. L., Kim, D. \& Reschly, A. L. (2006). Measuring cognitive and psychological engagement: Validation of the student engagement instrument. Journal of School Psychology, 44, 427-445.

Bandura, A. (1977). Self-efficacy: Toward a unifying theory of behavioral change. Psychology Review, 84, 191-215.

Betts, J., Appleton, J. J., Reschly, A., L., Christenson, S. L., \& Huebner, S. (2010). A study of factorial invariance of the Student Engagement Instrument (SEI): Results from middle and high school students. School Psychology Quarterly, 25(2), 8493.

Birch, S. H., \& Ladd, G. W. (1997). The teacher-child relationship and children's early school adjustment. Journal of School Psychology, 35, 61-79.

Bodovski, K. \& Farkas, G. (2007). Mathematics growth in early elementary school: The 
roles of beginning knowledge, student engagement, and instruction. The Elementary School Journal, 108(2), 115-130.

Burrus, J. \& Roberts, R. D. (February, 2012). Dropping out of high school: Prevalence, risk factors, and remediation strategies. Retrieved from http://www.ets.org/research/policy_research_reports/publications/periodical/2012/ jeav

Caldas, S. J. (1993). Reexamination of input and process factor effects in public school achievement. Journal of Educational Research, 86, 206-214.

Carter, C., Reschly, A., Lovelace, M., Appleton, J., \& Thompson, D. (2012). Measuring student engagement among elementary students: Pilot of the student engagement instrument-elementary version. School Psychology Quarterly, 27 (2), 61-73. Doi: $10.1037 / \mathrm{a} 0029229$

Cherryholmes, C. H. (1992). Notes on pragmatism and scientific realism. Educational Researcher, 14, 13-17.

Christenson, S. L., Reschly, A. L., Appleton, J. J., Berman-Young, S., Spanjers, D. M., Varro, P. (2008). Best practices in fostering student engagement. In A. Thomas and J. Grimes (Eds.), Best practices in school psychology V (pp. 1099-1119). Washington, DC: National Association of School Psychologists.

Christenson, S. L., Reschly, A. L., Wylie, C. (2012) Handbook of research on student engagement. New York: Springer.

Connell, J. P. (1990). Context, self and action: A motivational analysis of self-system processes across the life span. In D. Cicchetti \& M. Beeghly (Eds.), The self in transition: Infancy to childhood (pp.61-97). Chicago: University of Chicago 
Press.

Connell, J. P. \& Wellborn, J. G. (1991). Competence, autonomy and relatedness: A motivational analysis of self-system processes. In M. R. Gunnar \& L. A. Sroufe (Eds.), Self Processes and Development (Vol. 23, pp. 43-77). Hillsdale, NJ: Erlbaum.

Dolezal, S. E., Welsh, L. M., Pressley M., \& Vincent, M. M. (2003). How nine thirdgrade teachers motivate student academic engagement. The Elementary School Journal, 103 (3), 239-267.

Doll, B. (1996). Children without friends: Implications for practice and policy. School Psychology Review, 25, 165-183.

Dunleavy, J., \& Milton, P. (2008). Student engagement for effective teaching and deep learning. Education Canada, 48(5), 4-8.

Entwisle, D. R., \& Hayduk, L. A. (1988). Lasting effects of elementary school. Sociology of Education, 61, 147-159.

Evertson, C. M. (1982). Differences in instructional activities in higher- and lowerachieving junior high English and math classes. The Elementary School Journal, 82(4), 329-350.

Field, A. (2009). Discovering statistics using SPSS (3 ${ }^{\text {rd }}$ ed.). London: Sage Publications Ltd.

Finn, J. D. (1989). Withdrawing from school. Review of Educational Research, 59, 117142.

Finn, J. D., Pannozzo, G. M., \& Voelk1, K. E. (1995). Disruptive and inattentivewithdrawn behavior and achievement among fourth graders. The Elementary 
School Journal, 95, 421-454.

Finn, J. D., \& Zimmer, K. S. (2012). Student engagement: What is it? Why does it really matter? In S. L. Christenson, A. L. Reschley, \& C. Wylie (Eds.) The handbook of research on student engagement (pp. 97-130). New York, NY: Springer.

Fisher, C. W., \& Berliner, D. C. (1985). Perspectives on instructional time. New York: Longman.

Fredricks, J.A., Blumenfeld, P., Friedel, J., \& Paris, A. (2005). School engagement. In K.A. Moore \& L. Lippman (Eds.), What do children need to flourish?: Conceptualizing and measuring indicators of positive development. New York, NY: Springer Science and Business Media.

Fredricks, J. A., Blumenfeld, P.C., \& Paris, A. H. (2004). School engagement: Potential of the concept, state of the evidence. Review of Educational Research, 74, 59-109. doi:10.3102/00346543074001059

Fredricks, J. A., Blumenfeld, P.C., Friedel, J., \& Paris, A. (2005). School engagement. In K.A. Moore and L. Lippman (Eds.), What do children need to flourish?: Conceptualizing and measuring indicators of positive development. New York: Kluwer Academic/Plenum Press.

Fredricks, J., McColskey, W., Meli, J., Mordica, B., Montrosse, B., \& Mooney, K. (2011). Measuring student engagement in upper elementary through high school: A description of 21 instruments (Issues \& Answers Report, REL 3022-No. 098). Washington, DC: U.S. Department of Education, Institute of Education Sciences, National Center for Education Evaluation and Regional Assistance, Regional Educational Laboratory Southeast. Retrieved from http://ies.ed.gov/ncee/edlabs 
Furlong, M. J., Whipple, A. D., St. Jean, G., Simental, J., Soliz, A., \& Punthuna, S. (2003). Multiple contexts of school engagement: Moving toward a unifying framework for educational research and practice. The California School Psychologist, 8, 99-113.

Furrer, C. \& Skinner, E. (2003). Sense of relatedness as a factor in children's academic engagement and performance. Journal of Educational Psychology, 95(1), 148162.

Goodenow, C. \& Grady, K. E. (1993). The relationship of school belonging and friends' values to academic motivation among urban adolescent students. The Journal of Experimental Education, 62(1), 60-71.

Gottfried, M. A. (2009). Excused versus unexcused: How student absences in elementary school affect academic achievement. Educational Evaluation and Policy Analysis, $31,392-415$.

Greene, B. A., \& Miller, R. B. (1996). Influences on achievement: Goals, perceived ability and cognitive engagement. Contemporary Educational Psychology, 21, 181-192.

Greenwood, C. R. (1991). Longitudinal analysis of time, engagement, and achievement in at-risk versus non-risk students. Exceptional Children, 57, 521-535.

Guba, E. G. \& Lincoln, Y. S. (2005). Paradigmatic, controversies, contradictions, and emerging confluences. In N. K. Denzin \& Y. S. Lincoln (Eds.), The Sage handbook of qualitative research ( $3^{\text {rd }}$ ed.) (pp. 191-216). Thousand Oaks, CA: Sage Publications.

Hamre, B. K. \& Pianta, R. C. (2001). Early teacher-child relationships and the trajectory 
of children's school outcomes through eighth grade. Child Development, 72(2), 625-638.

Hamre, B. K. \& Pianta, R. C. (2005). Can instructional and emotional support in the firstgrade classroom make a difference for children at risk of school failure? Child Development, 76(5), 949-967.

Hardre, P. L. \& Reeve, J. (2003). A motivational model of rural students' intentions to persist in, versus drop out of, high school. Journal of Educational Psychology, 95(2), 347-356.

Howse, R. B., Lange, G., Farran, D. C., \& Boyles, C. D. (2003). Motivation and selfregulation as predictors of achievement in economically disadvantaged young children. The Journal of Experimental Education, 71(2), 151-174.

Hughes, J. N. \& Kwok, O. (2005). Classroom engagement mediates the effect of teacherstudent support on elementary students' peer acceptance: A prospective analysis. Journal of School Psychology, 43, 465-480.

Hughes, J. N., Luo, W., Kwok, O., \& Loyd, L. K. (2008). Teacher-student support, effortful engagement, and achievement: A 3-year longitudinal study. $J$. Educational Psychology, 100(1), 1-14.

Hussar, W. J., \& Bailey, T. M. (2013). Projections of education statistics to 2021 (NCES 2-13-008). U. S. Department of Education National Center for Educational Statistics. Washington, DC: U.S. Government Printing Office. Institute of Education Sciences. (2012). Status dropout rates (Indicator 33-2012). Retrieved from http://nces.ed.gov/programs/coe/indicator_sde.asp 
Johnson, R. B. \& Onwuegbuzie, A. J. (2004). Mixed methods research: A research paradigm whose time has come. Educational Researcher, 33(7), 14-26.

Juniper Gardens Children's Project. Lawrence, KS: University of Kansas. Retrieved January 2, 2014, from ebass.ku.edu/instruments/

Klem, A. M. \& Connell, J. P. (2004). Relationships matter: Linking teacher support to student engagement and achievement. Journal of School Health, 74(7), 262-273.

Kortering, L. J. \& Christenson, S. (2009). Engaging students in school and learning: The real deal for school completion. Exceptionality, A Special Education Journal, 17(1), 5-15.

Lamdin, D. J. (1996). Evidence of student attendance as an independent variable in education production functions. Journal of Educational Research, 89, 155-162.

Lehr, C.A., Sinclair, M. F., \& Christenson, S. L. (2004). Addressing student engagement and truancy prevention during the elementary school years: A replication study of the Check \& Connect model. Journal of Education for Students Placed at Risk, $9(3), 279-301$.

Libbey, H. P. (2004). Measuring student relationships to school: Attachment, bonding, connectedness, and engagement. Journal of School Health, 74, 274-283.

Linnenbrink, E. A., \& Pintrich, P. R. (2003). The role of self-efficacy beliefs in student engagement and learning in the classroom. Reading \& Writing Quarterly: Overcoming Learning Difficulties, 19(2), 119-137.

Lopez, S. J. (2011). The highs and lows of student engagement. Phi Delta Kappan, 93(2), 72-32. 
Lutz, S. L., Guthrie, J. T., \& Davis, M. H. (2006). Scaffolding for engagement in elementary school reading instruction. The Journal of Educational Research, 100 (1), 3-18.

Lynch, M., \& Cicchetti, D. (1997). Children's relationships with adults and peers: An examination of elementary and junior high school students. Journal of School Psychology, 35(1), 81-99.

Lynch, M., \& Wellborn, J. G. (1988). Peer influences on student engagement and disaffection. Paper presented at the annual metting of the American Educational Research Association, New Orleans, LA, April, 1988.

Mahatmya, D., Lohman, B. J., Matjaska, J. L., \& Farb, A. F. (2012). Engagement across developmental periods. In S. L. Christenson, A. L. Reschley, \& C. Wylie (Eds.) The handbook of research on student engagement (pp. 45-63). New York, NY: Springer.

Marks, H. M. (2000). Student engagement in instructional activity: Patterns in the elementary, middle, and high school years. American Educational Research Journal, 37 (1), 153-184.

Maxwell, J. A. (2005). Qualitative research design: An interactive approach (2 ${ }^{\text {nd }}$ ed.). Thousand Oaks, CA: Sage Publications, Inc.

McDougall, P., \& Hymel, S. (1998). Moving into middle school: Individual differences in the transition experience. Canadian Journal of Behavioral Science, 30(2), 108120. 
Meece, J. L., Blumenfeld, P. C., \& Hoyle, R. H. (1988). Students' goal orientations and cognitive engagement in classroom activities. Journal of Educational Psychology, 80(4), 514-523.

Metallidou, P., \& Vlachou, A. (2007). Motivational beliefs, cognitive engagement, and achievement in language and mathematics in elementary school children. International Journal of Psychology, 42 (1), 2-15.

Murdock, T. B. (1999). The social context of risk: Status and motivational predictors of alienation in middle school. Journal of Educational Psychology, 91, 63-75.

Newmann, F. M. (1981). Reducting student alienation in high schools: Implications of theory. Harvard Educational Review, 51, 546-564.

Newmann, B. M. \& Newmann, P. R. (2003). Development through life: A psychosocial approach ( $8^{\text {th }}$ ed.). Belmont, CA: Wadsworth/Thomson Learning.

Newmann, F., Wehlage, G. G., \& Lamborn, S. D. (1992). The significance and sources of student engagement. In F. Newmann (Ed.), Student engagement and achievement in secondary schools (p. 11-39). New York: Teachers College Press.

Oregon Department of Education. (2012-2013). Report card download. Retrieved from http://www.ode.state.or.us/data/reportcard/reports.aspx.

Peterson, P. L., Swing, S. R., Stark, K. D., \& Waas, G. A. (1984). Students' cognitions and time on task during mathematics instruction. American Educational Research Journal, 21(3), 487-515.

Piaget, J. (1972). Intellectual evolution from adolescence to adulthood. Human Development, 15, 1-12. 
Pianta, R. C. \& Steinberg, M. S. (1992). Teacher-child relationships and the process of adjusting to school. New Directions for Child Development, 57, 61-80.

Reschly, A., \& Christenson, S. L. (2006). Promoting school completion. In G. Bear \& K. Minke (Eds.) Children's needs III: Understanding and addressing the developmental needs of children (pp. 103-113). Bethesda, MD: National Association of School Psychologists.

Reschly, A. L., \& Christenson, S. L. (2012) Jingle, jangle, and conceptual haziness: Evolution and future directions of the engagement construct. In S. L. Christenson, A. L. Reschly, \& C. Wylie (Eds.), The handbook of research on student engagement (pp. 3-19). New York, NY: Springer.

Roby, D. E. (2004). Research on school attendance and student achievement: A study of Ohio schools. Educational Research Quarterly, 28(1), 3-14.

Roehrig, A., \& Christensen, E. (2010). Development and use of a tool for evaluating teacher effectiveness in grades k-12. In V. J. Shute, B. J. Becker (Eds.), Innovative assessment for the $21^{\text {st }}$ century (pp. 207-228). New York, NY: Springer.

Roeser, R., Strobel, K. R., \& Quihuis, G. (2002). Studying early adolescents' academic, motivation, social-emotional functioning, and engagement in learning: Variableand person-centered approaches. Anxiety, Stress, and Coping, 15, 345-368.

Rowe, K. J., \& Rowe, K. S. (1992). The relationship between inattentiveness in the classroom and reading achievement (Part B): An explanatory study. Journal of the American Academy of Child and Adolescent Psychiatry, 31(2), 357-368. 
Rumberger, R. W. (1987). High school dropouts: A review of issues and evidence. Review of Educational Research, 57, 101-121.

Rumberger, R. W. \& Lim, S. A. (2008). Why students drop out of school and what can be done. Paper presented at the forum Dropouts in America: How sever is the problem? What do we know about intervention and preventions? Cambridge, MA: Harvard University, Civil Rights Project.

Ryan, A. M. (2000). Peer groups as a context for the socialization of adolescents' motivation, engagement, and achievement in school. Educational Psychologist, 35(2), 101-111.

Sedaghat, M., Abedin, A., Hejazi, E., \& Hassanabadi, H. (2011). Motivation, cognitive engagement, and academic achievement. Procedia Social and Behavioral Sciences, 15, 2406-2410.

Skinner, E. Department of Psychology, Portland State University. Professor website. Retrieved January 2, 2014, from http://www.pdx.edu/psy/ellen-skinner-1.

Skinner, E. A. \& Belmont, M. J. (1993). Motivation in the classroom: Reciprocal effects of teacher behavior and students engagement across the school year. Journal of Educational Psychology, 85(4), 571-581.

Skinner, E. A., Furrer, C., Marchand, G., \& Kindermann, T. (2008). Engagement and disaffection in the classroom: Part of a larger motivational dynamic? Journal of Educational Psychology. 100(4), 765-781.

Skinner, E. A., Kindermann, T. A., Connell, J. P., \& Wellborn, J. G. (2009). Engagement and disaffection as organizational constructs in the dynamics of motivational 
development. In K. Wentzel \& A Wigfield (Eds.), Handbook of motivation in school. Malwah, NJ: Erlbaum.

Skinner, E. A., Welborn, J. G., \& Connell, J. P. (1990). What it takes to do well in school and whether I've got it: A process model of perceived control and children's engagement and achievement in school. Journal of Educational Psychology, 82(1), 22-32.

Stallings, J. (1980). Allocated academic learning time revisited, or beyond time on task. Educational Researcher, 9(11), 11-16.

Sutton, A., \& Soderstrom, I. (1999). Predicting elementary and secondary school achievement with school-related and demographic factors. The Journal of Educational Research, 92(6), 330-338.

Taylor, B. M., Pearson, P. D., Peterson, D. S., \& Rodriguez, M. C. (2003). Reading growth in high-poverty classrooms: The influence of teacher practices that encourage cognitive engagement in literacy learning. The Elementary School Journal, 104(1), 3-28.

Tyler, J. H., \& Lofstrom, M. (2009). Finishing high school: Alternative pathways and dropout recovery. The Future of Children, 19(1), 77-103.

United States Department of Education. (2004). Title 1 - Improving the academic achievement of the disadvantaged. Retrieved from http://www2.ed.gov/policy/elsec/leg/esea02/pg1.html

Voelk1, K. E. (2012). School Identification. In S. L. Christenson, A. L. Reschley, \& C. Wylie (Eds.) The handbook of research on student engagement (pp. 193-218). New York, NY: Springer. 
Warren, J. R. \& Saliba, J. (2012). First- through eighth-grade retention rates for all 50 states: A new method and initial results. Educational Researcher, 41, 320-329.

Washburne, C., Vogel, M., \& Gray, W. S. (1926). Results of practical experiments in fitting schools to individuals. Journals of Educational Research, Supplementary Issue. Bloomington, IL: Public School Publishing Company.

Wentzel, K. R. (1998). Social relationships and motivation in middle school: The role of parents, teachers, and peers. Journal of Educational Psychology, 90(2), 202-209.

Wigfield, A., Guthrie, J. C., Perenchevich, K.C., Taboaba, A., Klauda, S.L., McCrae, A., \& Barbosa, P. (2008). Role of reading engagement in mediating effects of reading comprehension instruction on reading outcomes. Psychology in the Schools, 45, 432-445. 
Appendix A

\section{Principal's Consent Form for Research}

\section{Research Background}

Title of the Study: Student Engagement in the Fourth Grade Classroom

Name of Researcher: Nicole Van Gasse Organization: Portland State University

Street address: [Address Removed]

E-mail: [Email removed]

Phone: 314-xxx-xxxx

\section{Description of Research Proposal}

This year I will be conducting a research study at six elementary schools in the [Name Removed] School District. The study will look specifically at two fourth grade classrooms at each of the school sites, with the goal of increasing students' cognitive and affective engagement levels.

The study will take place between December 2013 and April 2014. The study will require no additional work for the principal. Teachers who volunteer and are selected for the study will participate in 2-3 interviews (approximately 30 minutes each) and will be asked to leave the room two separate times while I administer an engagement pre- and post-survey to their students. Half of the participating teachers will also be asked to create an intervention plan to try and increase overall engagement scores for the students in their class.

This study has been approved by the Assistant Superintendent of the [Name Removed] School District and will be reviewed by Portland State's Institutional Review Board before implementation will begin at any school site. Confidentiality will be strictly maintained for all participants in this study (students, teachers, schools, and the [Name Removed] School District). 


\section{Agreement (to be completed by principal)}

I, understand:

, principal of school,

- the study and what it requires of the staff, students, and/or parents in my school,

- that the privacy and confidentiality of all staff and students will be protected, - that I have the right to allow or refuse to agree to support this research study in my school,

- that I have the right to terminate the research study at any time, and

- that I have the right to review all consent forms before making a decision.

I grant permission to the researcher to conduct the above named research in my school as described in the proposal.

I DO NOT grant permission to the researcher to conduct the above named research in my school as described in the proposal.

Signature of Principal 
Appendix B

Email to Teachers

Dear Fourth Grade Teachers,

Hello, my name is Nicole Van Gasse and I am a doctoral student at Portland State University. I am conducting a research study this year on student engagement of fourth grade students and wanted to invite you to participate in the study. I have already received approval from the [Name Removed] School District and your building principal, and was hoping to have the opportunity to discuss the study in greater detail with you in the near future. You are under no obligation to participate in the study, nor will you be penalized in any way for not participating, but I am hoping that you would be open to hearing a bit more about this opportunity.

Should you choose to participate, you would be asked to pass out and collect parent permission forms, to leave your room twice for 15-30 minutes, so that I may administer a student engagement survey to your students, and to participate in 2 or 3 short interviews. These interviews can be done through Skype or at a location of your choice. All participants of the study will also receive a $\$ 25$ gift card at the end of the study, as a thank you for your time.

I am available to meet with your fourth grade team at your school on from to The meeting will take about 10 minutes of your time and will allow you to hear a brief summary of the research on student engagement, to ask any questions you might have about the study, and to determine if this study is right for you. I look forward to the opportunity of speaking with you and your teammates in the near future.

Have a wonderful day,

Nicole Van Gasse 
Appendix C

\section{Informed Consent Form}

Teacher participants

\section{Student Engagement in the Fourth Grade Classroom}

Student Researcher: Nicole Van Gasse, doctoral student at Portland State University and $4^{\text {th }}$ grade teacher in the [Name Removed] School District

[Email address and phone number removed]

\section{Purpose}

You are invited to participate in a dissertation research study on student engagement. The purpose of this study is to investigate the use of an engagement survey to promote interventions that increase student engagement in fourth grade. Specifically, the study will look into students' thinking about learning and their sense of belonging in the classroom and school setting. The results of this study will help determine if this survey provides beneficial knowledge for other elementary teachers trying to increase student engagement. I am recruiting up to twelve, fourth grade teachers in your school district to participate in this study.

\section{Teacher Requirements}

In order to be eligible for this study, each participating teacher must meet the following criteria:

1. The teacher must teach a regular education $4^{\text {th }}$ grade classroom.

2. The classroom must be a typical representation of the school population (example: ELL or Talented and Gifted students are not clustered)

3. There must be two fourth grade teachers from your elementary school who volunteer for the study in order to be considered possible participants.

\section{Procedures}

If you choose to take part in this study, you will be asked to participate in two or three interviews that will each be approximately thirty minutes long. You will be provided with student and parent consent forms that you will be asked to distribute, collect, and return to the researcher. At the beginning and the end of the study, you will be asked to leave you classroom for approximately thirty minutes while the researcher administers the engagement survey to the students in your class. At each of the schools, one teacher participant will receive a summary of their students' survey results during the study, while the other teacher will not receive their data until the study is complete.

\section{Risks}

There are no known risks to participating in this study. Principals and the [Name Removed] School District will not have access to the raw data collected during this study. 
The results of the student survey data will not be used to assess student learning or to evaluate the teacher.

\section{Benefits}

All teacher participants will receive engagement data on their students. This data will provide insight into the students in the classroom and could help inform the teacher on an intervention that could have lasting impacts on the students' overall engagement levels.

\section{Confidentiality}

The information collected during this study will be kept confidential at all times. Audio recordings of teacher interviews and study surveys will be kept in a locked cabinet and will only be accessible to the researcher and their assistant.

The only public release of this data will be in presentations for educators or other researchers and in my dissertation. In these cases, the names of students, teachers, schools, and the district will be changed. There will be no way to identify any of the participants or schools that are involved in the research study.

\section{Compensation}

All teachers who participate fully in the study will receive a $\$ 25$ gift card to a location of their choice.

\section{Contact}

If you have questions at any time about the study or the procedures, you may contact Nicole Van Gasse at [Email Removed] or

314-xxx-xxxx. You may also contact my advisor at Portland State University, Emily de la Cruz, at [Email Removed].

\section{Consent}

Your signature on this form indicates that you have understood to your satisfaction the information regarding this research project and agree to participate as a subject. You understand that even if you meet all of the criteria, it is possible that you may not be selected for this study.

Participant's Name (print)

Participant's Name (signature)

Date

School 
Appendix D

\section{PARENT PERMISSION LETTER}

Dear Parent or Guardian,

I am a doctoral student at Portland State University. I am conducting a research project on student engagement in fourth grade classrooms. I am requesting permission for your child to participate.

The study consists of two, 24-question surveys that will be given to students in multiple fourth grade classrooms across the district. The project will be explained in terms that your child can understand, and your child will participate only if he or she is willing to do so. Only my faculty advisors at Portland State, my research assistant, and I will have access to your child's survey information. At the conclusion of the study, children's responses will be reported as an average of their survey responses. No names will be connected to any of the survey results.

Participation in this study is voluntary. Your decision whether or not to allow your child to participate will not affect the services normally provided to your child by the [Name Removed] School District. Your child's participation in this study will not lead to the loss of any benefits to which he or she is otherwise entitled. Even if you give your permission for your child to participate, your child is free to choose not to participate. If your child agrees to participate, he or she is free to end participation at any time.

Any information that is obtained in connection with this study will remain confidential. Confidentiality will be maintained by storing students' responses in a locked cabinet, and limiting data access to only my research assistant and myself. School and teacher names will be changed when presenting this data to any other sources, and no student names will be published at any time.

Should you have any questions, or desire further information, please email me at [Email Removed]. My faculty sponsor at Portland State, Emily de la Cruz, can also be reached at [Email Removed].

If you have any questions about the rights as research participants, you may contact the Portland State University Institutional Review Board (IRB) by email at rmc4@pdx.edu or by phone at (503)725-2227.

Sincerely,

Nicole Van Gasse, Portland State University 
Please indicate whether or not you wish to allow your child to participate in this project by checking one of the statements below, signing your name and returning this page only to your child's fourth grade teacher.

I grant permission for my child to participate in Nicole Van Gasse's study on student engagement in fourth grade.

I do not grant permission for my child to participate in Nicole Van Gasse's study on student engagement in fourth grade. I understand that my child will still complete the survey if I choose this option, so that other students in the class will be unaware of their non-participation. If this happens, my child's survey will be immediately shredded and none of their data will be used in the study in any way. 
Appendix E

\section{CARTA DE PERSMISO DE LOS PADRES}

Querido/a Madre, Padre o Apoderado/a:

Soy una profesora del Distrito Escolar de [Name Removed] y estudiante de doctorado de la Universidad Estatal de Portland. Estoy realizando una investigación sobre la participación en el aula (sala de clases) de los estudiantes de cuarto grado. Yo estoy pidiendo su permiso para que su hijo/a pueda participar de esta investigación.

Este estudio de investigación consiste en dos cuestionarios de 24 preguntas cada uno, los cuales serán entregados a los estudiantes en doce de los cursos de cuarto grado de todo el Distrito Escolar de [Name Removed]. Este estudio será explicado en términos en los que su hijo/a podrá entender fácilmente, y tu hijo/a participará solo si él o ella están dispuestos a hacerlo. Sólo mi profesora guía de la Universidad del Estado de Portland, mi asistente de investigación y yo tendremos acceso a las respuestas del cuestionario que respondió su hijo/a. En las conclusiones de este estudio, las respuestas de los estudiantes serán reportadas de acuerdo al promedio de la clase. Los nombres de los estudiantes no serán vinculados con ninguno de los resultados de esta investigación.

La participación en este estudio es totalmente voluntaria. La decisión de que su hijo/a participe o no de este estudio no afectará los servicios que normalmente se le entregan a su hijo/a por el Distrito Escolar de [Name Removed]. La participación de tu hijo/a en este estudio no generará riesgo en perder alguno de los beneficios que su hijo/a ya tiene. Incluso si usted otorga permiso para que tu hijo/a participe, él o ella son libres de elegir si participar o no. Si tu hijo/a acepta participar, él o ella es libre de poner fin a su participación en cualquier momento durante el estudio.

Cualquier información obtenida en este estudio será y se mantendrá confidencial. La confidencialidad está respaldada ya que todas las respuestas e historias de todos los estudiantes serán mantenidas en un lugar cerrado y con llave y un limitado acceso a esa información la tendrán solo yo, como investigador y mi asistente de investigación. Los nombres de las escuelas y los profesores serán modificados cuando se presenten los datos y resultados a otras personas, y ningún nombre de estudiante será publicado en ningún momento.

Si tu deseas cualquier información extra o tienes alguna pregunta, por favor envíame un email a mi correo electrónico [Email Removed]. Mi profesor guía de investigación, Emily de la Cruz, también podrá responder cualquier pregunta o consulta futura en el siguiente email [Email Removed].

Si usted tiene cualquier pregunta acerca de los derechos de los participantes de esta investigación, puede contactar directamente al Comité de Revisión Institucional de la Universidad Estatal de Portland vía email a rmc4@pdx.edu o vía telefónica a (503)725-2227.

Sinceramente,

Nicole Van Gasse, Universidad del Estado de Portland. 
Por favor indicar si tú deseas o no dar permiso a tu hijo/a para participar de este proyecto de investigación. Para ello debes chequear una de las afirmaciones descritas más abajo, firmando con tu nombre y devolviendo este documento sólo a la profesora de tu hijo/a correspondiente al cuarto grado.

Yo entrego permiso para que mi hijo/a participe en el estudio de investigación de Nicole Van Gasse sobre la participación de los estudiantes de cuarto grado.

Yo no entrego permiso para que mi hijo participe en el en el estudio de investigación de Nicole Van Gasse sobre la participación de los estudiantes de cuarto grado. Yo entiendo que mi hijo/a todavia completar la encuesta si elijo esta opción, de esta manera otros estudiantes en su clase no sabrán que él o ella no están participando. Si esto sucediera, la encuesta de mi hijo/a inmediatamente será eliminada y ninguno de los datos será usado en el estudio de ninguna manera.

Firma del Padre/Madre/Apoderado/a

Nombre del estudiante
Nombre del Padre/Madre/Apoderado/a

\section{Fecha}


Appendix F

\section{ASSENT TO PARTICIPATE IN RESEARCH}

\section{Fourth Grade Student Engagement Study}

1. My name is Nicole Van Gasse. I am a doctoral student at Portland State University.

2. I am asking you to take part in a research study because I am trying to learn more about how students are involved in their learning. I am hoping to find out how students are participating in and thinking about learning across the district. This information will help teachers make school more interesting.

3. If you agree to be in this study, you will be asked to complete two, 24-question surveys given by the researcher. You will provide your name to the researcher, but your teacher will not know how you answered any of the questions. Your teacher will receive a class summary of the answers with no student names attached.

4. There are no known risks to participating in this study.

5. By participating in this study, your teacher will have more accurate information on the engagement levels of the students in his/her classroom. They may be able to use this information to create a more engaging classroom environment.

6. Your parents have given their permission for you to take part in this study. Even though your parents said "yes," it is your decision to participate in this study or not.

7. If you do not want to be in this study, you do not have to participate. Remember, being in this study is up to you and no one will be upset if you do not want to participate. If you do choose to participate, you may change you mind at any time.

8. You can ask any questions that you have about the study. If you have a question later that you cannot think of now, I would be happy to answer it the next time I visit.

9. Signing your name at the bottom means that you agree to be in this study. You and your parents will be given a copy of this form after you have signed it.

Signature of Participant

Printed Name of Participant

Date 
Appendix G

\section{CONSENTIMIENTO PARA PARTICIPAR EN UNA INVESTIGACION}

\section{Estudio sobre la participación de los estudiantes de cuarto grado}

1. Mi nombre es Nicole Van Gasse. Soy un estudiante de doctorado de la Universidad del Estado de Portland.

2. Yo estoy consultando si tú quieres ser parte de una investigación ya que estoy interesada en conocer y aprender más acerca de cómo los estudiantes se involucran con su aprendizaje. Espero averiguar cómo los estudiantes están participando en y pensando acerca de su aprendizaje en todo el distrito de [Name Removed]. Esta información ayudará a los profesores a hacer más interesante la escuela para sus alumnos.

3. Si tú aceptas ser parte de éste estudio, tendrás que completar dos cuestionarios de 24 preguntas cada una, realizadas por el investigador. Además, tendrás que entregar tu nombre al investigador, pero el profesor no sabrá cómo tú respondiste las preguntas de los cuestionarios. Tu profesor recibirá un resumen de las respuestas de la clase en general sin una identificación particular de los nombres de los estudiantes.

4. Quiero que sepas que no hay riesgos conocidos en participar de este estudio.

5. Participando de este estudio, tu profesor tendrá información más detallada y específica sobre el nivel de participación de los estudiantes de tu curso en la sala de clases. Esta información podrá ser usada para crear un ambiente más participativo en el aula (sala de clase).

6. Tus padres han dado el permiso para que tú puedas ser parte de este estudio. Sin embargo, a pesar de que tus padres dijeron "sí", finalmente es tu decisión participar en este estudio o no.

7. Si tú no quieres ser parte de este estudio, tú no tienes que participar. Recuerda, ser parte de este estudio depende solo de ti y nadie puede estar molesto si tú no quieres participar. Si tú eliges participar de este estudio, debes saber que tú puedes cambiar de opinión en cualquier momento.

8. Tú puedes realizar cualquier pregunta que tengas respecto de este estudio. Si quieres realizar alguna pregunta en un momento posterior a hoy, yo estaré feliz de responderla la próxima vez que visite tu escuela y sala de clase.

9. Si firmas con tu nombre al final de esta hoja significa que tú aceptas ser parte de este estudio. Una copia de esta forma ya firmada será entregada a ti y a tus padres.

Firma del participante

Nombre y apellido del participante

Fecha 
Appendix $\mathrm{H}$

\section{Fourth Grade Student Engagement Study}

Full Name

\section{School}

Gender: (circle) Male Female
Student Number

Teacher

Ethnicity: (circle) White African-American Asian/Pacific Islander Hispanic American-Indian Other

Directions: Listen to each question as it is read aloud. Circle the number that most accurately represents your answer. Please be as honest as possible and remember to only circle one number per question.

4=Strongly Agree, 3=Agree, 2=Disagree, 1=Strongly Disagree

1. My family/guardians are there for me when I need them..4 $\begin{array}{lllll}3 & 2 & 1\end{array}$

2. My teachers are there for me when I need them........ $4 \quad 3 \quad \begin{array}{llll}3 & 2\end{array}$

3. Other students here like me the way I am.............. $4 \begin{array}{lll}3 & 2 & 1\end{array}$

4. Adults at my school listen to the students...............4 $3 \begin{array}{lll}2 & 1\end{array}$

5. Other students care about me.......................4 $3 \quad 3 \quad 2 \quad 1$

6. Students at my school are there for me when I need them.............................

................................................. 4

7. My education will create many chances for me to reach my future goals................

.................................................. $4 \quad 3 \quad 2$

8. The rules at my school are fair........................4 $34 \begin{array}{lll}2 & 1\end{array}$

9. Continuing to learn after high school is important..... $4 \begin{array}{lllll}4 & 3 & 2 & 1\end{array}$ 
10. My family/guardian(s) want to know when something good happens at school......... ................................................ 34

11. Most teachers care about me as a person, not just a student.

.............................................. 4.42

12. Students here respect when I have to say............. $4 \quad 3 \quad \begin{array}{lll}2 & 1\end{array}$

13. My teachers are honest with me.....................4 $34 \begin{array}{lll}2 & 1\end{array}$

14. I plan to go to college after I graduate high school......4 $3 \begin{array}{lll}3 & 2 & 1\end{array}$

15. School is important for reaching my future goals..... $4 \begin{array}{llll}3 & 2 & 1\end{array}$

16. When I have problems at my school my family/guardian(s) are ready to help me.....

17. Adults at my school are fair towards students most of the time.

..................................................4 4

18. I like talking to the teachers here.................... $4 \begin{array}{lll}3 & 2 & 1\end{array}$

19. I enjoy talking to the students here....................4 3424

20. I have friends at school............................. $4 \quad 3 \quad 2 \quad 1$

21. I feel safe at school...............................4 $4 \begin{array}{lll}3 & 2\end{array}$

22. My family/guardian(s) want me to keep trying when things are tough at school.......

.................................................. 4

23. I am hopeful about my future.......................4 $4 \begin{array}{lll}2 & 1\end{array}$

24. Teachers at my school care about students. ............4 $3 \begin{array}{lll}3 & 2 & 1\end{array}$ 
Appendix I

First Interview Questions for All Participating Teachers

Name of Participant

Date of Interview

School of Participant

1. How long have you been teaching? How long have you been teaching fourth grade? How long have you been at this current school location?

2. What would someone see if they walked into your classroom on a typical day?

3. Finish this sentence. A good teacher is someone who...

4. Describe the typical family involvement in your school and/or classroom.

5. How do you plan for upcoming lessons?

6. In what ways does data impact your teaching?

7. How much autonomy do you have in what and how you teach each day? Explain.

8. Why did you volunteer to participate in this study?

9. Are there any questions that I can answer about the study? 
Appendix $\mathbf{J}$

Second Interview Questions for Control Group

Name of Participant

Date of Interview

School of Participant

1. Describe your experience in the study so far.

2. Have you intentionally made any changes to your classroom since your students completed the survey with the intention of increasing cognitive or affective engagement? If so, please explain. (If yes, ask questions 3-5. If not, skip to question 6).

3. Did you hope to increase engagement in any of the following areas: Student-Teacher Relationships Peer Support for Learning Family Support for Learning Future Goals and Aspirations

4. Who was the target of your intervention? If not the entire classroom, how did you select these students?

5. What were the outcomes of your interventions? How do you know?

6. Do you feel there were any other unexpected results from your participation in this study?

**Present the pre and post survey data to teachers. 
7. What is your initial reaction after seeing your students' data?

8. Are there any areas of engagement you would like to continue to focus on in your classroom?

9. Do you feel this type of data is helpful for teachers? If so, how?

10. Do you have any suggestions for improving the study?

11. Is there anything else you feel I should know? 
Appendix K

Second Interview Questions for the Test Group

Name of Participant

Date of Interview

School of Participant

1. Describe your experience in the study so far.

2. Are there any changes that you expect to see in your students' engagement scores? Why?

3. Have you intentionally made any changes to your classroom since your students completed the survey with the intention of increasing cognitive or affective engagement? If so, please explain. (If yes, ask questions 4-6. If not, skip to question 7).

4. Did you hope to increase engagement in any of the following areas: Student-Teacher Relationships Peer Support for Learning Family Support for Learning Future Goals and Aspirations

5. Who was the target of your intervention? If not the entire classroom, how did you select these students?

6. What were the outcomes of your interventions? How do you know?

*Present the participant with their classroom's post-survey results.

7. What is your initial reaction after seeing your post-survey results? 
8. Are there any engagement areas you would like to continue to focus on in your classroom? If so, what might this look like?

9. Do you feel there were any other unexpected results from your participation in this study?

10. Do you have any suggestions for improving this study?

11. Do you feel this type of data would be helpful for teachers? If so, how?

12. Is there anything else you feel I should know? 
Appendix L

Pre-Survey Summary Report for Control Teacher 1

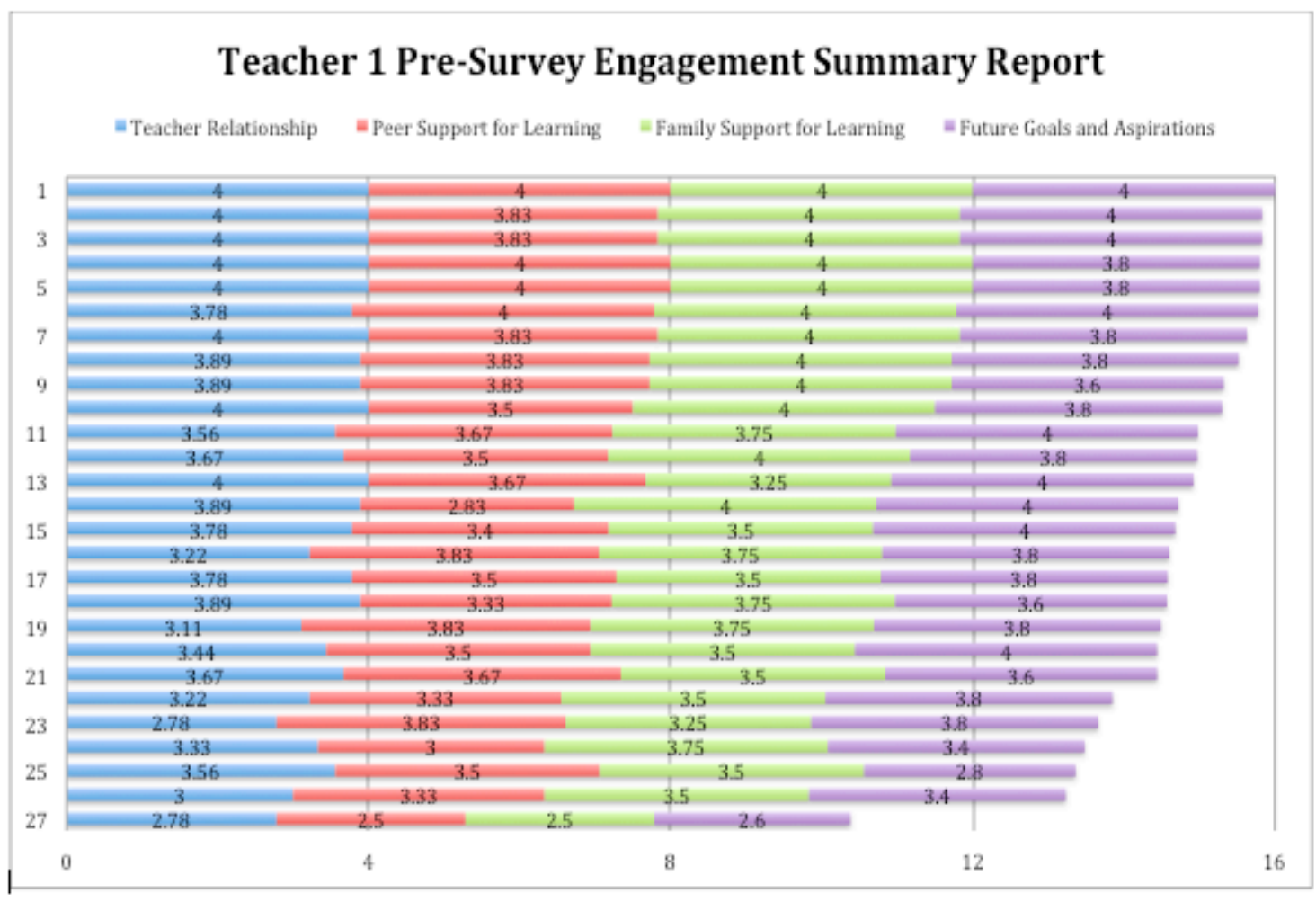

Class Averages

Teacher Relationship $=3.64$

Peer Support for Learning $=3.59$

Family Support for Learning $=3.71$

Future Goals and Aspirations $=3.73$ 
Appendix M

Post-Survey Summary Report for Control Teacher 1

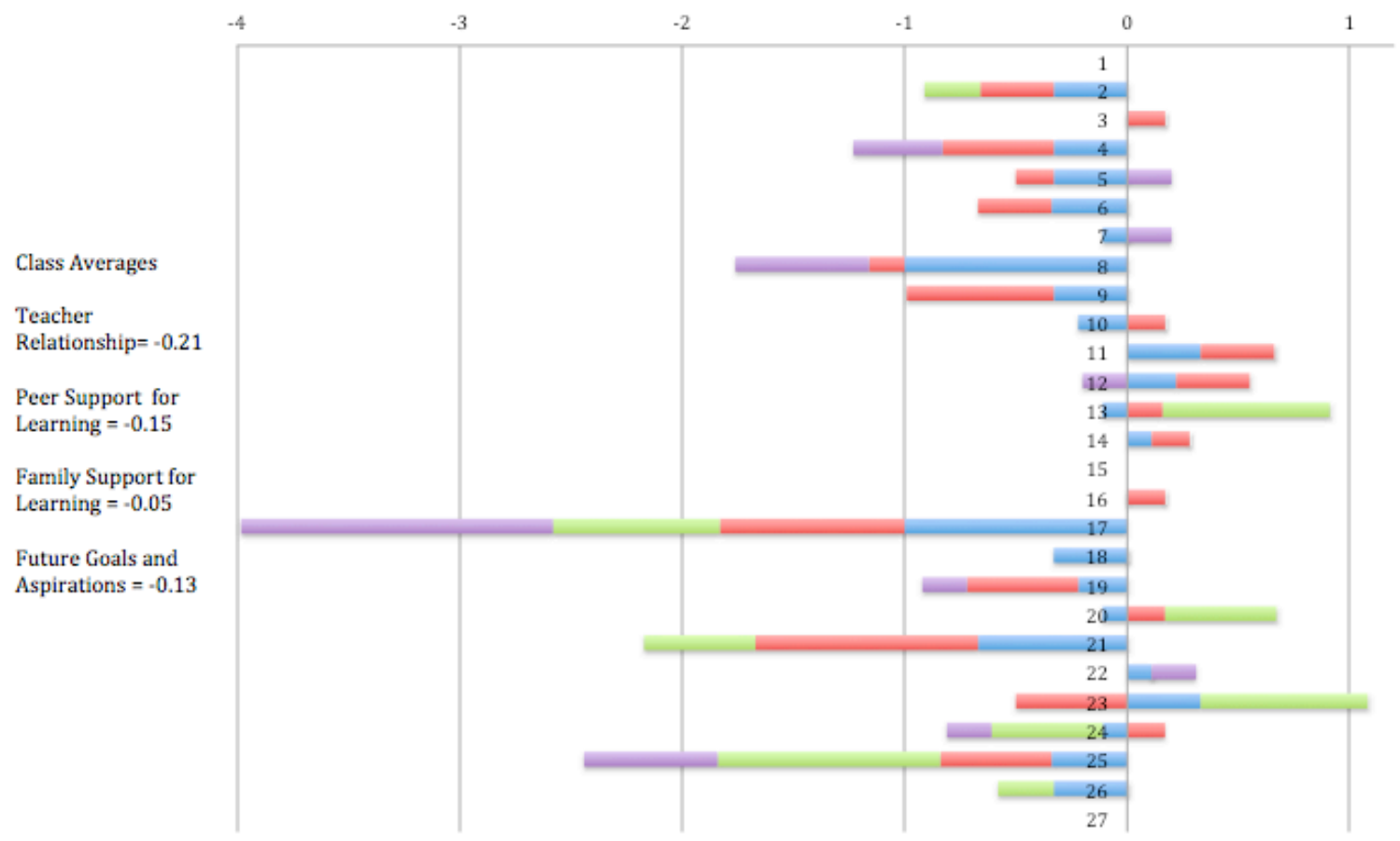

\begin{tabular}{|l|l|l|l|l|l|l|l|l|l|l|l|l|l|l|}
\hline Student \# & $\mathbf{2 7}$ & $\mathbf{2 6}$ & $\mathbf{2 5}$ & $\mathbf{2 4}$ & $\mathbf{2 3}$ & $\mathbf{2 2}$ & $\mathbf{2 1}$ & $\mathbf{2 0}$ & $\mathbf{1 9}$ & $\mathbf{1 8}$ & $\mathbf{1 7}$ & $\mathbf{1 6}$ & $\mathbf{1 5}$ & $\mathbf{1 4}$ \\
\hline $\begin{array}{l}\text { Teacher } \\
\text { Relationship }\end{array}$ & & -0.33 & -0.34 & -0.11 & 0.33 & 0.11 & -0.67 & -0.11 & -0.22 & -0.33 & -1 & 0 & & 0.11 \\
\hline $\begin{array}{l}\text { Peer Support } \\
\text { for Learning }\end{array}$ & & 0 & -0.5 & 0.17 & -0.5 & 0 & -1 & 0.17 & -0.5 & 0 & -0.83 & 0.17 & & 0.17 \\
\hline $\begin{array}{l}\text { Family } \\
\text { Support for } \\
\text { Learning }\end{array}$ & & -0.25 & -1 & -0.5 & 0.75 & 0 & -0.5 & 0.5 & 0 & 0 & -0.75 & 0 & & 0 \\
\hline $\begin{array}{l}\text { Future Goals } \\
\text { and } \\
\text { Aspirations }\end{array}$ & & 0 & -0.6 & -0.2 & 0 & 0.2 & 0 & 0 & -0.2 & 0 & -1.4 & 0 & & 0 \\
\hline
\end{tabular}

\begin{tabular}{|l|l|l|l|l|l|l|l|l|l|l|l|l|l|}
\hline Student \# & $\mathbf{1 3}$ & $\mathbf{1 2}$ & $\mathbf{1 1}$ & $\mathbf{1 0}$ & $\mathbf{9}$ & $\mathbf{8}$ & $\mathbf{7}$ & $\mathbf{6}$ & $\mathbf{5}$ & $\mathbf{4}$ & $\mathbf{3}$ & $\mathbf{2}$ & $\mathbf{1}$ \\
\hline $\begin{array}{l}\text { Teacher } \\
\text { Relationship }\end{array}$ & -0.11 & 0.22 & 0.33 & -0.22 & -0.33 & -1 & -0.11 & -0.34 & -0.33 & -0.33 & 0 & -0.33 & \\
\hline $\begin{array}{l}\text { Peer Support } \\
\text { for Learning }\end{array}$ & 0.16 & 0.33 & 0.33 & 0.17 & -0.66 & -0.16 & 0 & -0.33 & -0.17 & -0.5 & 0.17 & -0.33 & \\
\hline $\begin{array}{l}\text { Family Support } \\
\text { for Learning }\end{array}$ & 0.75 & 0 & 0 & 0 & 0 & 0 & 0 & 0 & 0 & 0 & 0 & -0.25 & \\
\hline $\begin{array}{l}\text { Future Goals } \\
\text { and Aspirations }\end{array}$ & 0 & -0.2 & 0 & 0 & 0 & -0.6 & 0.2 & 0 & 0.2 & -0.4 & 0 & 0 & \\
\hline
\end{tabular}


Appendix N

Pre-Survey Summary Report for Test Teacher 2

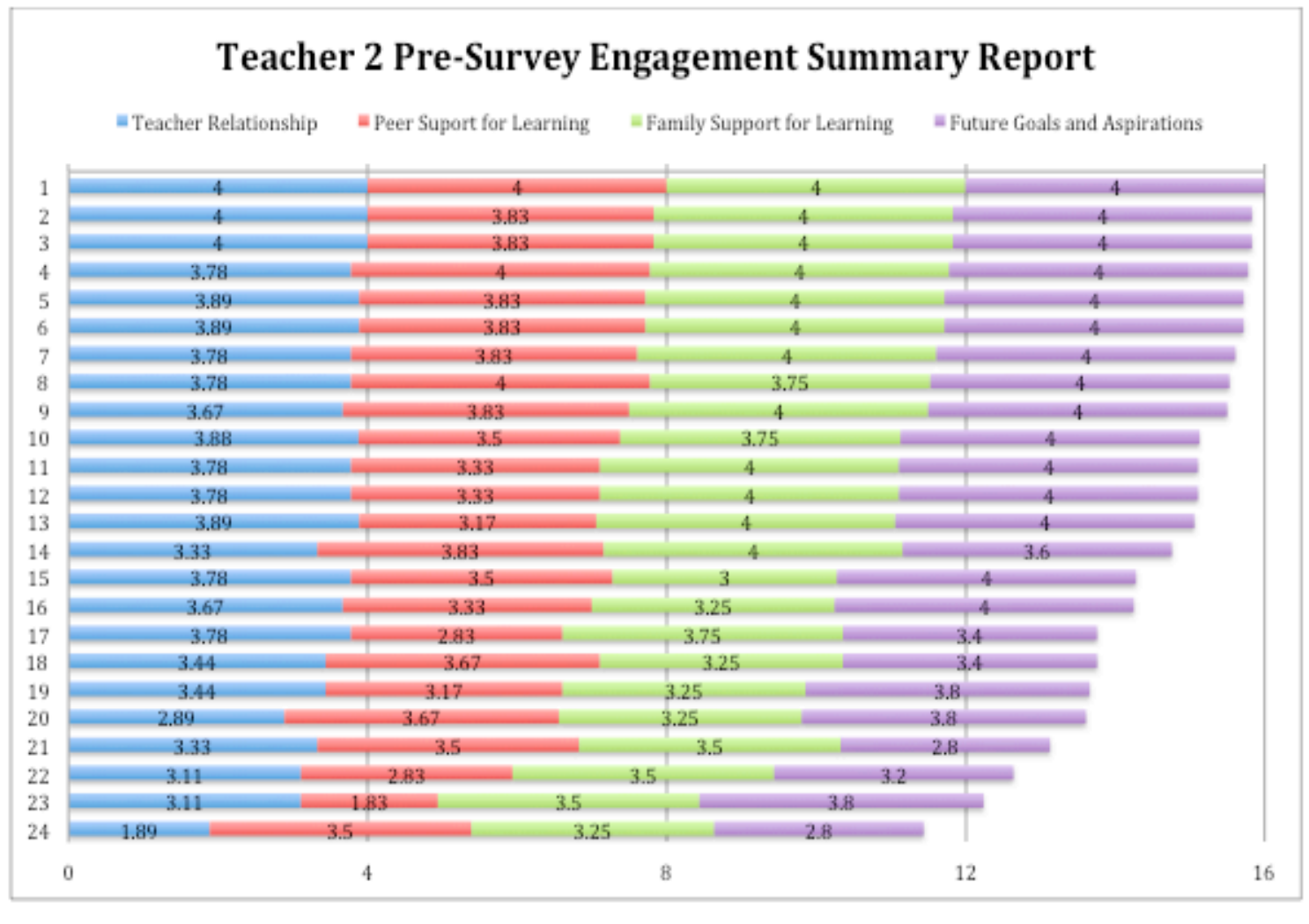

Class Averages

Teacher Relationship $=3.58$

Family Support for Learning $=3.71$
Peer Support for Learning $=3.50$

Future Goals and Aspirations $=3.78$ 
Appendix O

Post-Survey Summary Report for Test Teacher 2

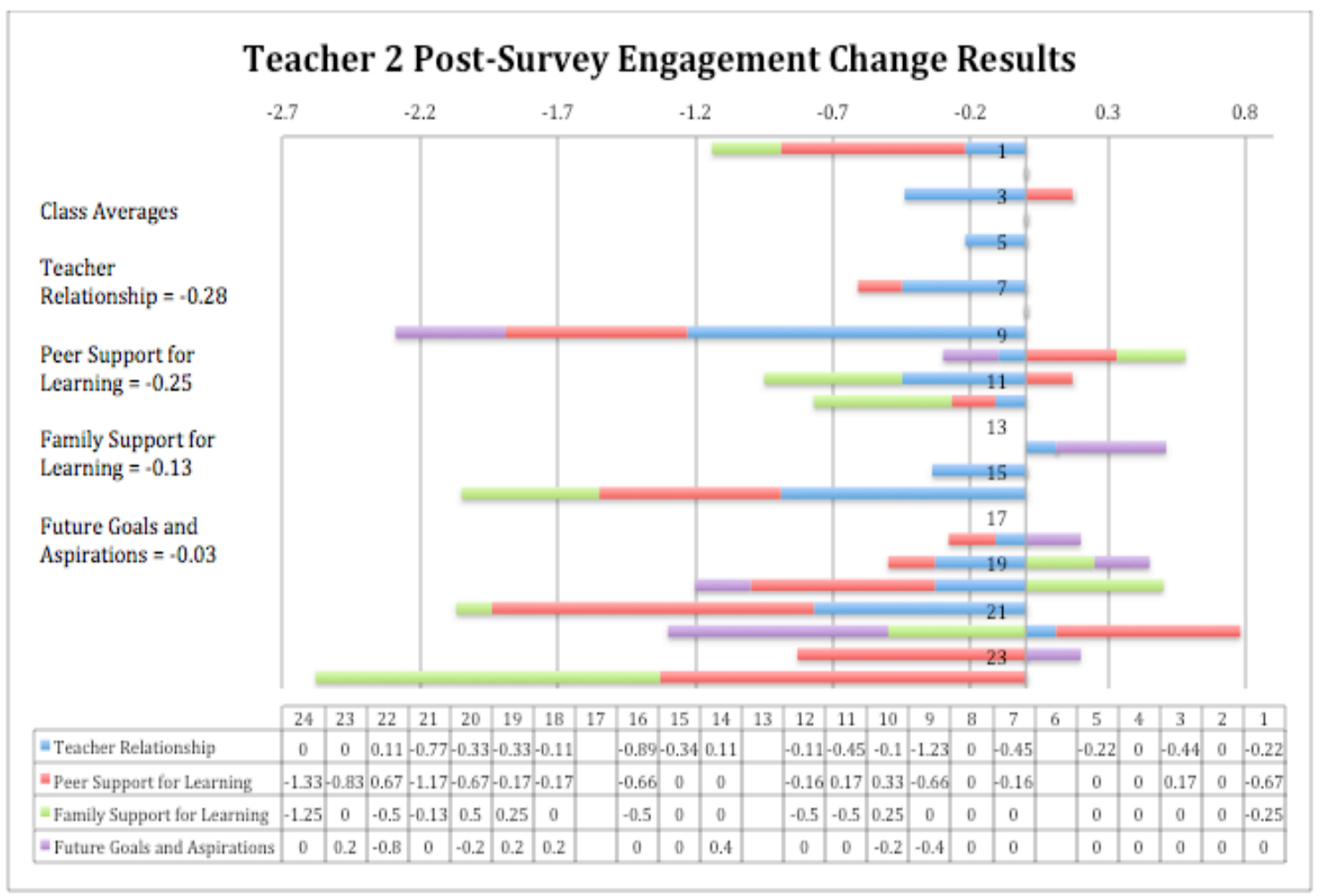


Appendix P

Pre-Survey Summary Report for Control Teacher 3

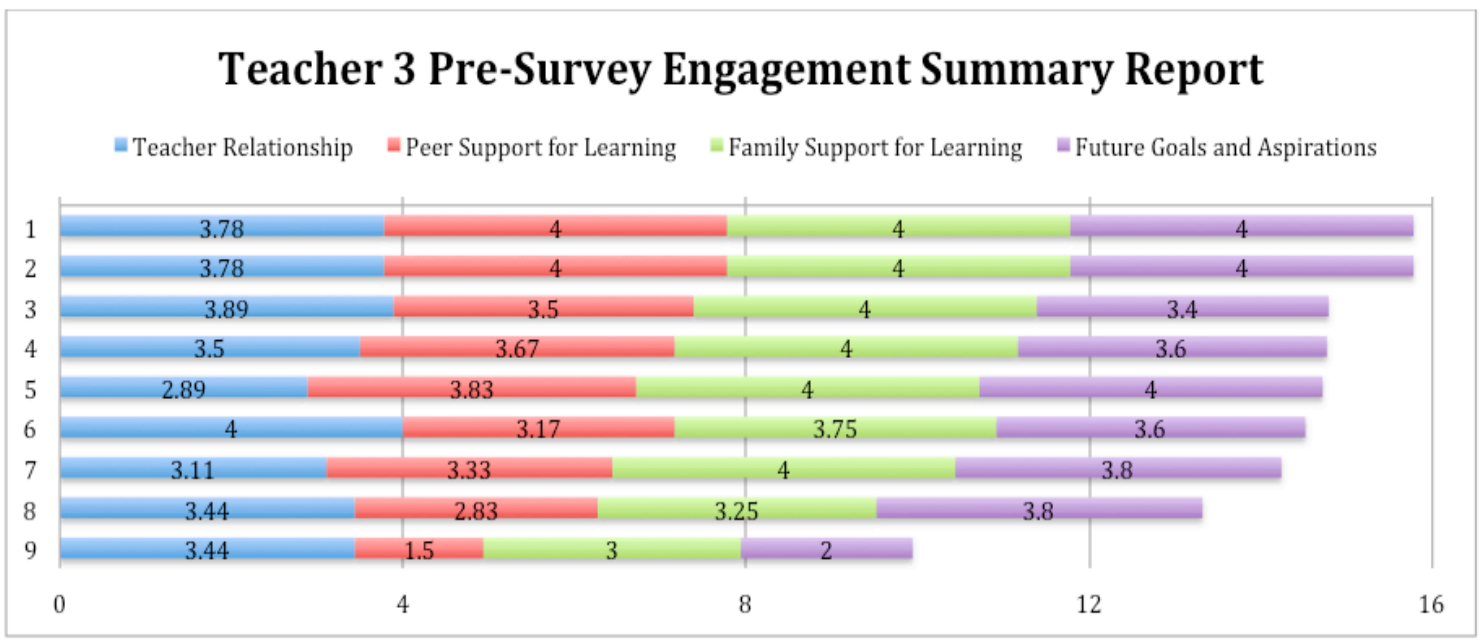

Class Averages

Teacher Relationship $=3.54$

Family Support for Learning $=3.78$
Peer Support for Learning $=3.31$

Future Goals and Aspirations $=3.58$ 
Appendix Q

Post-Survey Summary Report for Control Teacher 3

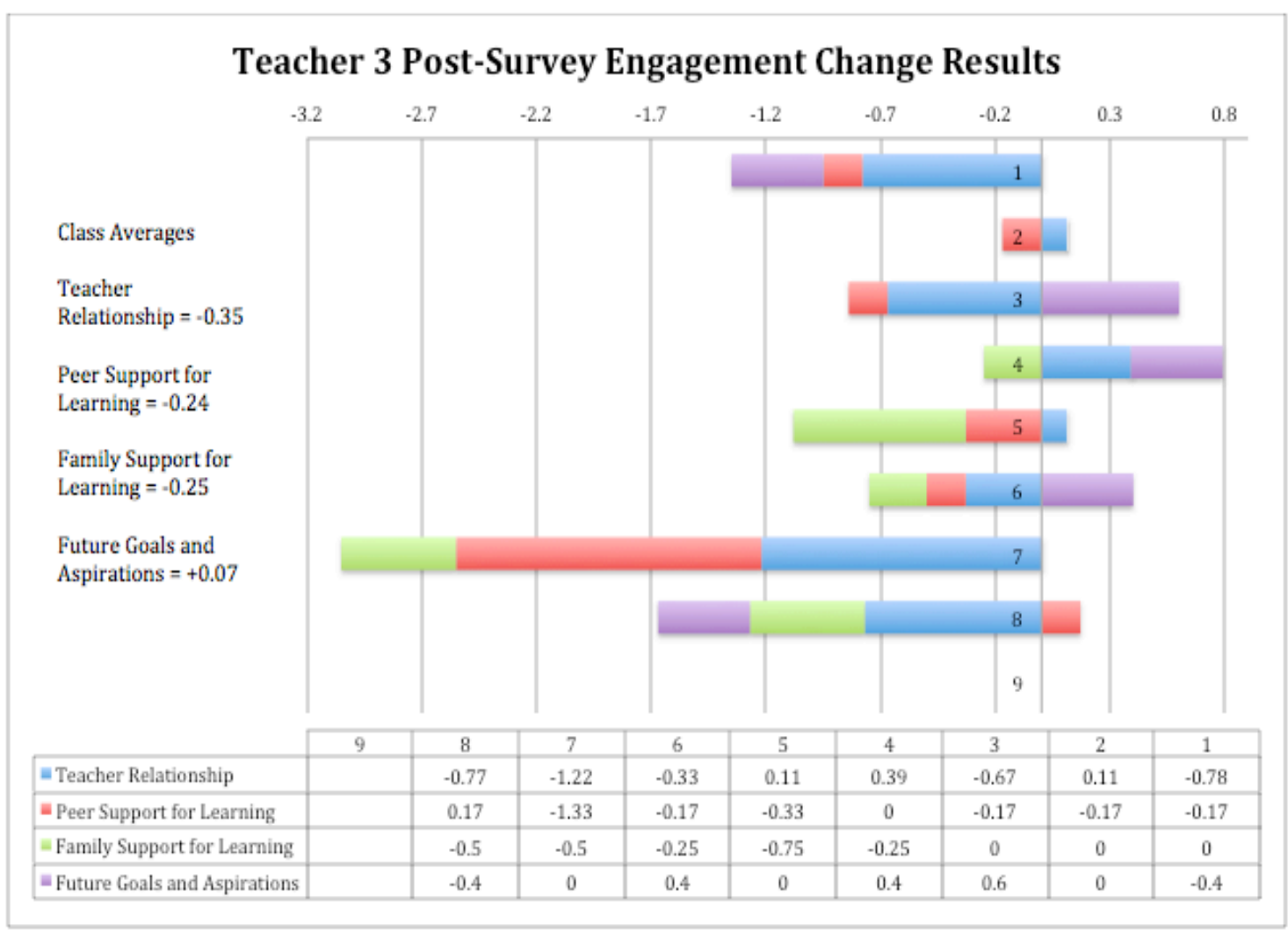


Appendix R

Pre-Survey Summary Report for Test Teacher 4

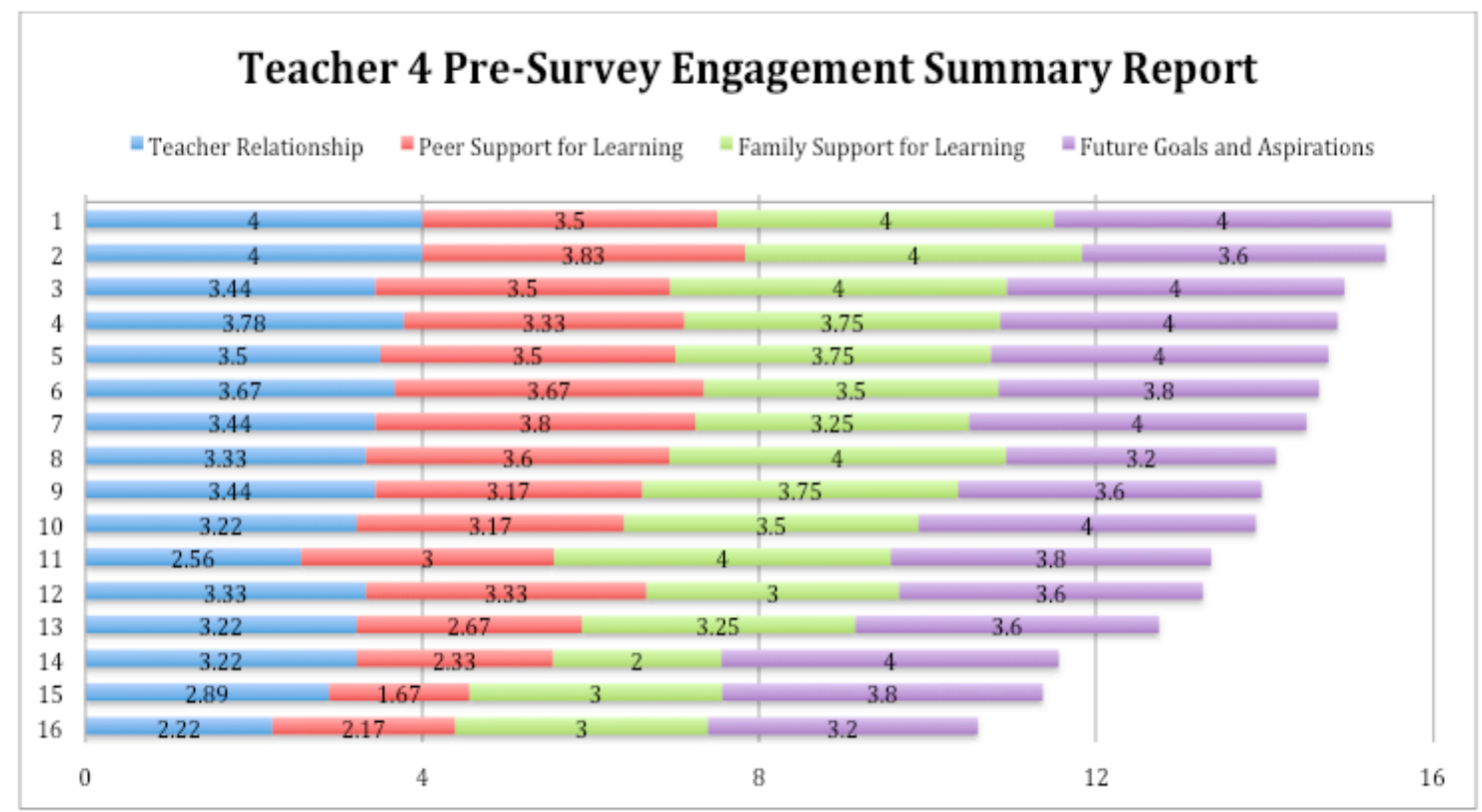

Class Averages

Teacher Relationship $=3.33$

Family Support for Learning $=3.48$
Peer Support for Learning $=3.14$

Future Goals and Aspirations $=3.76$ 
Appendix S

Post-Survey Summary Report for Test Teacher 4

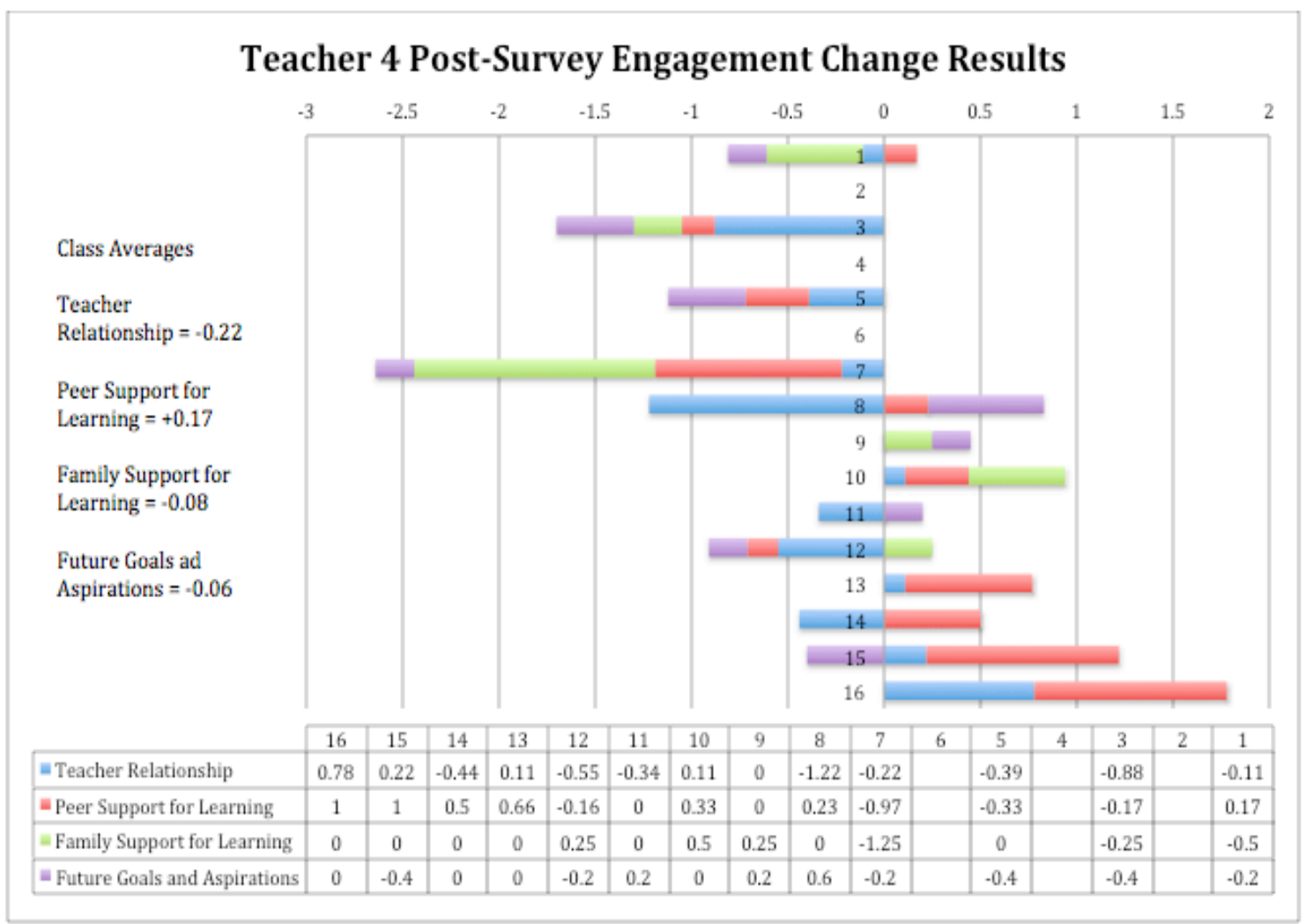


Appendix T

Pre-Survey Summary Report for Control Teacher 5

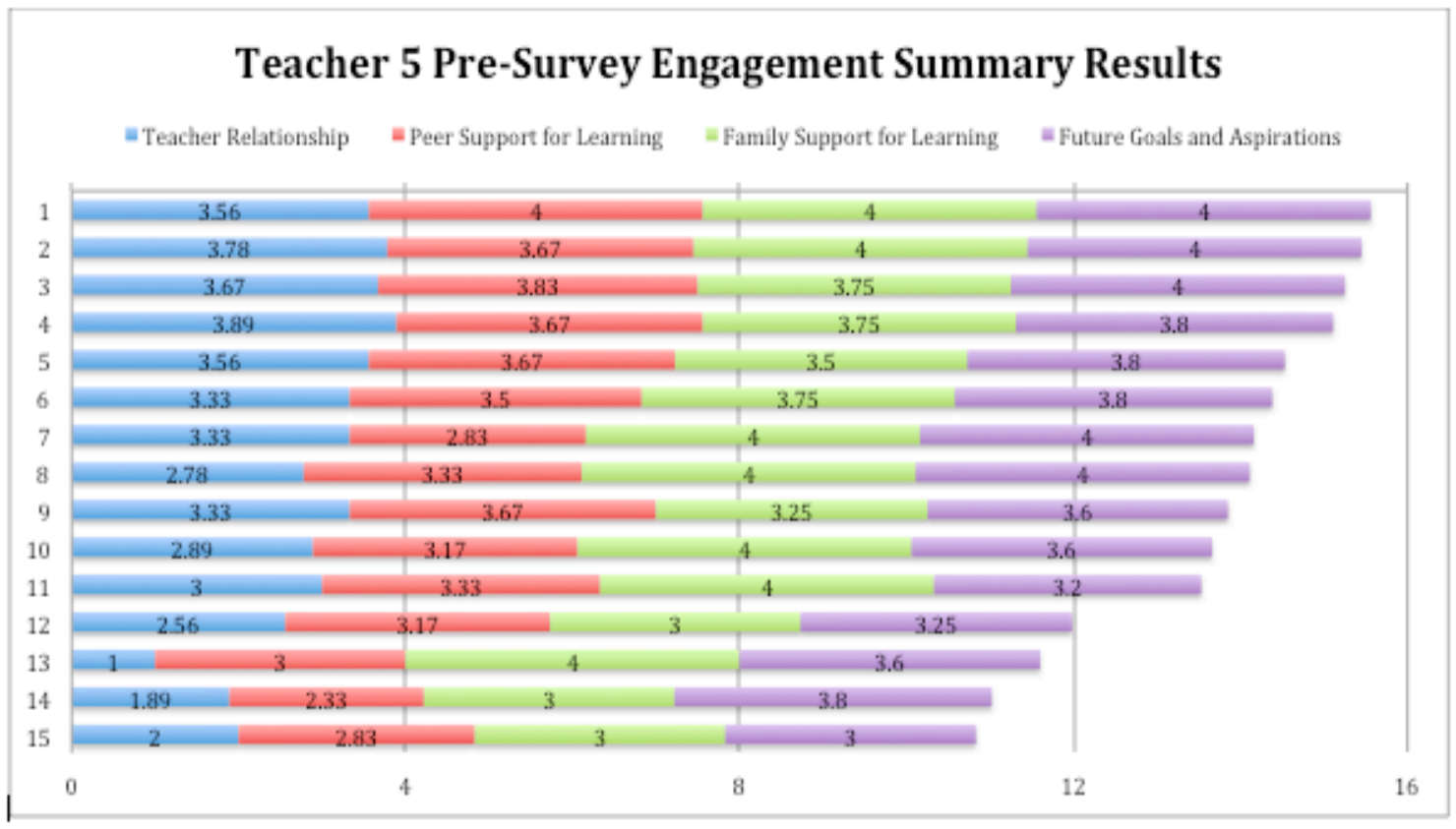

Class Averages

Teacher Relationship $=2.97$

Family Support for Learning $=3.67$
Peer Support for Learning $=3.33$

Future Goals and Aspirations $=3.70$ 
Appendix U

Post-Survey Summary Report for Control Teacher 5

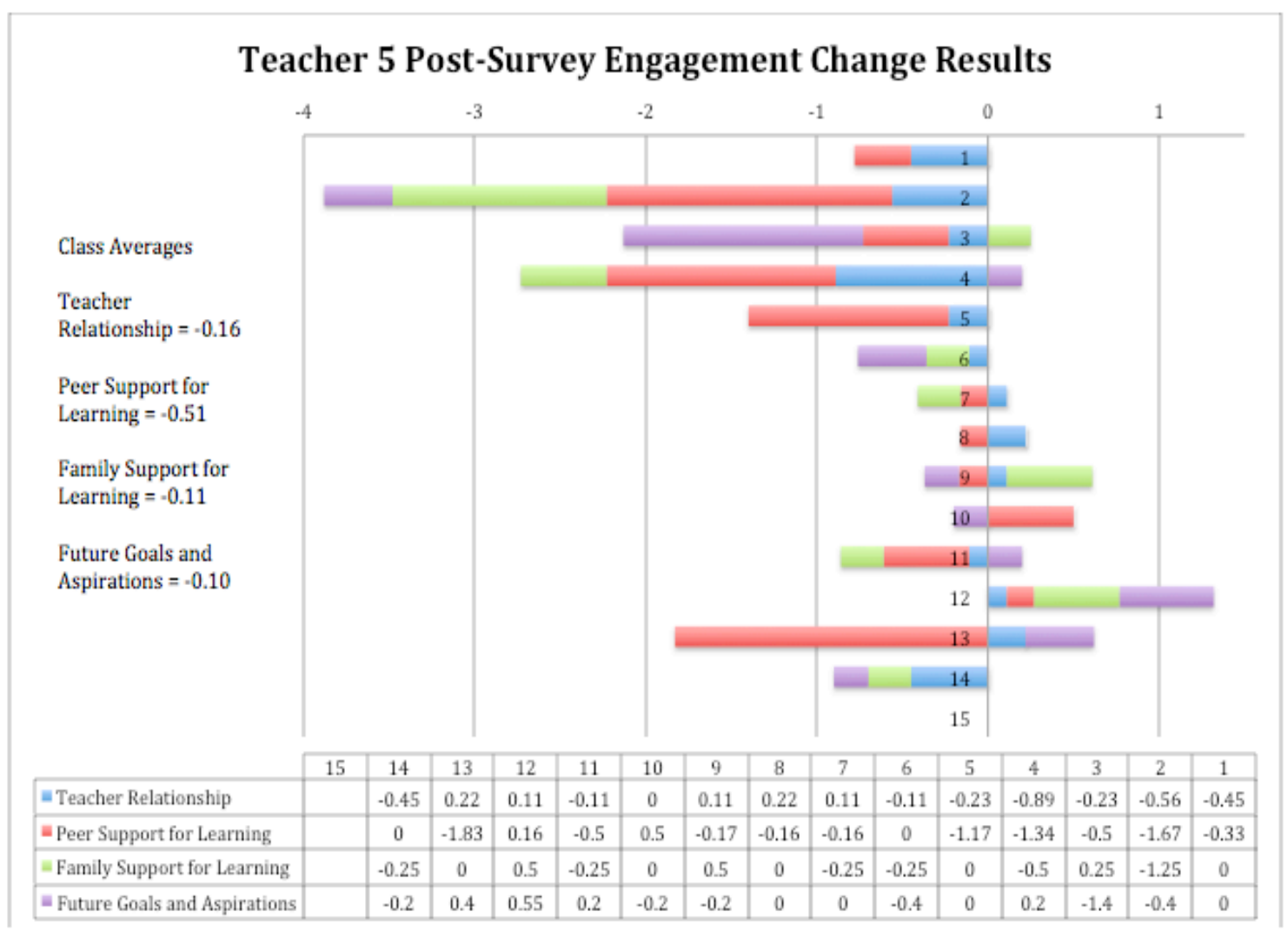




\section{Appendix V}

Pre-Survey Summary Report for Test Teacher 6

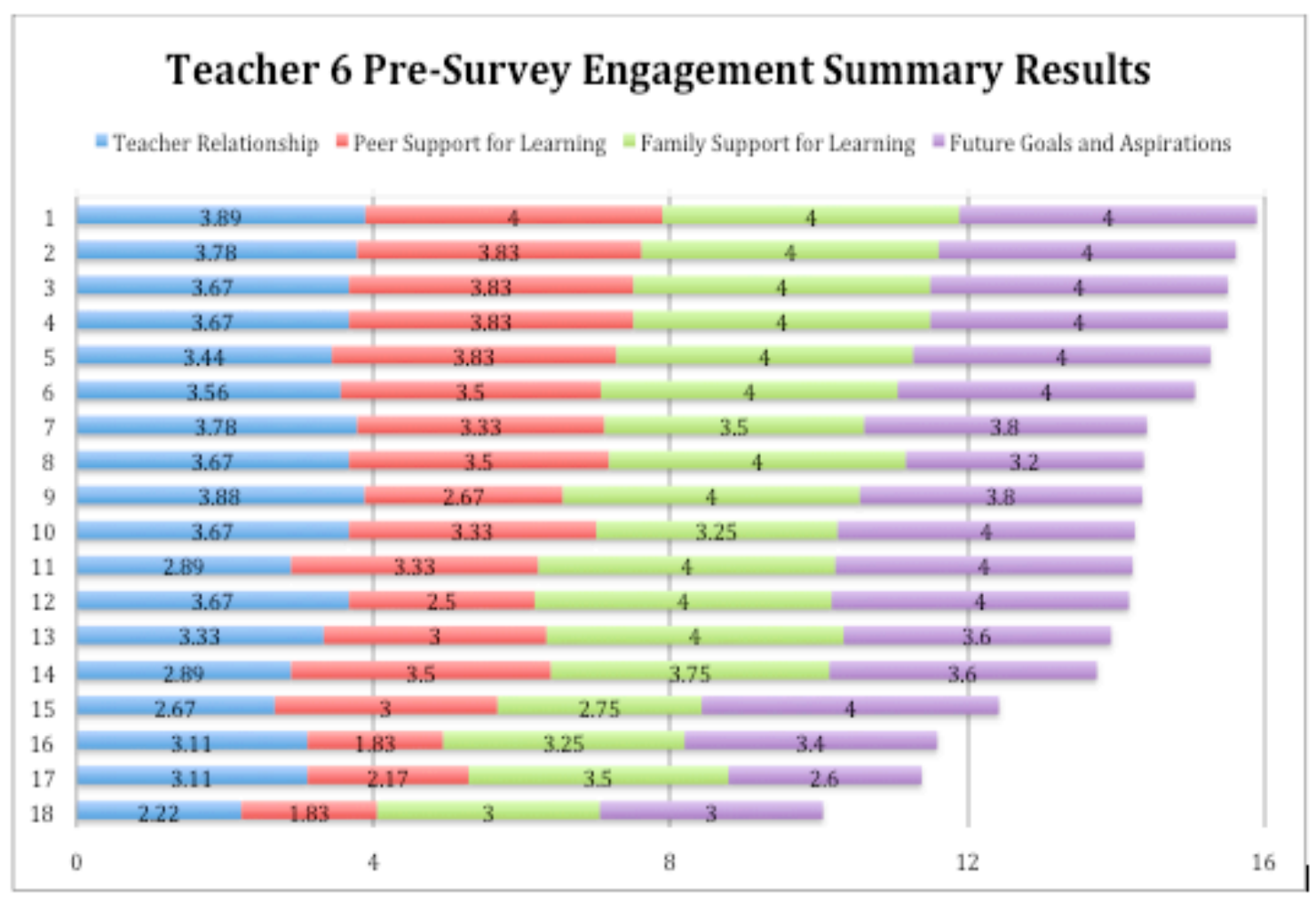

Class Averages

Teacher Relationship $=3.38$

Family Support for Learning $=3.72$
Peer Support for Learning $=3.16$

Future Goals and Aspirations $=3.72$ 
Appendix W

Post-Survey Summary Report for Test Teacher 6

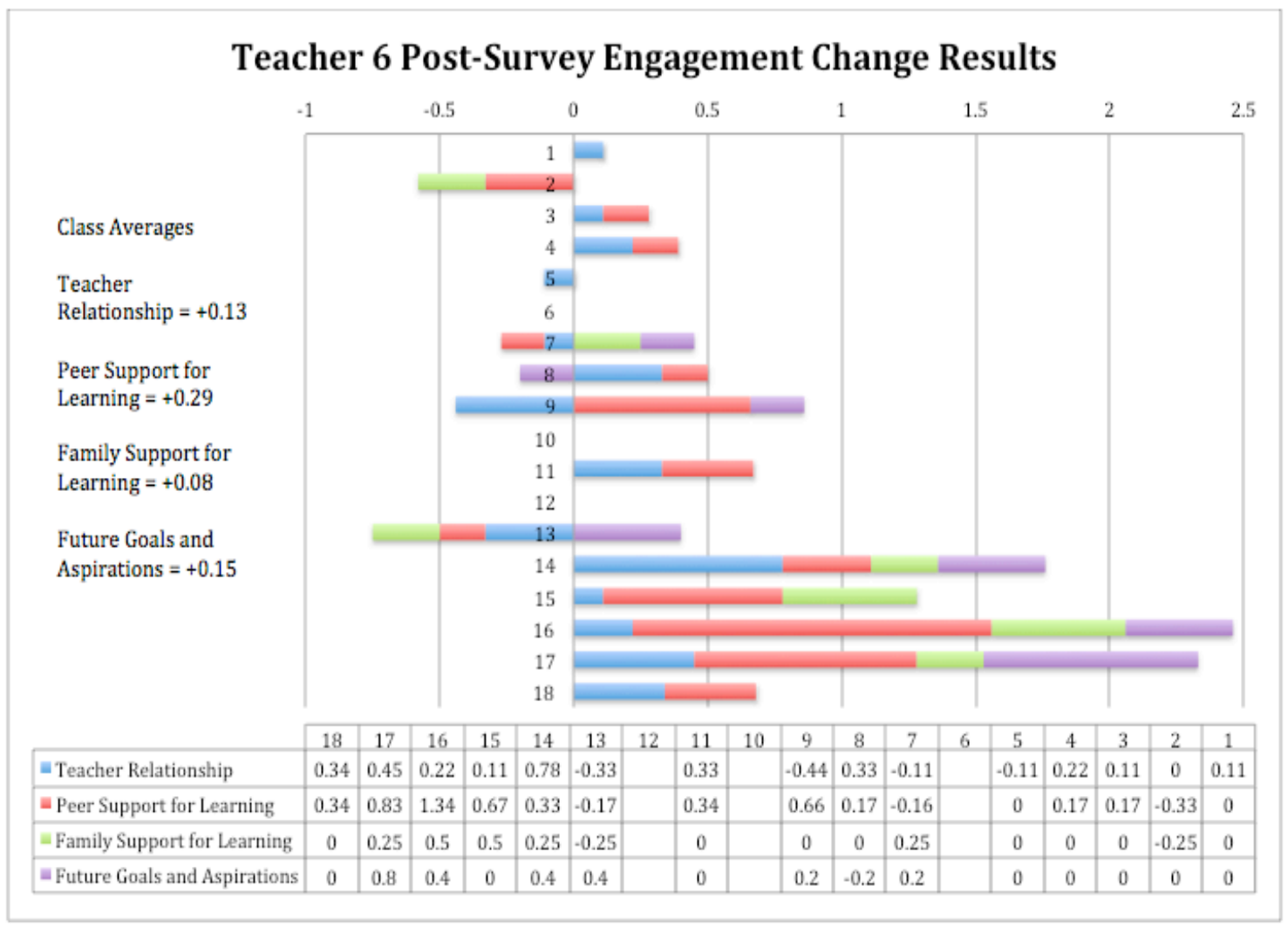

